\title{
Total Synthesis of Eupomatilones
}

Soumya Mitra, Srinivas Reddy Gurrala, and Robert S. Coleman*

Department of Chemistry, The Ohio State University, 100 West $18^{\text {th }}$ Avenue, Columbus, Ohio 43210-1185

coleman@chemistry.ohio-state.edu

Supplementary Information

Contents:

General Methods

$\mathrm{S} 2$

Experimental

S2-S5

Nuclear Magnetic Resonance Spectra

S6-S62 


\section{Supporting Information}

General Methods: NMR chemical shifts are reported in ppm relative to the $\mathrm{CDCl}_{3}$ peak at $7.27 \mathrm{ppm}\left({ }^{1} \mathrm{H}\right)$ or $77.0 \mathrm{ppm}\left({ }^{13} \mathrm{C}\right)$, the DMSO- $\mathrm{d}_{6}$ peak at $2.49 \mathrm{ppm}\left({ }^{1} \mathrm{H}\right)$ or $39.5 \mathrm{ppm}\left({ }^{13} \mathrm{C}\right)$, and the Acetone- $\mathrm{d}_{6}$ peak at $2.05 \mathrm{ppm}\left({ }^{1} \mathrm{H}\right)$ or $29.8 \mathrm{ppm}\left({ }^{13} \mathrm{C}\right)$. Unless otherwise specified, all reactions were run under an inert atmosphere of nitrogen or argon. All reactions were carried out in oven-dried $\left(120^{\circ} \mathrm{C}\right)$ glassware or flame-dried glassware. All solvents were freshly distilled before use. Tetrahydrofuran (THF) was distilled from benzophenone ketyl. Triethylamine, ether, dichloromethane were all distilled from calcium hydride prior to use. Yields reported refer to isolated material that was determined to be pure by NMR spectroscopy and thin layer chromatography (TLC), unless specified otherwise in the text.

6-bromo-7-hydroxybenzo[d][1,3]dioxole-5-carbaldehyde. A solution of 5-hydroxypiperonal (2.0 g, $12.0 \mathrm{mmol})$ in dioxane (80 mL) was cooled to $-15^{\circ} \mathrm{C}$. A solution of $N$-bromosuccinimide $(2.14 \mathrm{~g}, 12.0 \mathrm{mmol})$ in dioxane $(20 \mathrm{~mL})$ was added dropwise by syringe over $2 \mathrm{~h}$ at this temperature. The reaction mixture was stirred for $12 \mathrm{~h}$ between $-15^{\circ} \mathrm{C}$ to $-19{ }^{\circ} \mathrm{C}$ and was quenched by the addition of saturated aqueous $\mathrm{Na}_{2} \mathrm{~S}_{2} \mathrm{O}_{3}(10 \mathrm{~mL})$. The mixture was concentrated, and the residue was dissolved in EtOAc (100 mL) and washed with saturated aqueous $\mathrm{Na}_{2} \mathrm{~S}_{2} \mathrm{O}_{3}$, water, and saturated aqueous $\mathrm{NaCl}$. The organic layer was dried $\left(\mathrm{Na}_{2} \mathrm{SO}_{4}\right)$, concentrated, and the residue was purified by flash chromatography (silica, 15\% EtOAc/hexane) to afford the required pure product (2.84 g, 97\%) as a solid:

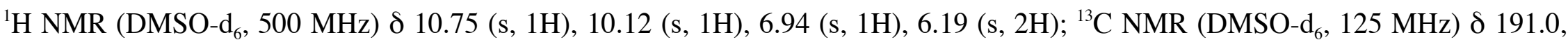


148.6, 141.4, 138.6, 128.2, 112.6, 103.3, 100.8; IR (KBr) $v_{\max } 3042,2362,1660,1594,1497,1480,1460,1416,1355,1256,1124$, 1083, 1040, 994, 922, 836, 747, $668 \mathrm{~cm}^{-1}$; HRMS (ESI), $m / z$ calcd for $\mathrm{C}_{8} \mathrm{H}_{5} \mathrm{BrO}_{4} \mathrm{Na}$ : 266.9269; found: 266.9270.

6-Bromo-7-methoxybenzo[d][1,3]dioxole-5-carbaldehyde (10). A mixture of 6-bromo-7-hydroxy-benzo[1,3]dioxole-5carbaldehyde (1.8 g, $7.4 \mathrm{mmol}), \mathrm{K}_{2} \mathrm{CO}_{3}(1.52 \mathrm{~g}, 11.0 \mathrm{mmol})$ and dimethyl sulfate $(0.84 \mathrm{~mL}, 8.8 \mathrm{mmol})$ in acetone (20 mL) was heated at $56{ }^{\circ} \mathrm{C}$ for $2 \mathrm{~h}$. After cooling to room temperature, the mixture was filtered and concentrated. The residue was dissolved in EtOAc $(50 \mathrm{~mL})$, and was washed with water and saturated aqueous $\mathrm{NaCl}$. The organic layer was dried $\left(\mathrm{Na}_{2} \mathrm{SO}_{4}\right)$, concentrated, and the residue was recrystallized from $\mathrm{CH}_{2} \mathrm{Cl}_{2} /$ hexane to afford the pure compound $\mathbf{1 0}(1.62 \mathrm{~g}, 85 \%)$ as a light yellow solid: ${ }^{1} \mathrm{H}$ NMR $\left(\mathrm{CDCl}_{3}, 500 \mathrm{MHz}\right) \delta 10.26(\mathrm{~s}, 1 \mathrm{H}), 7.16(\mathrm{~s}, 1 \mathrm{H}), 6.09$ (s, 2H), 4.06 (s, 3H); ${ }^{13} \mathrm{C} \mathrm{NMR}\left(\mathrm{CDCl}_{3}, 125 \mathrm{MHz}\right) \delta 190.7,149.2,143.0,140.3$, 128.6, 115.8, 103.2, 102.7, 60.4; HRMS (ESI), $m / z$ calcd for $\mathrm{C}_{9} \mathrm{H}_{7} \mathrm{BrO}_{4} \mathrm{Na}$ : 280.9424; found: 280.9425.

5-((1S*,2R*)-1-(tert-Butyldimethylsilyl)oxy-2,3-dimethyl-3-butenyl)-6-Bromo-7-methoxybenzo[d][1,3]dioxole (13). 2,6-Lutidine $(0.21 \mathrm{~mL}, 1.8 \mathrm{mmol})$ was added to a solution of alcohol $11(0.40 \mathrm{~g}, 1.2 \mathrm{mmol})$ in $\mathrm{CH}_{2} \mathrm{Cl}_{2}(10 \mathrm{~mL})$ at $-78{ }^{\circ} \mathrm{C}$. After $10 \mathrm{~min}, t$ BuMe $_{2} \operatorname{SiOTf}(0.31 \mathrm{~mL}, 1.3 \mathrm{mmol})$ was added and the reaction mixture was stirred for $20 \mathrm{~min}$ at this temperature. The reaction mixture was diluted with $\mathrm{CH}_{2} \mathrm{Cl}_{2}(50 \mathrm{~mL})$ and the organic layer was washed with water and saturated aqueous $\mathrm{NH}_{4} \mathrm{Cl}$. The organic layer was dried $\left(\mathrm{Na}_{2} \mathrm{SO}_{4}\right)$, concentrated, and the residue was purified by flash chromatography (5\% EtOAc/hexane) to afford $\mathbf{1 3}$ $(0.53 \mathrm{~g}, 98 \%)$ as a syrup: ${ }^{1} \mathrm{H} \mathrm{NMR}\left(\mathrm{CDCl}_{3}, 500 \mathrm{MHz}\right) \delta 6.79(\mathrm{~s}, 1 \mathrm{H}), 5.97(\mathrm{ABq}, 2 \mathrm{H}, J=1.5 \mathrm{~Hz}, \Delta v=10.9 \mathrm{~Hz}), 5.05(\mathrm{~d}, 1 \mathrm{H}, J=3.7$ $\mathrm{Hz}), 4.79$ (s, 1H), 4.74 (s, 1H), 4.03 (s, 3H), 2.40-2.30 (m, 1H), 1.83 (s, 3H), 0.97 (d, 3H, J= 7.0 Hz), 0.88 (s, 9H), 0.02 (s, 3H), -0.20 $(\mathrm{s}, 3 \mathrm{H}) ;{ }^{13} \mathrm{C} \mathrm{NMR}\left(\mathrm{CDCl}_{3}, 500 \mathrm{MHz}\right) \delta 148.2,147.2,139.5,138.3,136.1,111.8,106.4,103.5,101.5,74.9,60.1,46.0,25.9,22.1,18.2$, $12.3,-4.8,-5.2 ;$ IR (neat) $v_{\max } 3051,2945,2839,1473,1403,1375,1265,1119,1081,1047,894,854,835,741,705 \mathrm{~cm}^{-1} ; \mathrm{HRMS}^{2}$ (ESI), $m / z$ calcd for $\mathrm{C}_{20} \mathrm{H}_{31} \mathrm{BrO}_{4} \mathrm{SiNa}$ : 465.1073; found: 465.1066. 
Methyl 3-hydroxy-2-methylenebutanoate (34). Dioxane (5.0 mL) and methylacrylate (11.72 g, $12.3 \mathrm{~mL}, 136.2 \mathrm{mmol})$ were added to a solution of DABCO $(5.12 \mathrm{~g}, 45.4 \mathrm{mmol})$ in water $(5.0 \mathrm{~mL})$. The reaction mixture was cooled to $0{ }^{\circ} \mathrm{C}$ and stirred for $10 \mathrm{~min}$ following by dropwise addition of acetaldehyde $(2.0 \mathrm{~g}, 2.54 \mathrm{~mL}, 45.4 \mathrm{mmol})$. The reaction mixture was stirred for $24 \mathrm{~h}$ at $25{ }^{\circ} \mathrm{C}$. The mixture was diluted with tert-butyl methyl ether $(30 \mathrm{~mL})$, the organic layer was separated, and the aqueous layer was re-extracted with tert-butylmethylether $(2 \times 20 \mathrm{~mL})$. The combined organic extracts were washed with saturated aqueous $\mathrm{NaCl}(3 \times 20 \mathrm{~mL})$, and were dried $\left(\mathrm{Na}_{2} \mathrm{SO}_{4}\right)$ and concentrated in vacuo to obtain crude $34(93 \%)$, which was used without further purification: ${ }^{1} \mathrm{H} \mathrm{NMR}\left(\mathrm{CDCl}_{3}\right.$, $400 \mathrm{MHz}) \delta 6.19(\mathrm{~s}, 1 \mathrm{H}), 5.82(\mathrm{~s}, 1 \mathrm{H}), 4.60(\mathrm{bd}, 1 \mathrm{H}, J=4.3 \mathrm{~Hz}), 3.76(\mathrm{~s}, 3 \mathrm{H}), 2.85(\mathrm{bs}, 1 \mathrm{H}), 1.35(\mathrm{~d}, 3 \mathrm{H}, J=6.5 \mathrm{~Hz})$.

Methyl 3-acetoxy-2-methylenebutanoate (44). A solution of methyl 3-hydroxy-2-methylenebutanoate (7.5 g, $57.5 \mathrm{~mL})$ in dichloromethane $(40 \mathrm{~mL})$ was treated with pyridine $(5 \mathrm{~mL}, 6.37 \mathrm{~g}, 80.53 \mathrm{mmol})$ for $10 \mathrm{~min}$ at $0{ }^{\circ} \mathrm{C}$ and acetic anhydride $(8.0 \mathrm{~mL}, 8.63$ $\mathrm{g}, 84.56 \mathrm{mmol}$ ) was added. The reaction mixture was cooled to $-15^{\circ} \mathrm{C}$ and was stirred below $0{ }^{\circ} \mathrm{C}$ for $30 \mathrm{~h}$. The reaction mixture was quenched by the addition of water $(20 \mathrm{~mL})$, and washed with $5 \% \mathrm{HCl}(3 \times 10 \mathrm{~mL})$, water $(2 \times 10 \mathrm{~mL})$, saturated aqueous $\mathrm{NaCl}(3 \times 20$ $\mathrm{mL}$ ), and was dried $\left(\mathrm{Na}_{2} \mathrm{SO}_{4}\right)$ and concentrated in vacuo. The residue was passed through a short pad of silica (10\% ether/hexane) to obtain 44 as a colorless oil $(9.5 \mathrm{~g}, 96 \%)$ : ${ }^{1} \mathrm{H}$ NMR $\left(\mathrm{CDCl}_{3}, 500 \mathrm{MHz}\right) \delta 6.28(\mathrm{~s}, 1 \mathrm{H}), 5.82(\mathrm{t}, 1 \mathrm{H}, J=1 \mathrm{~Hz}), 5.70(\mathrm{dq}, 1 \mathrm{H}, J=6.5,0.5$ $\mathrm{Hz}), 3.78(\mathrm{~s}, 3 \mathrm{H}), 2.07$ (s, 3H), $1.40(\mathrm{~d}, 3 \mathrm{H}, J=6.5 \mathrm{~Hz}) ;{ }^{13} \mathrm{C} \mathrm{NMR}\left(\mathrm{CDCl}_{3}, 125 \mathrm{MHz}\right) \delta 169.8,165.7,141.1,124.7,68.2,51.9,21.1$, 20.2; IR (film) $v_{\max } 3461,2107,1642,525 \mathrm{~cm}^{-1}$; HRMS (ESI), m/z calcd for $\mathrm{C}_{8} \mathrm{H}_{12} \mathrm{O}_{4} \mathrm{Na}$ : 195.0633; found: 195.0624 .

1,7,7-Trimethyl-2-phenylbicyclo[2.2.1]heptane-2,3-diol (49). A 1M solution of L-selectride in THF (15.0 mL, 15.0 mmol) was added via syringe to a solution of $(+)-(R)$-camphorquinone $(2.50 \mathrm{~g}, 15.0 \mathrm{mmol})$ in THF $(50 \mathrm{~mL})$ at $0{ }^{\circ} \mathrm{C}$ under nitrogen. The reaction mixture was stirred for $30 \mathrm{~min}$ between $0-5{ }^{\circ} \mathrm{C}$. A second flask was charged with $\mathrm{CeCl}_{3}(6.75 \mathrm{~g}, 18.05 \mathrm{mmol})$ (pre-dried at $140{ }^{\circ} \mathrm{C}$, at $10 \mathrm{~mm} \mathrm{Hg}$ for 2 days) and THF (50 mL) was added. A 3M solution of $\mathrm{PhMgBr}(6.0 \mathrm{~mL}, 18.0 \mathrm{mmol})$ was added dropwise to the slurry of $\mathrm{CeCl}_{3}$ to form a white suspension. The resulting suspension was stirred for $30 \mathrm{~min}$ at $0{ }^{\circ} \mathrm{C}$. To this white suspension, the reduction 
reaction mixture (L-selectride and $(+)-(R)$-camphorquinone) was added by cannula under nitrogen at $0{ }^{\circ} \mathrm{C}$. The reaction mixture was allowed to warm to $25^{\circ} \mathrm{C}$ and was vigorously stirred for $3 \mathrm{~h}$. The mixture was slowly poured onto a saturated aqueous solution of $\mathrm{NH}_{4} \mathrm{Cl}$, and the mixture was extracted with ether $(3 \times 20 \mathrm{~mL})$. The combined organic extracts were dried $\left(\mathrm{Na}_{2} \mathrm{SO}_{4}\right)$, filtered, and concentrated to afford a yellow oil $(5.7 \mathrm{~g})$. The resulting oil was dissolved in a mixture of THF $(25 \mathrm{~mL})$ and water $(12.5 \mathrm{~mL})$. Aqueous $1 \mathrm{M} \mathrm{NaOH}(25 \mathrm{~mL})$ and $30 \% \mathrm{H}_{2} \mathrm{O}_{2}(10 \mathrm{~mL})$ were added, and the resulting biphasic reaction mixture was stirred for $3 \mathrm{~h}$ at 25 ${ }^{\circ} \mathrm{C}$. The reaction mixture was extracted with ether $(3 \times 15 \mathrm{ml})$ and the combined extracts were washed with water $(1 \mathrm{x} 20 \mathrm{~mL})$, saturated aqueous $\mathrm{NaCl}(2 \times 20 \mathrm{~mL})$, and were dried $\left(\mathrm{Na}_{2} \mathrm{SO}_{4}\right)$ and concentrated. The resulting oil (3.6 g) was left under high vacuum $(<1 \mathrm{~mm} \mathrm{Hg})$ for $6 \mathrm{~h}$ and was re-crystallized from petroleum ether to afford after four crops, colorless crystals of the desired diol 49 $(2.2 \mathrm{~g}, 60 \%):{ }^{1} \mathrm{H} \mathrm{NMR}\left(\mathrm{CDCl}_{3}, 500 \mathrm{MHz}\right) \delta 7.52$ (d, 2H, J = 2.5 Hz), 7.35 (m, 2H), $7.29(\mathrm{~m}, 1 \mathrm{H}), 4.41(\mathrm{~d}, 1 \mathrm{H}, J=6.5 \mathrm{~Hz}), 2.92(\mathrm{~s}$, $1 \mathrm{H}), 2.62(\mathrm{~d}, 1 \mathrm{H}, J=6.5 \mathrm{~Hz}), 1.92(\mathrm{~d}, 1 \mathrm{H}, J=5.0 \mathrm{~Hz}), 1.77(\mathrm{~m}, 1 \mathrm{H}), 1.35(\mathrm{~s}, 3 \mathrm{H}), 1.99(\mathrm{~m}, 2 \mathrm{H}), 1.03(\mathrm{~m}, 1 \mathrm{H}), 0.95(\mathrm{~s}, 3 \mathrm{H}), 0.90(\mathrm{~s}$, $3 \mathrm{H}) ;{ }^{13} \mathrm{C} \mathrm{NMR}\left(\mathrm{CDCl}_{3}, 100 \mathrm{MHz}\right) \delta 144.5,127.7,127.1,126.8,84.3,80.5,53.2,51.9,50.7,31.6,30.4,24.4,23.1,22.3,14.1,9.9 ; \mathrm{IR}$ (thin film) $v_{\max } 3461,3286,2949,1481,1460,1443,1390,1369,1328,1284,1211,1093,1075,1040,951,899,759,723,702 \mathrm{~cm}^{-1}$; HRMS (ESI), $m / z$ calcd for $\mathrm{C}_{16} \mathrm{H}_{22} \mathrm{O}_{2} \mathrm{Na}$ : 269.1517; found: 269.1511 . 
6-Bromo-7-methoxybenzo[ $d][1,3]$ dioxole-5-carbaldehyde (10)

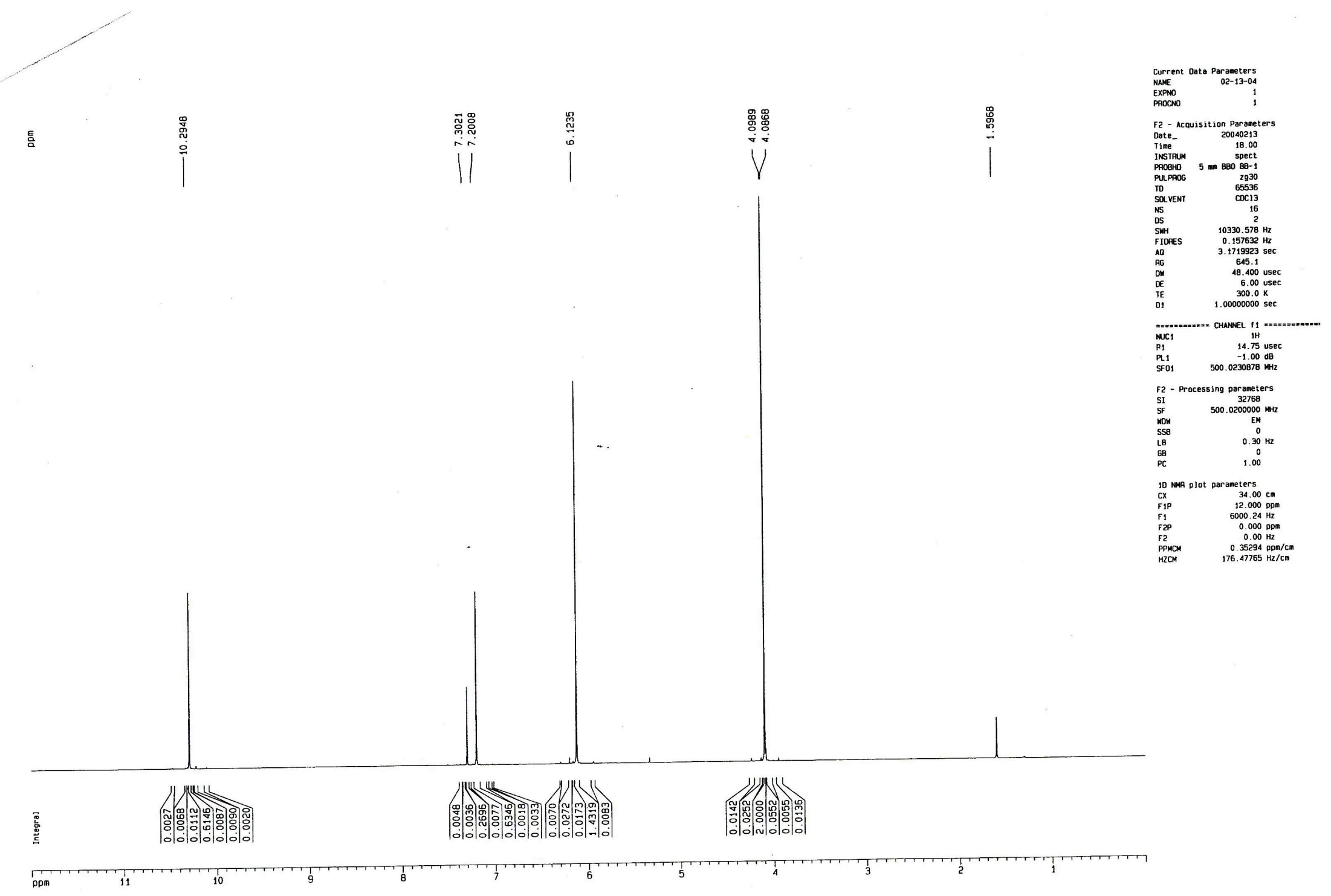


6-Bromo-7-methoxybenzo[ $d][1,3]$ dioxole-5-carbaldehyde (10)

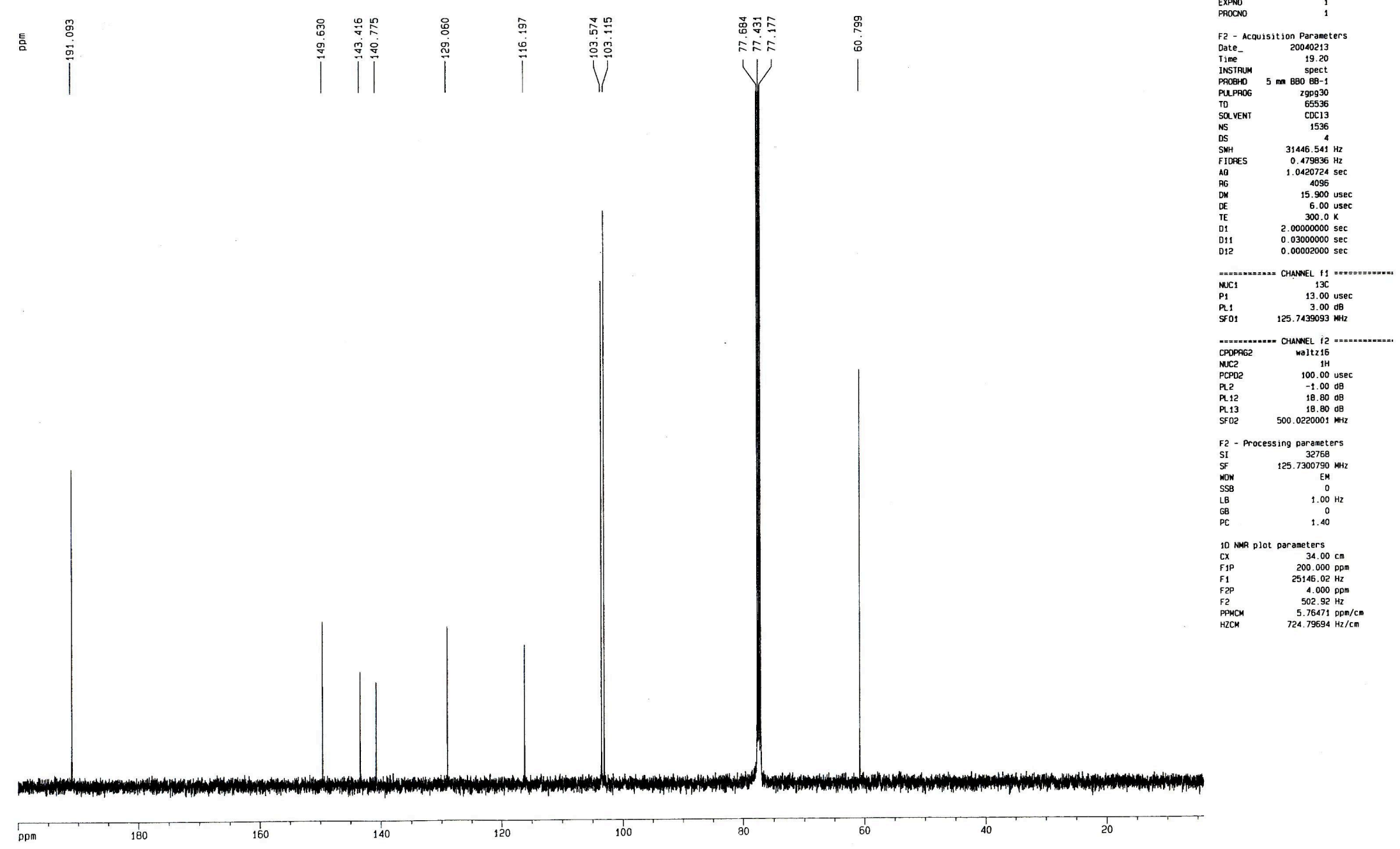




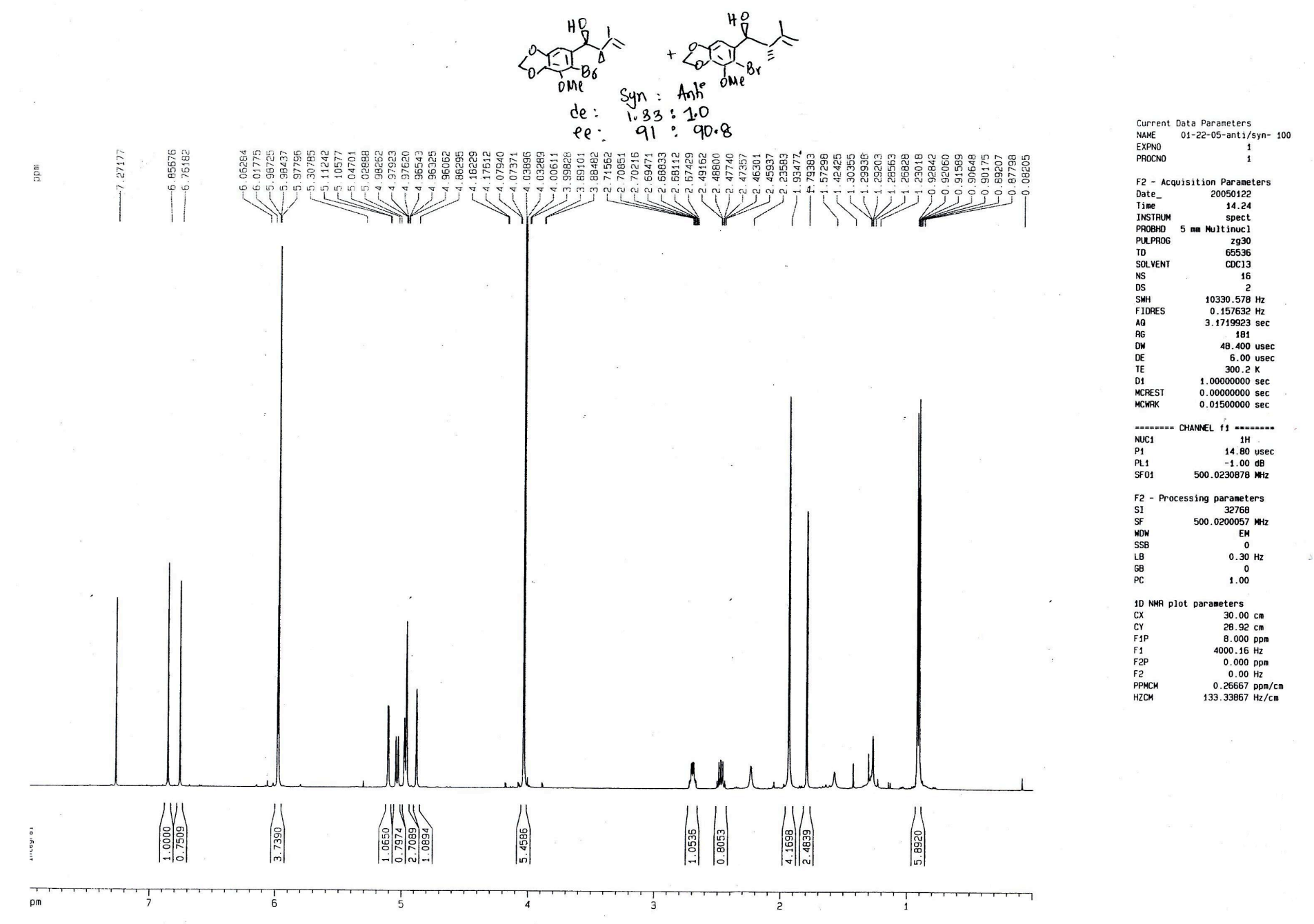


5-((1S*,2R*)-1-Hydroxy-2,3-dimethyl-3-butenyl)-6-Bromo-7-methoxy benzo[d][1,3]dioxole (11) (only $\boldsymbol{S y n})$

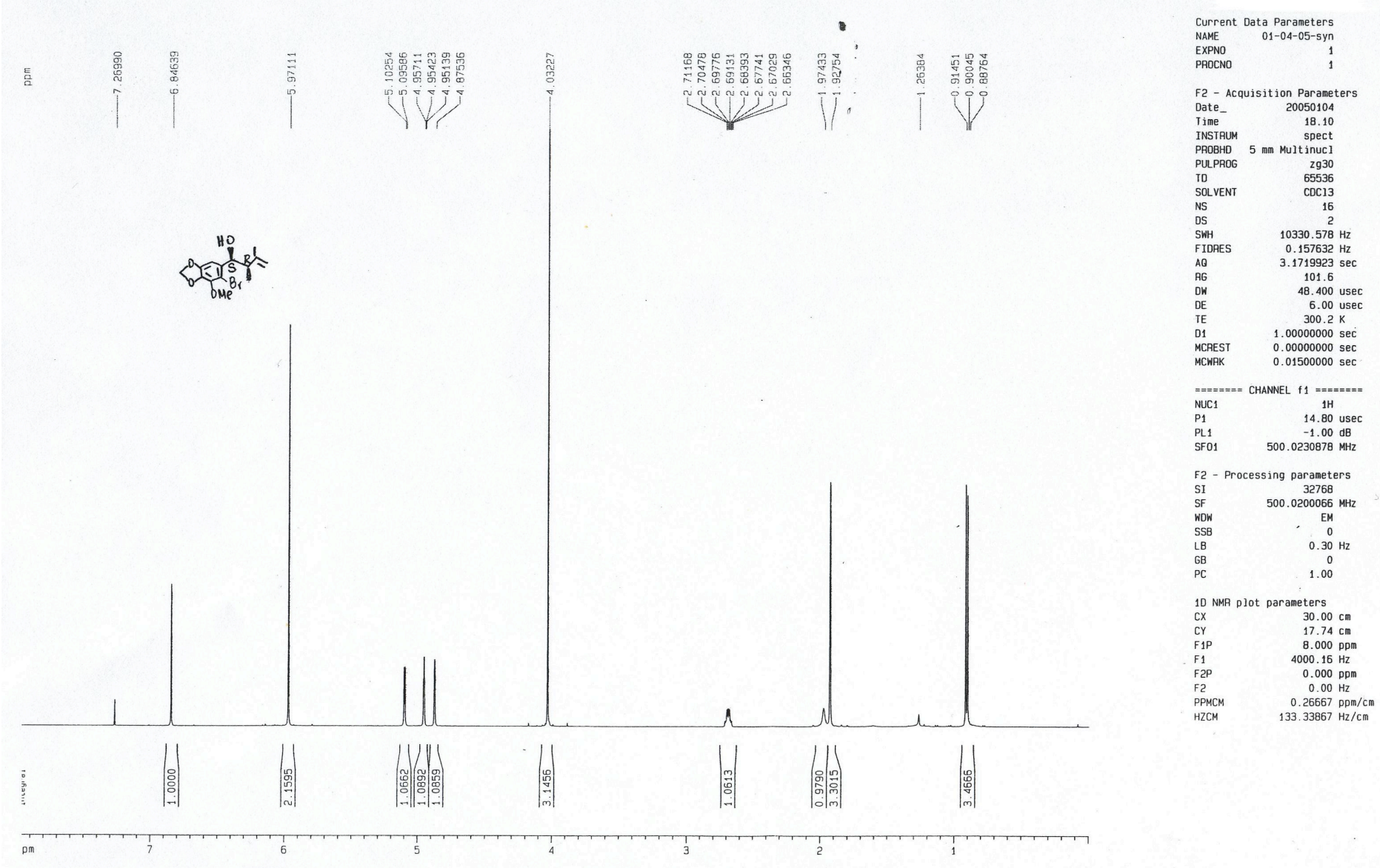


5-((1S*,2R*)-1-Hydroxy-2,3-dimethyl-3-butenyl)-6-Bromo-7-methoxy benzo[ $d][1,3]$ dioxole (11)

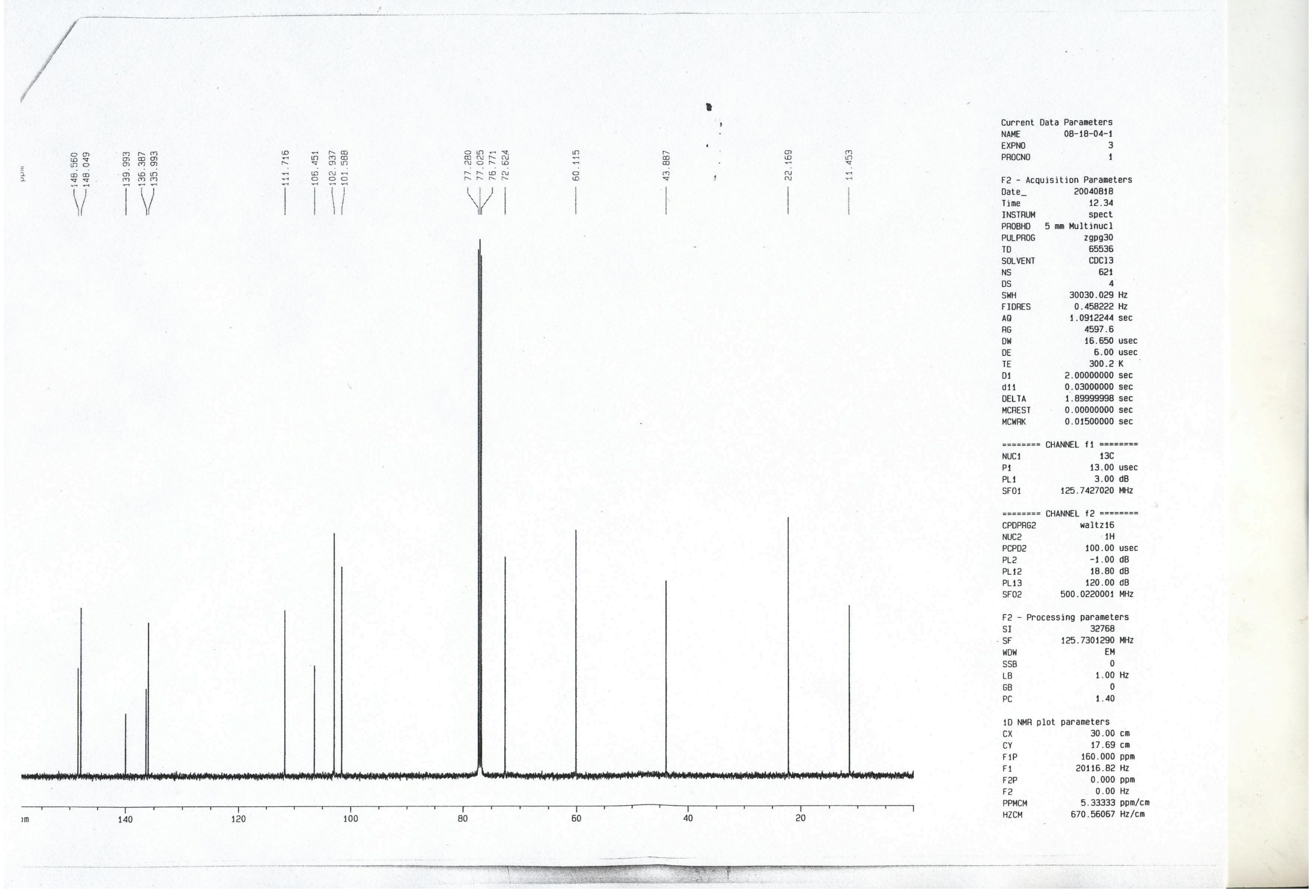


5-((1S*,2R*)-1-(tert-Butyldimethylsilyl)oxy-2,3-dimethyl-3-butenyl)-6-Bromo-7-methoxybenzo[d][1,3]dioxole (13)

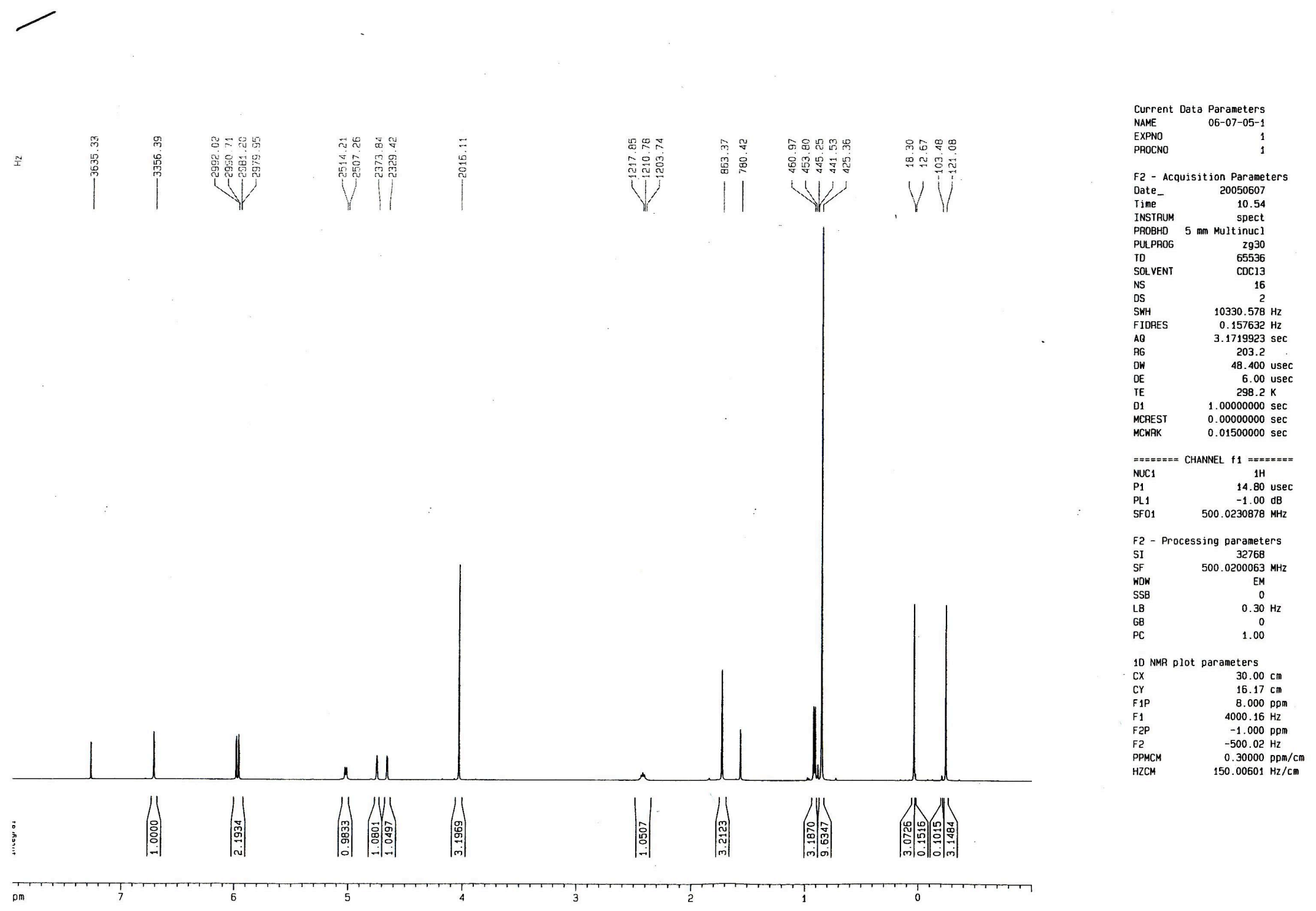



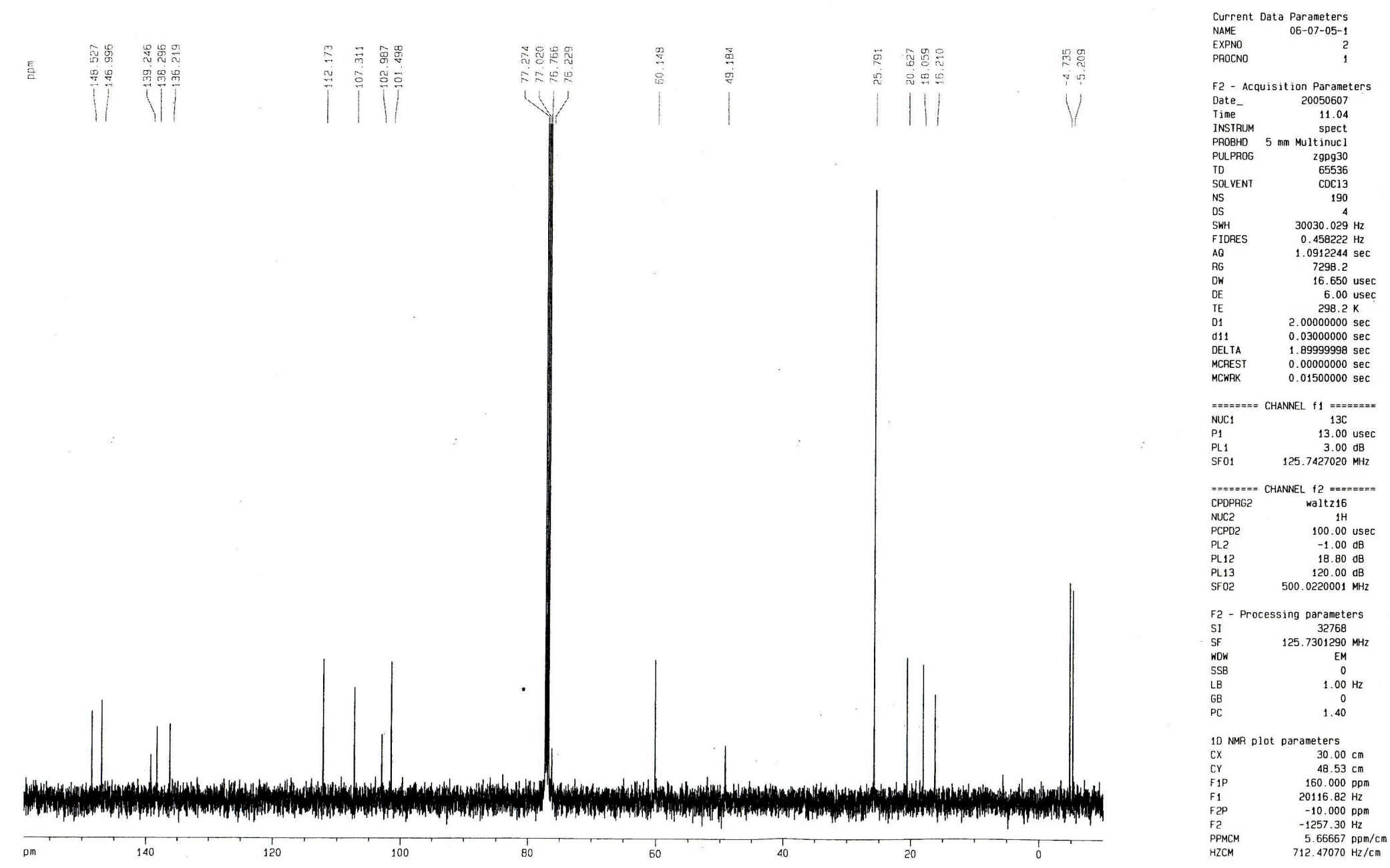
Biaryl silyl ether (18)

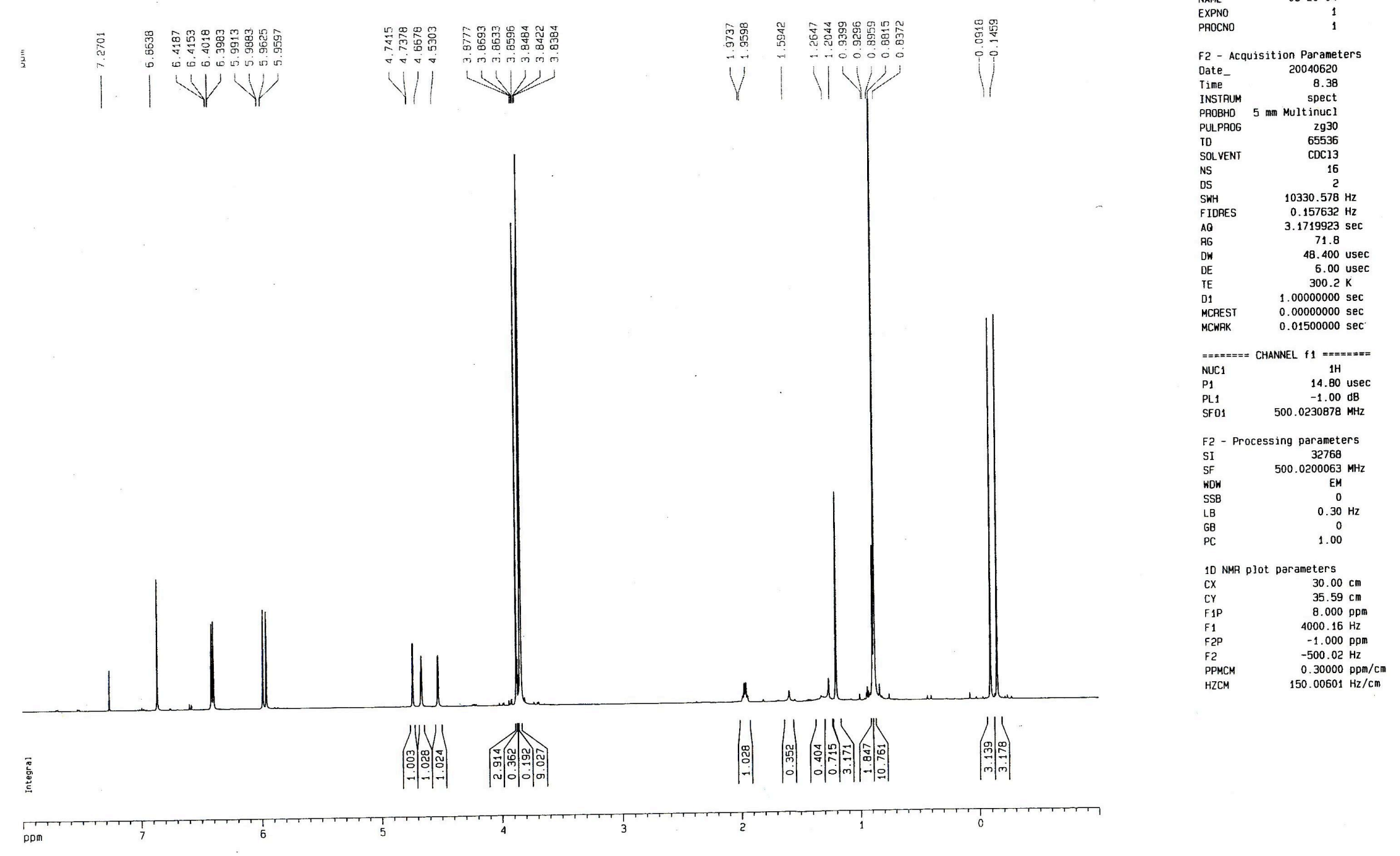


Intermediate alcohol (after hydroboration-oxidation of silyl ether 18)
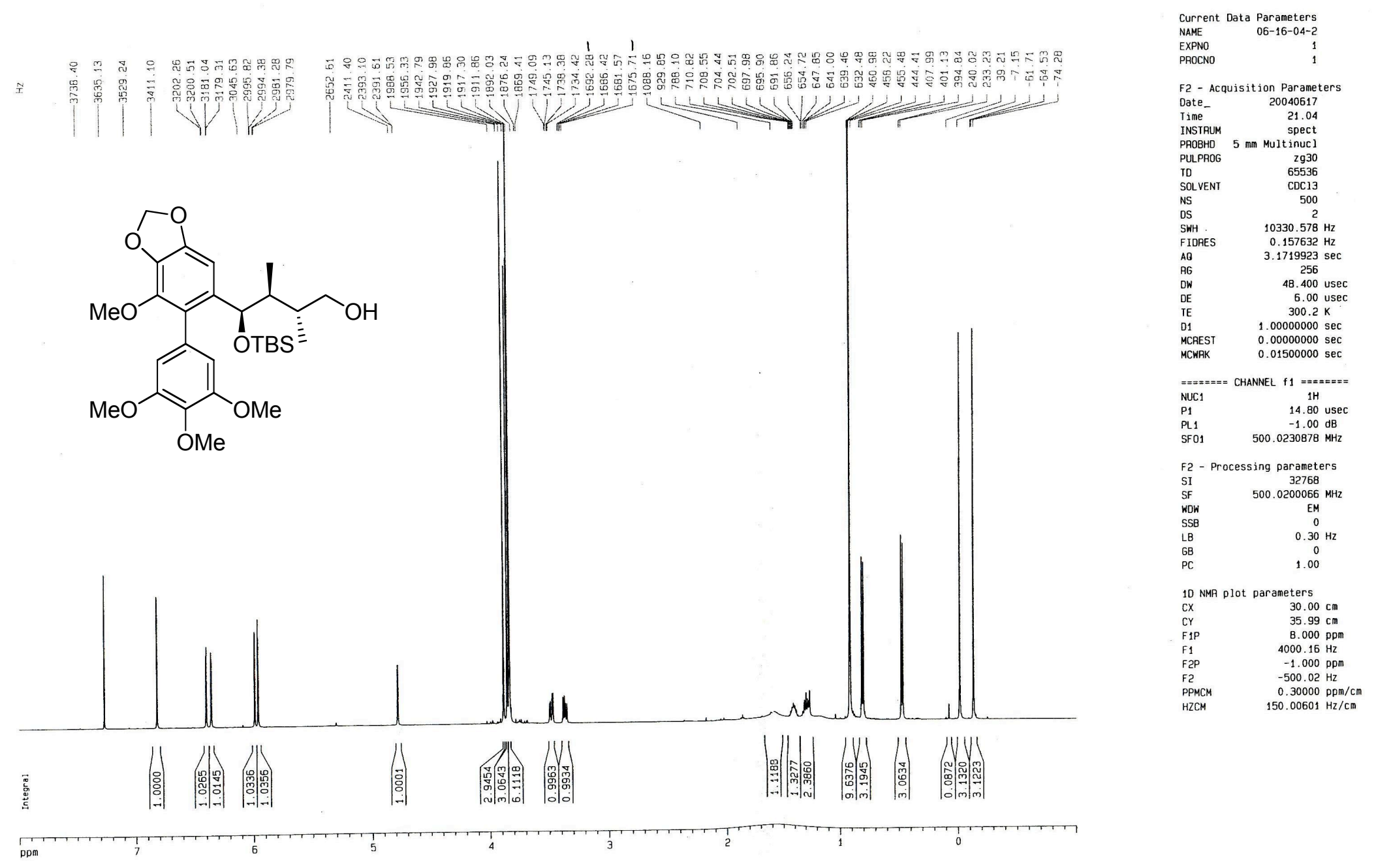
Intermediate alcohol (after hydroboration-oxidation silyl ether 18)
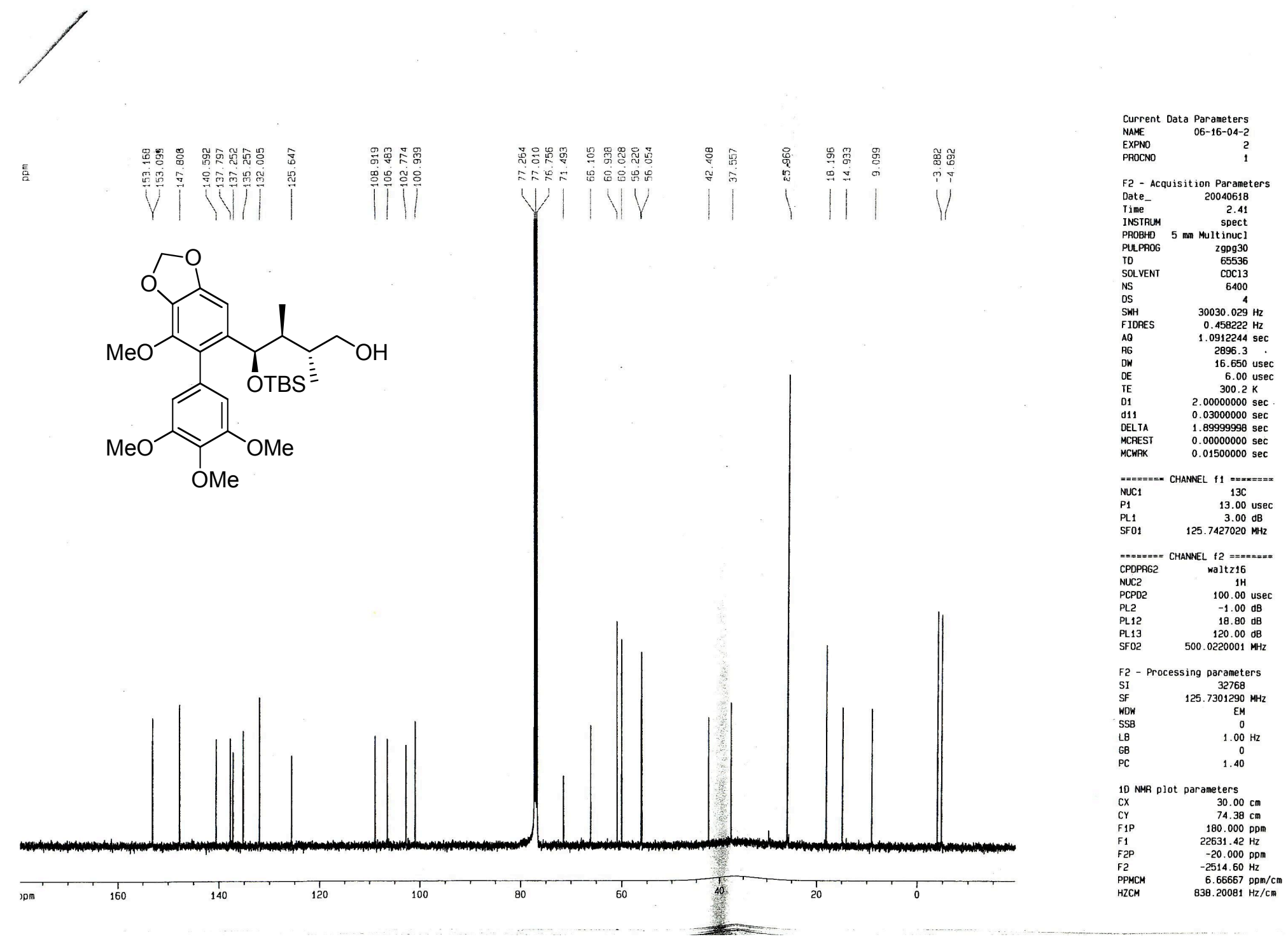
Diol (19)
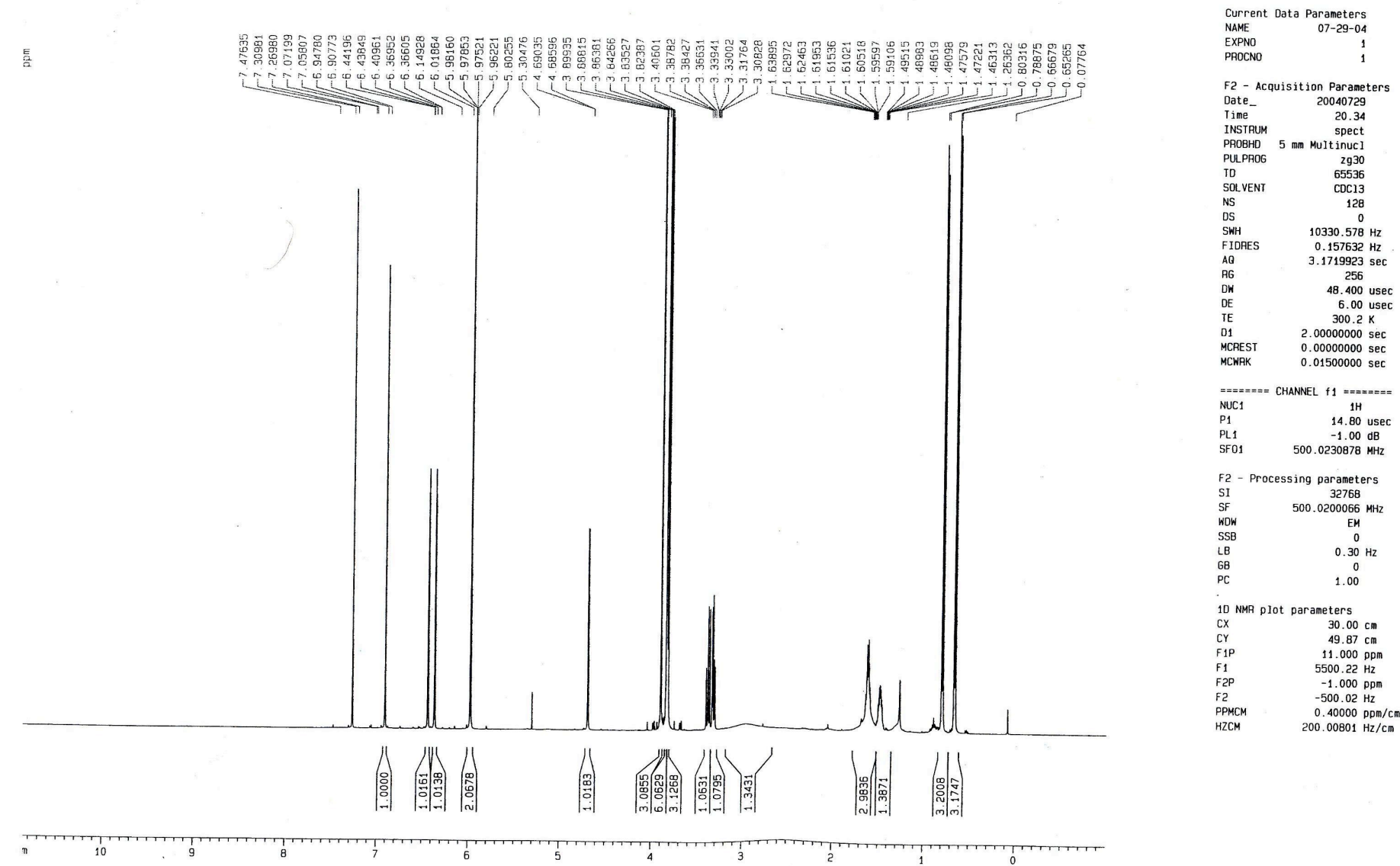
Diol (19)
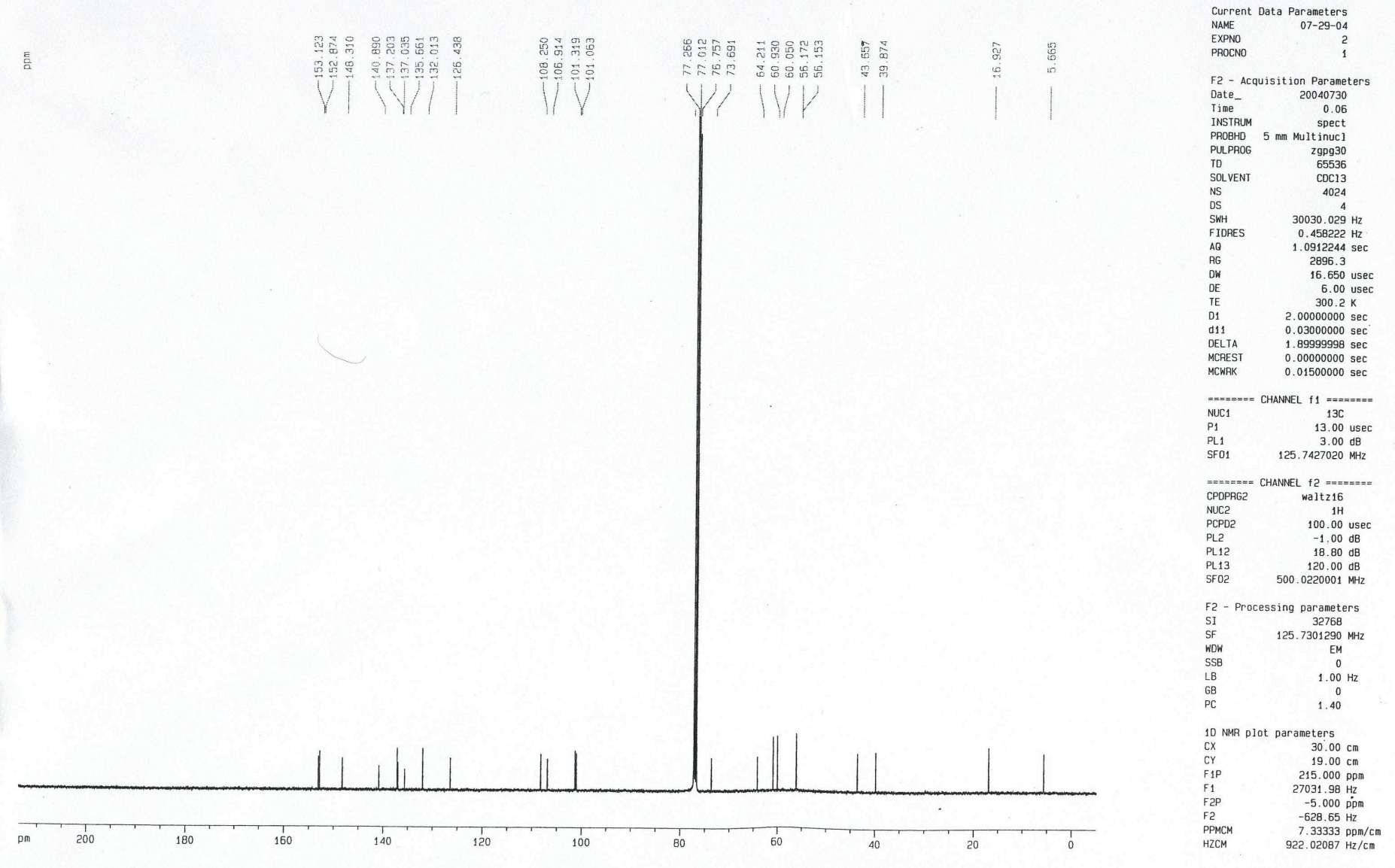
Eupomatilone 4 (1d)

\section{Eupo-4}
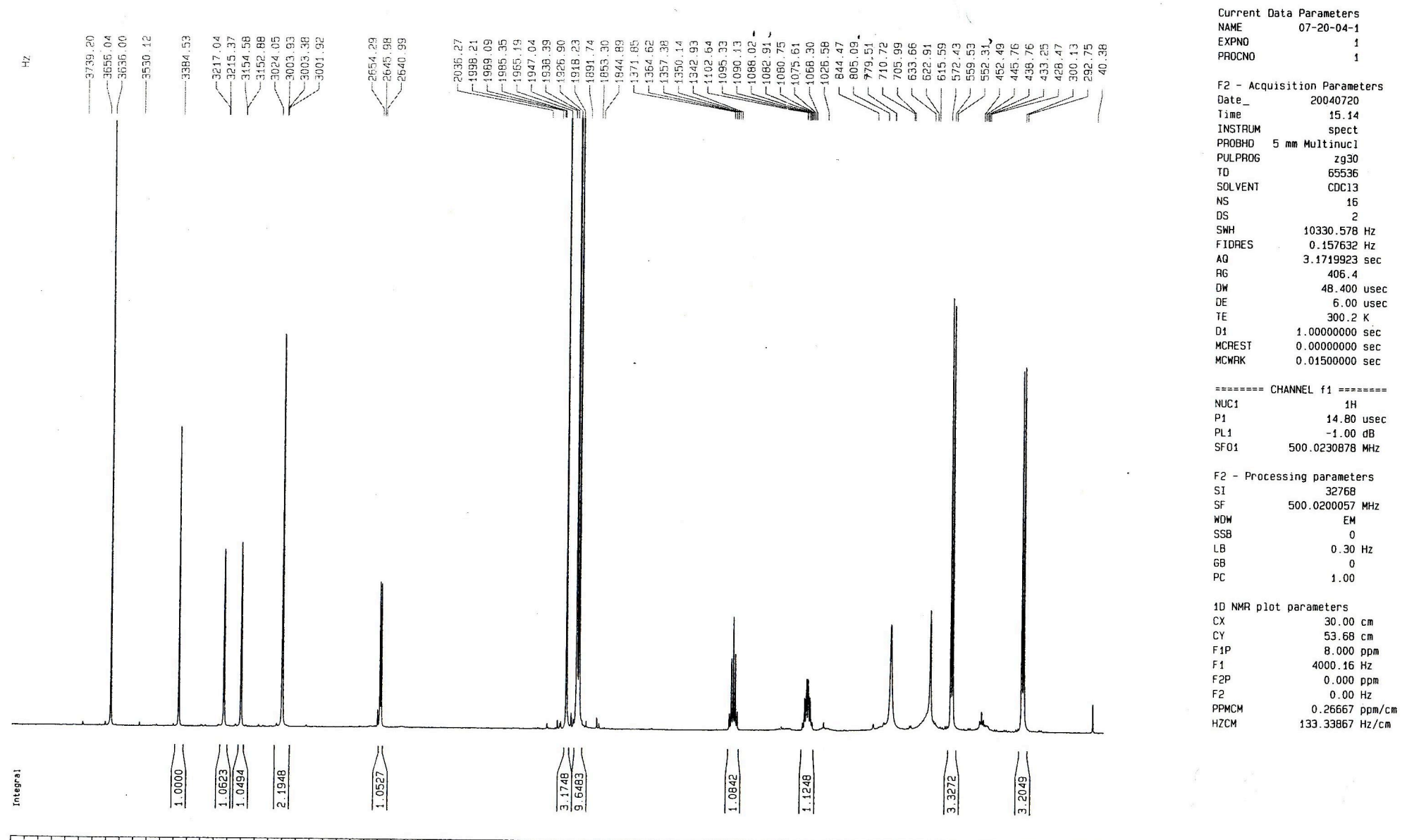

ppm 
Eupomatilone 4 (1d)
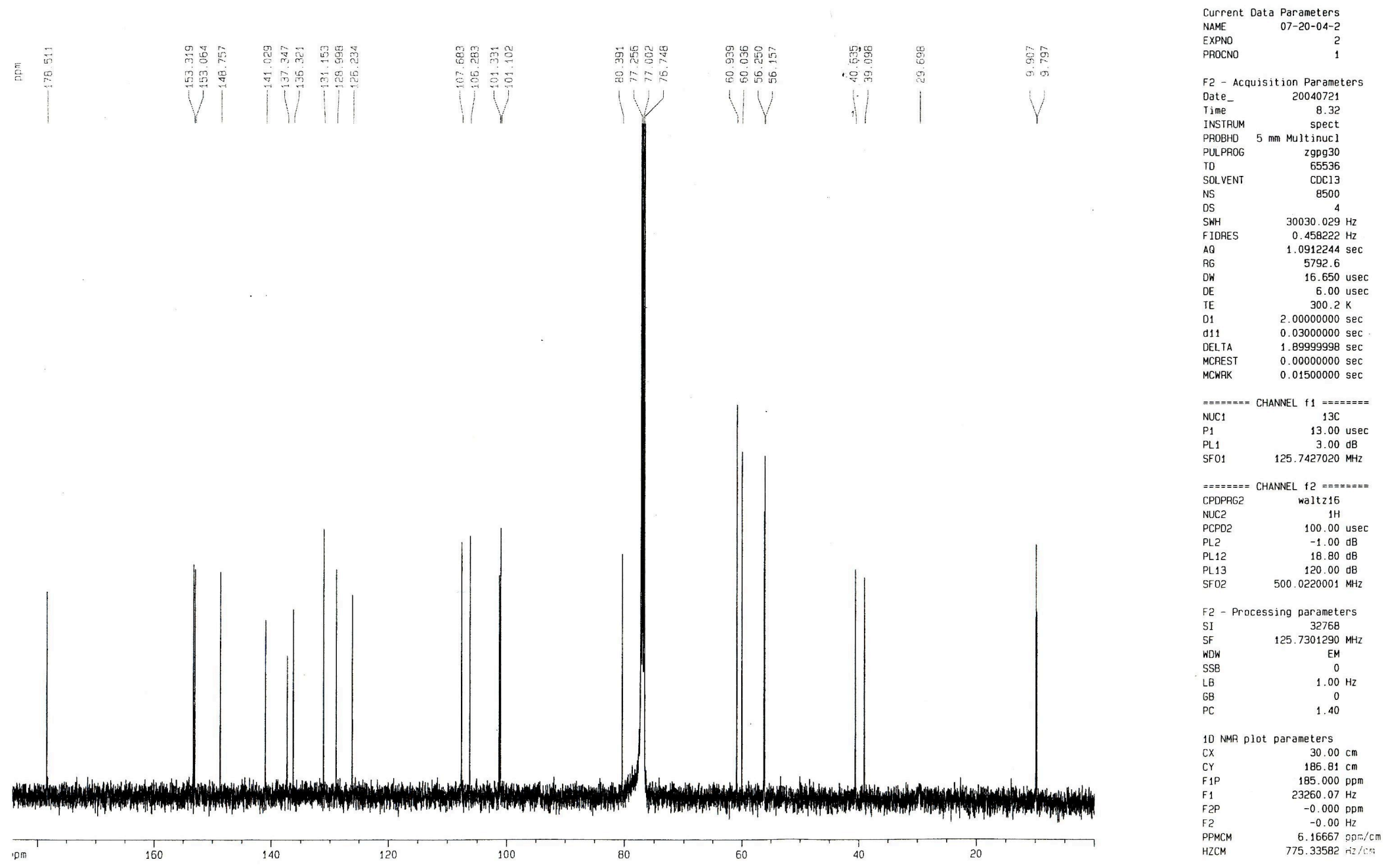
1-((1S*,2R*)-1-(tert-Butyldimethylsilyl)oxy-2,3-dimethyl-3-butenyl)-2-bromo-3,4,5-trimethoxybenzene (20)

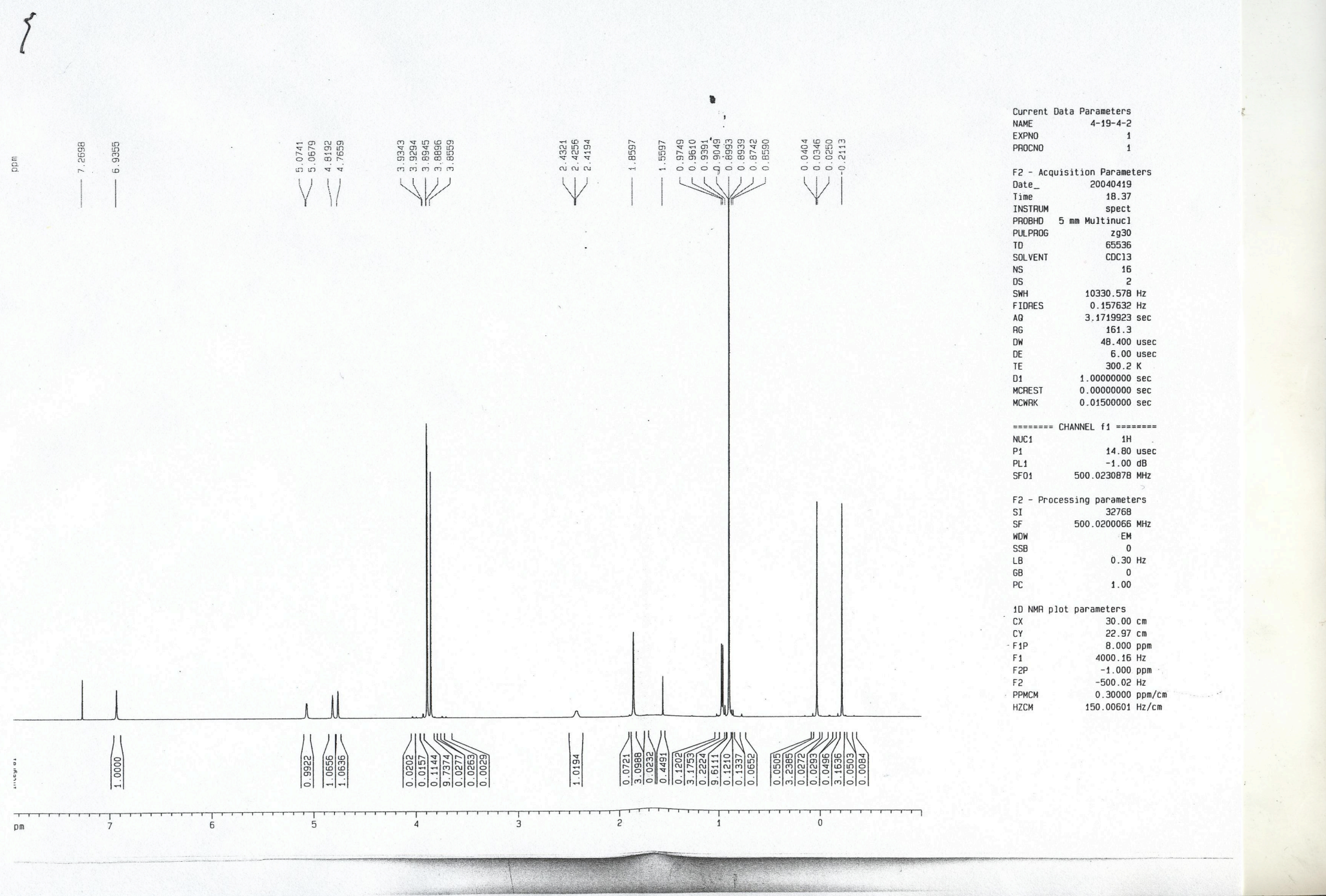




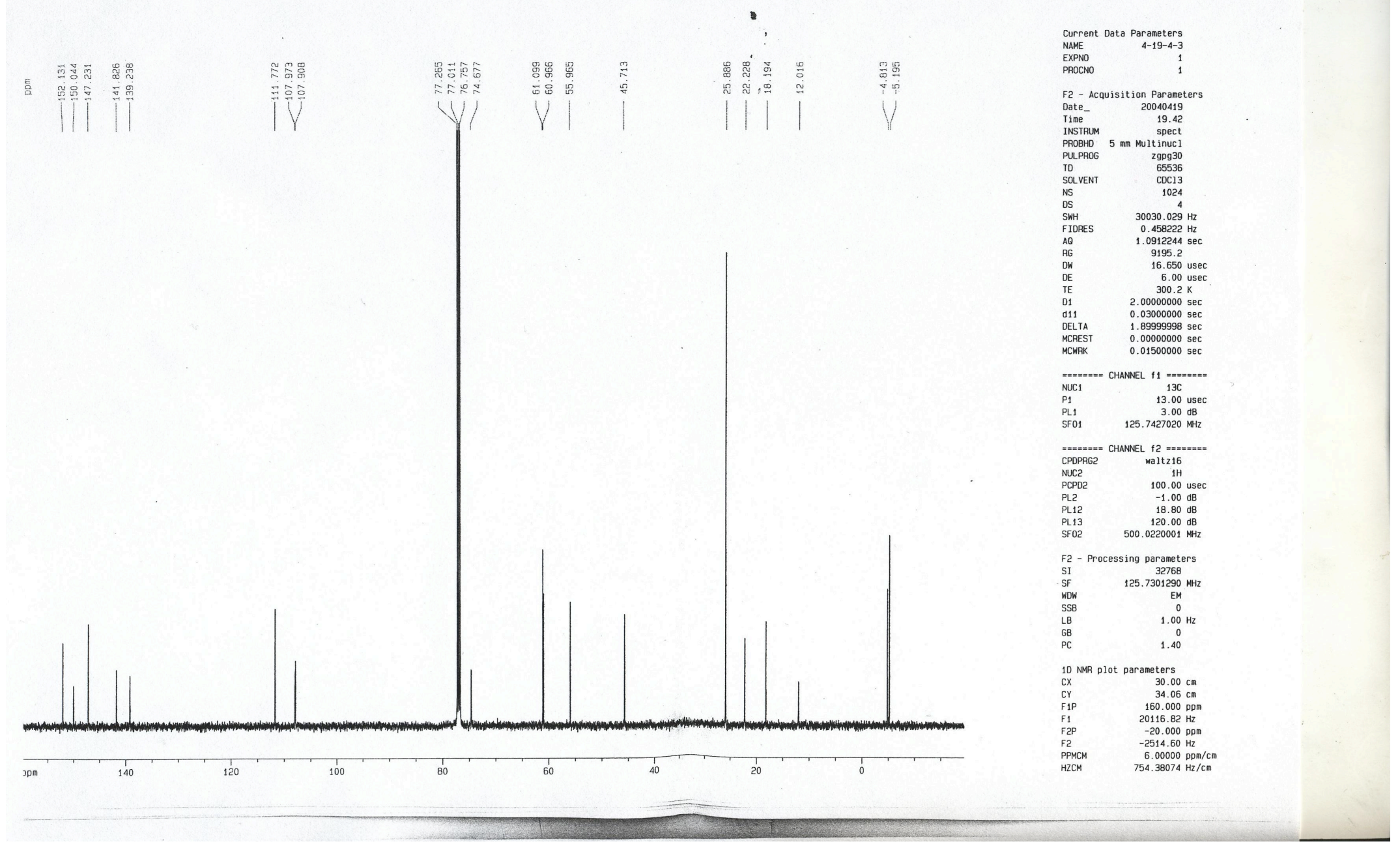




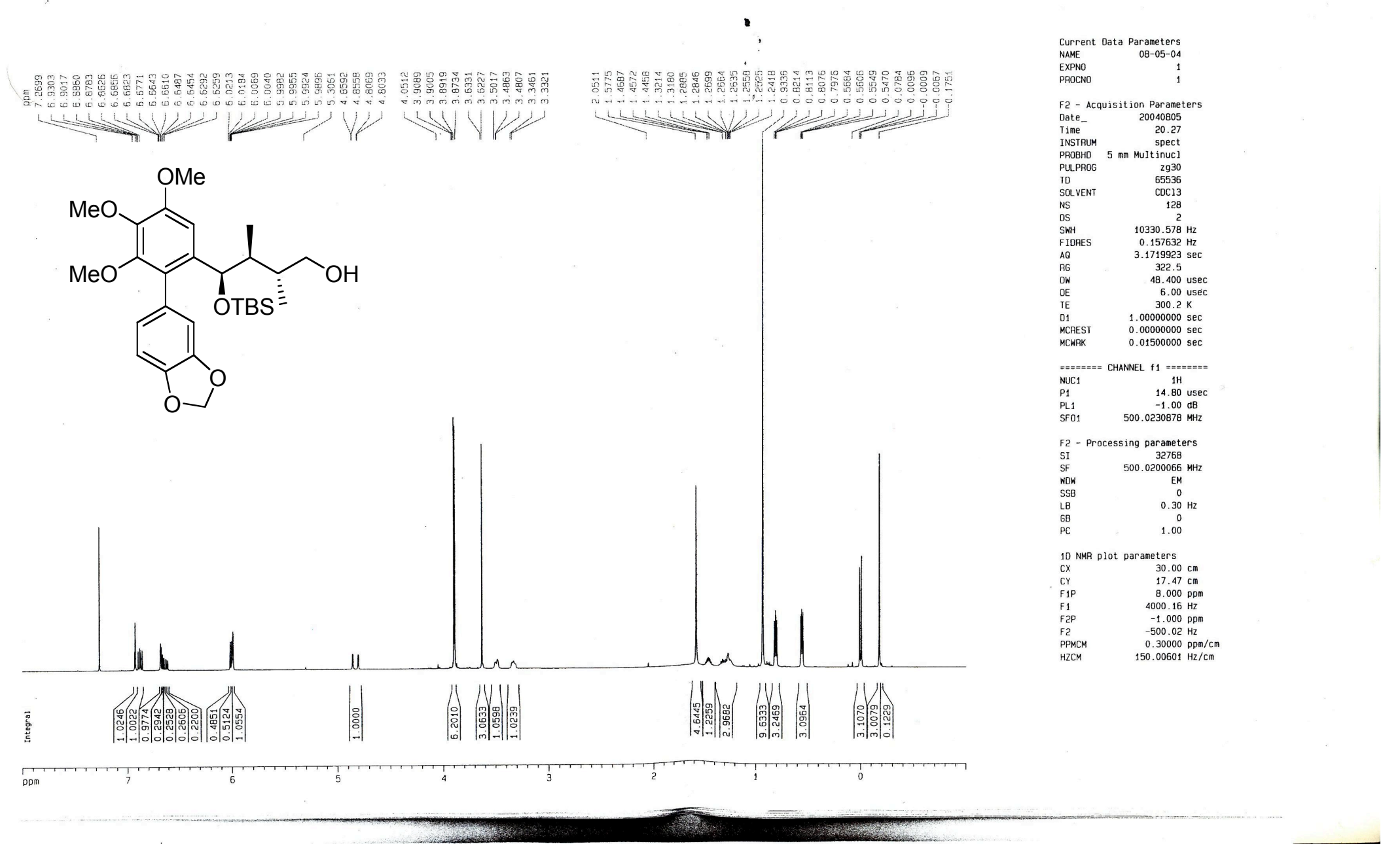


Primary Alcohol, after hydroboration-oxidation of $\mathbf{2 5}$

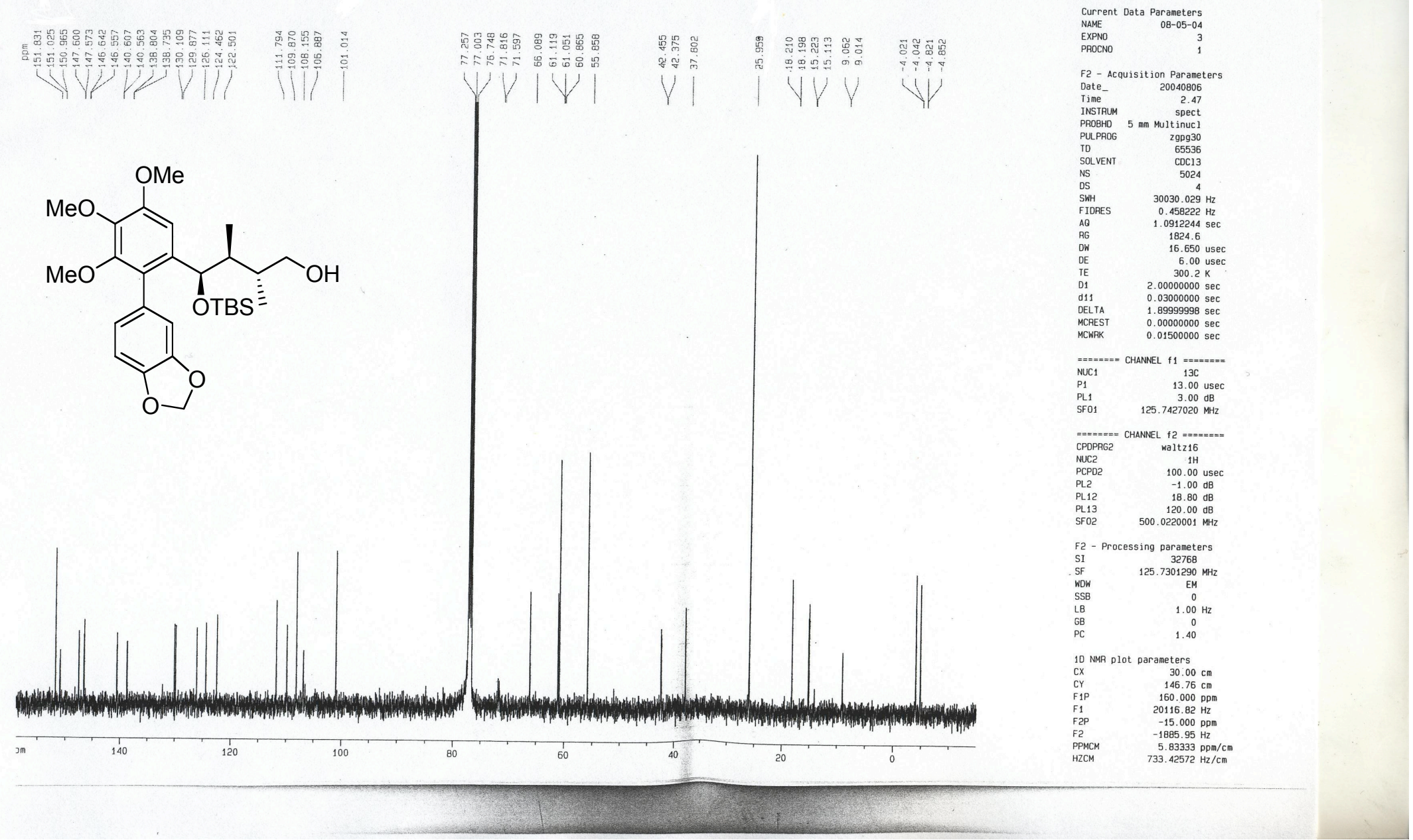


Diol, after TBAF deprotection from $\mathbf{2 5}$

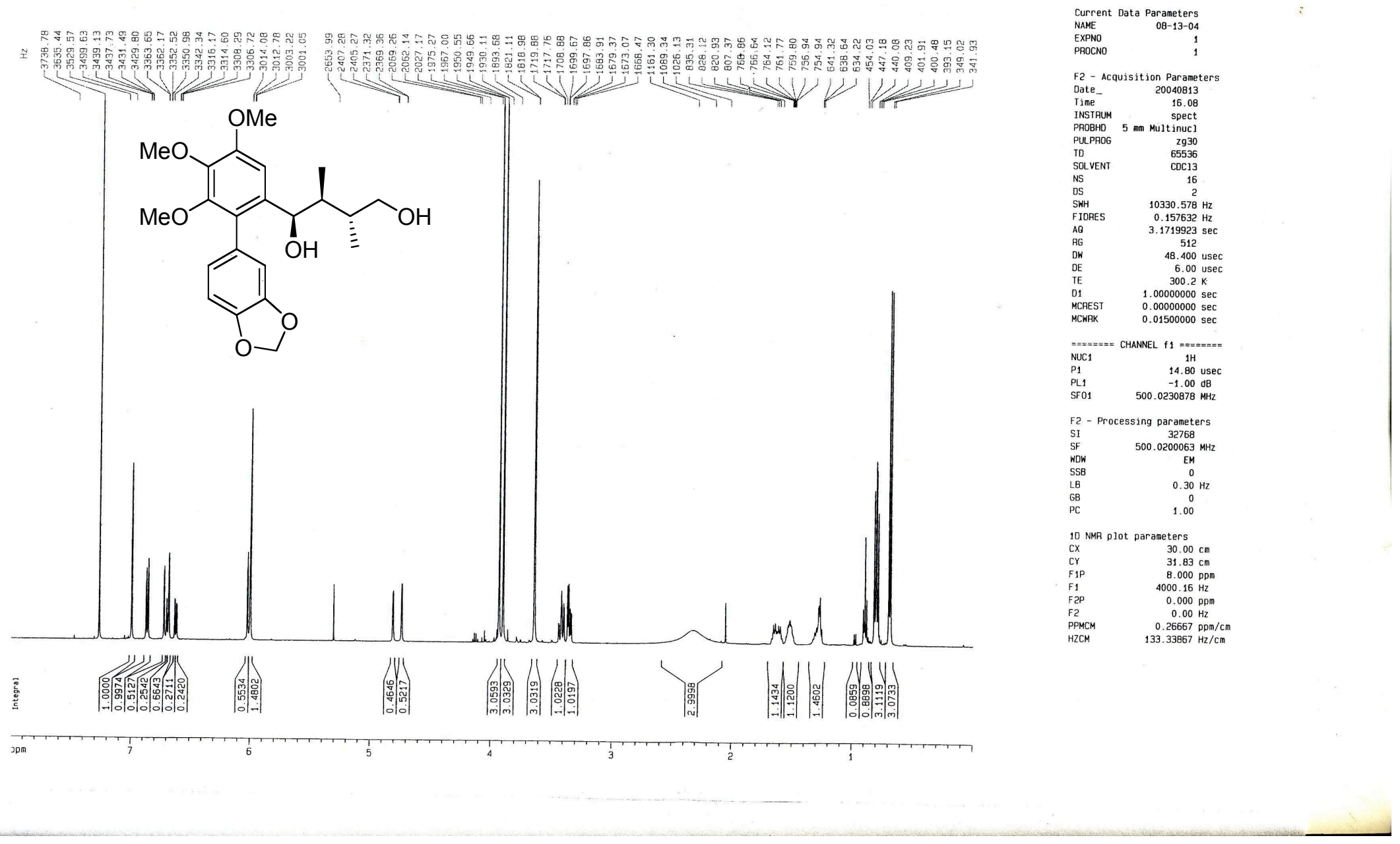


Diol, after TBAF deprotection from 25
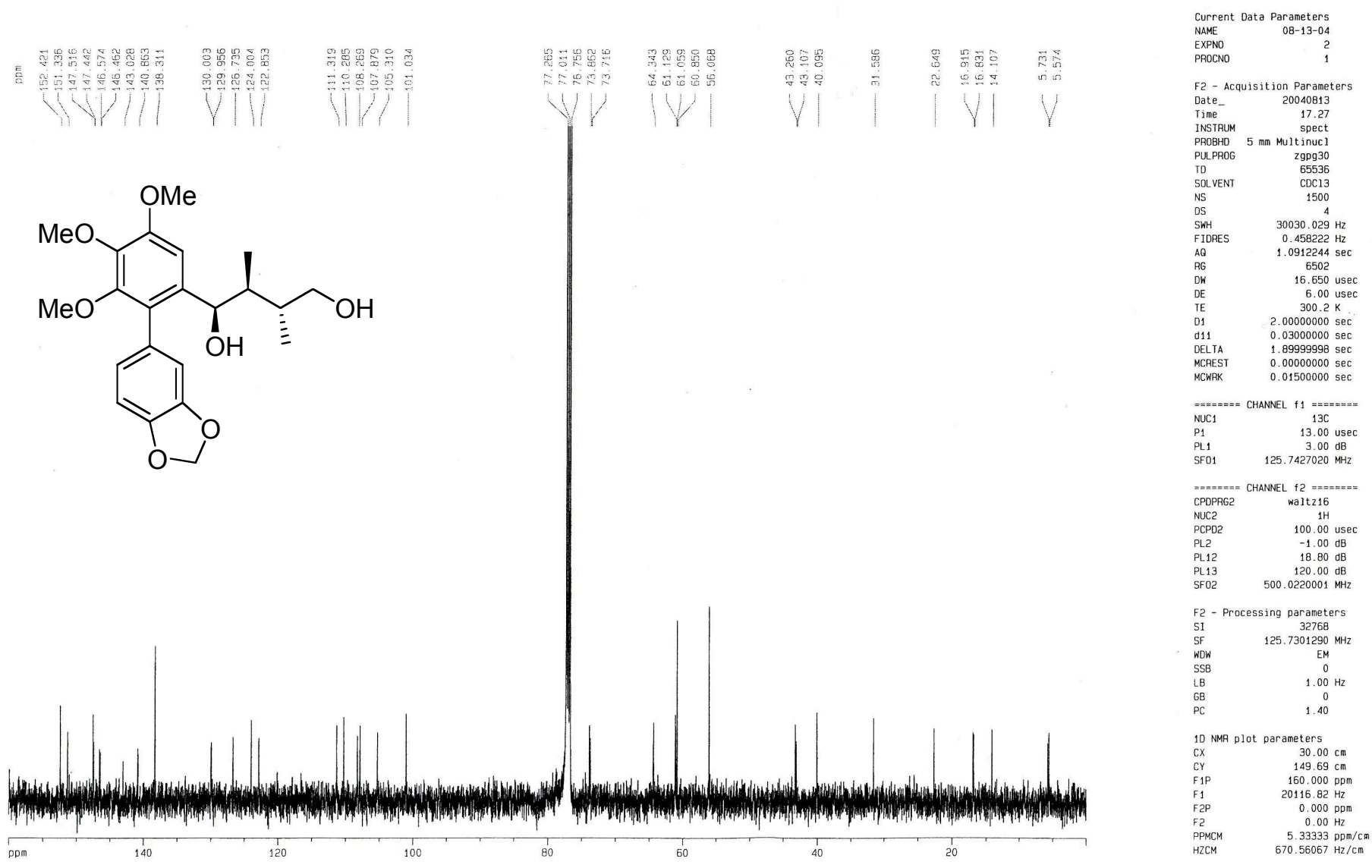
3-epi-eupomatilone 6 (26)
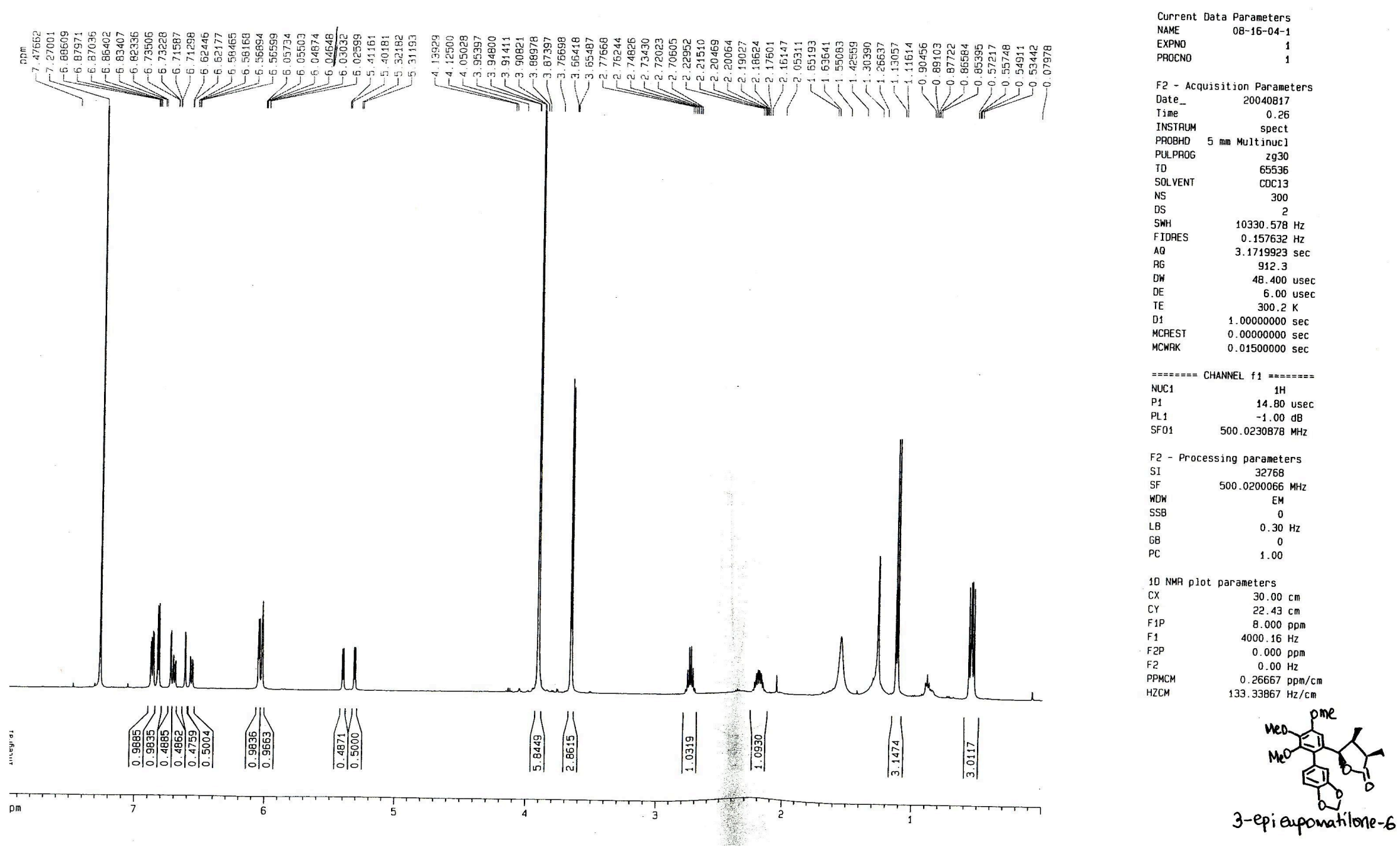
3-epi-eupomatilone 6 (26)
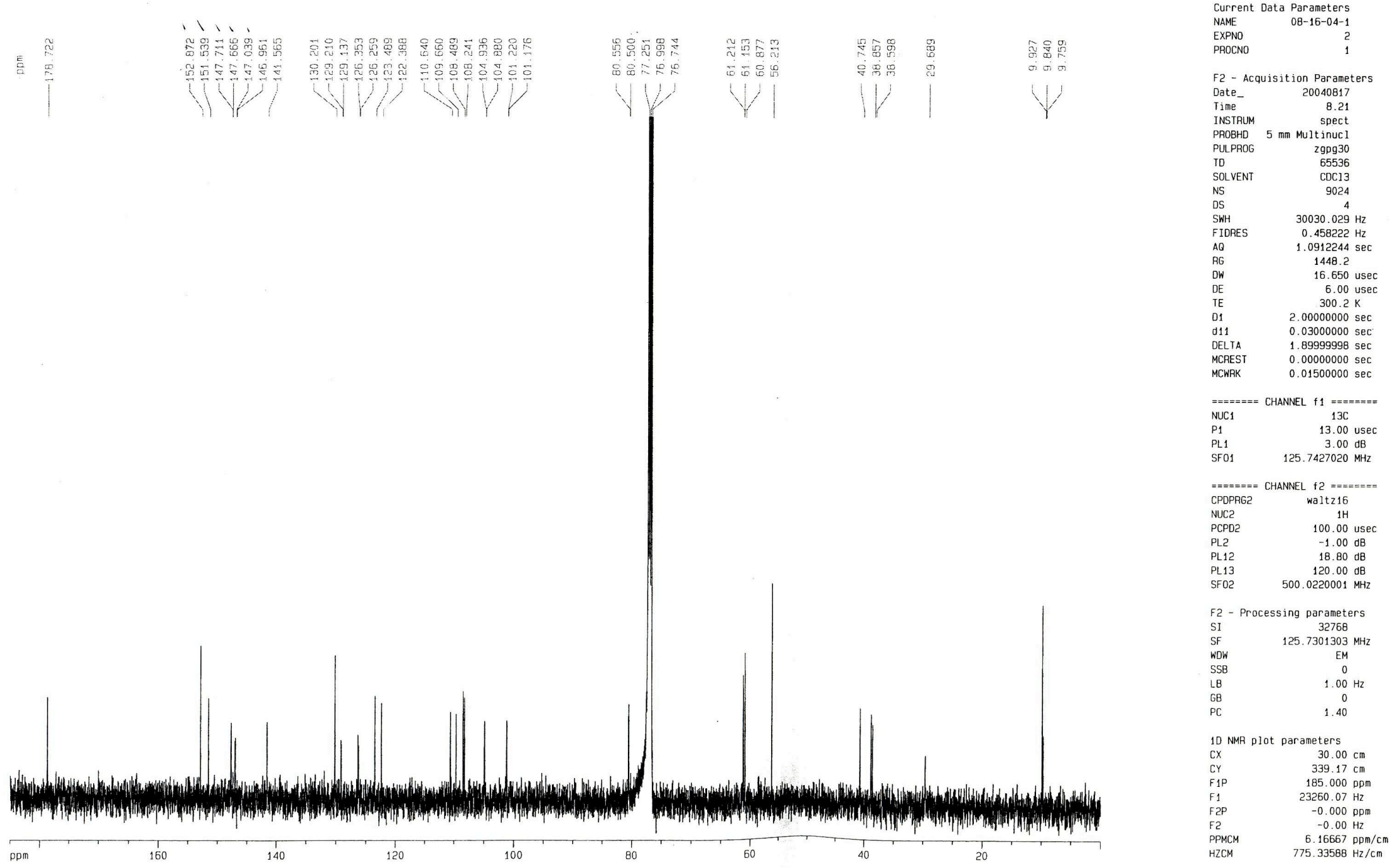
Eupomatilone 6 (1f)
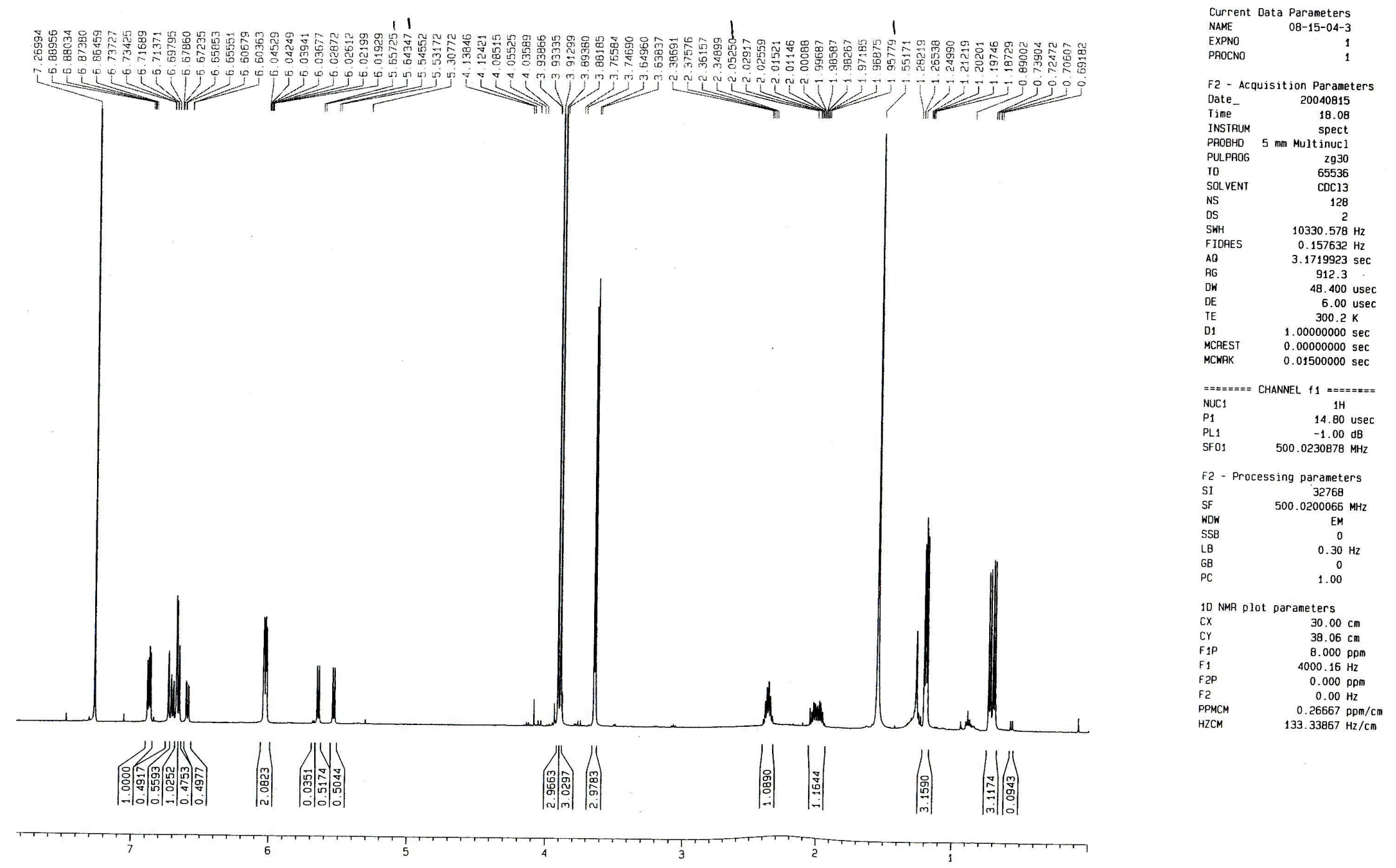
Eupomatilone 6 (1f)
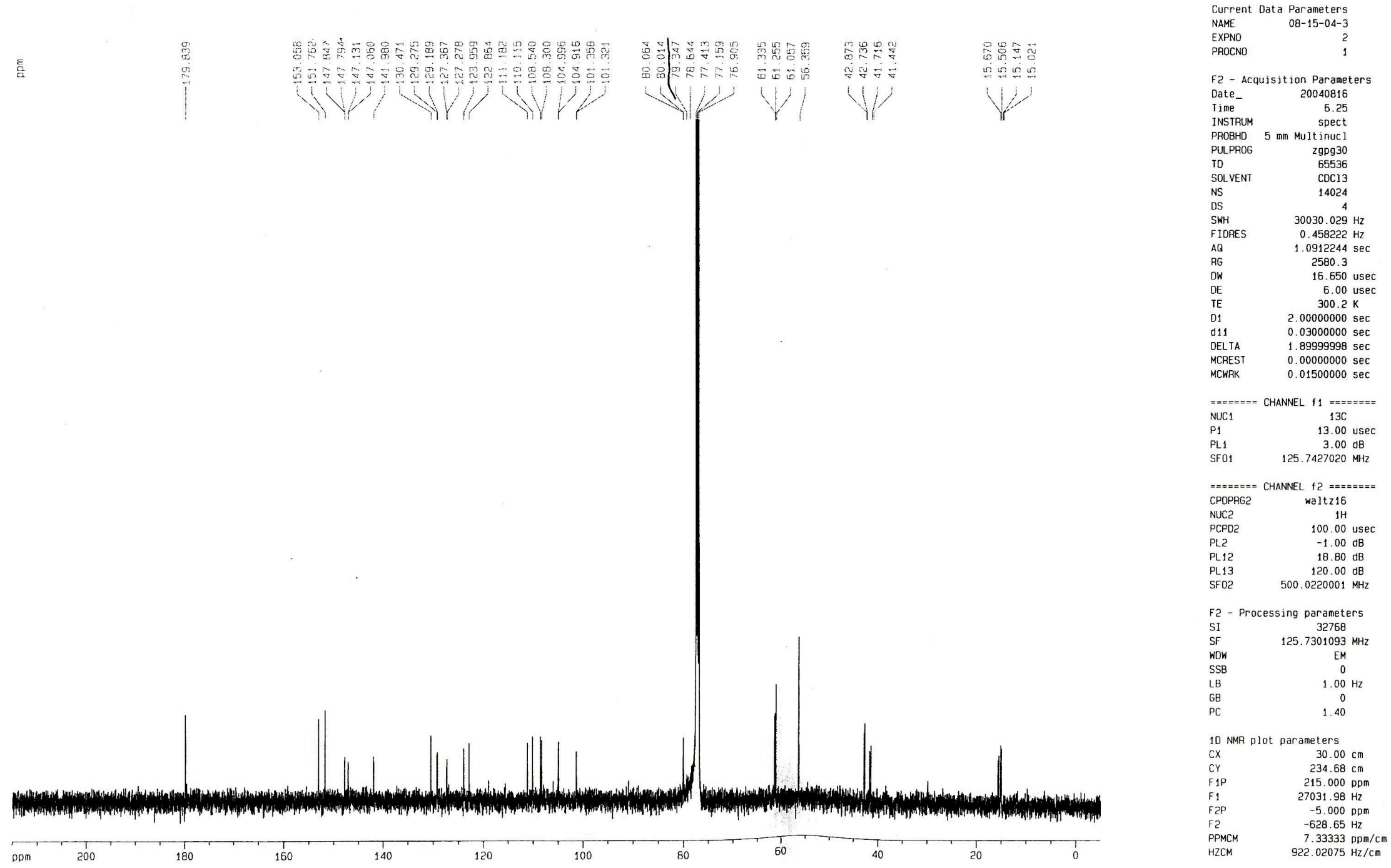
Baylis Hillman alcohol (34) (crude, carried over to next step)

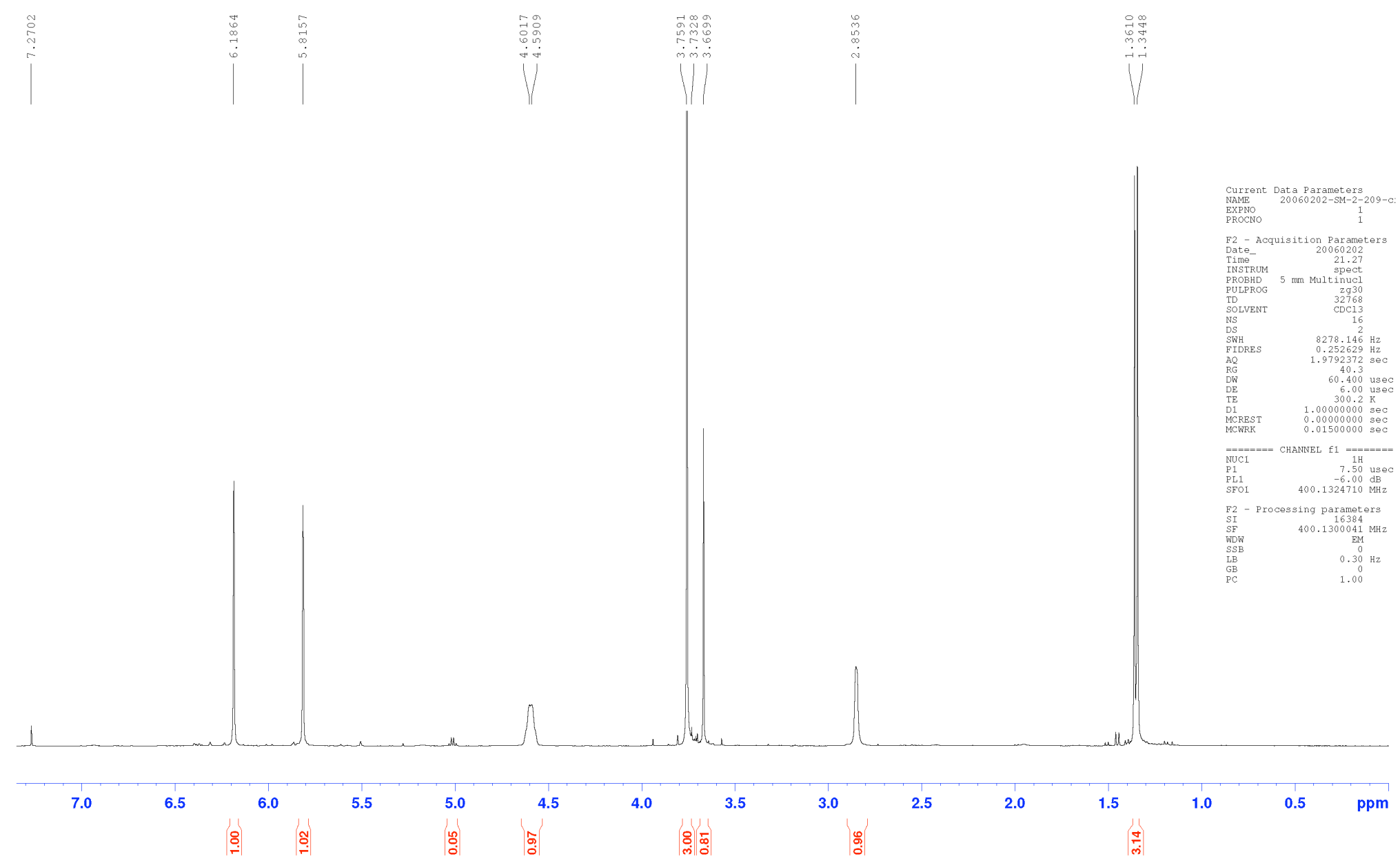


Bromide (35)
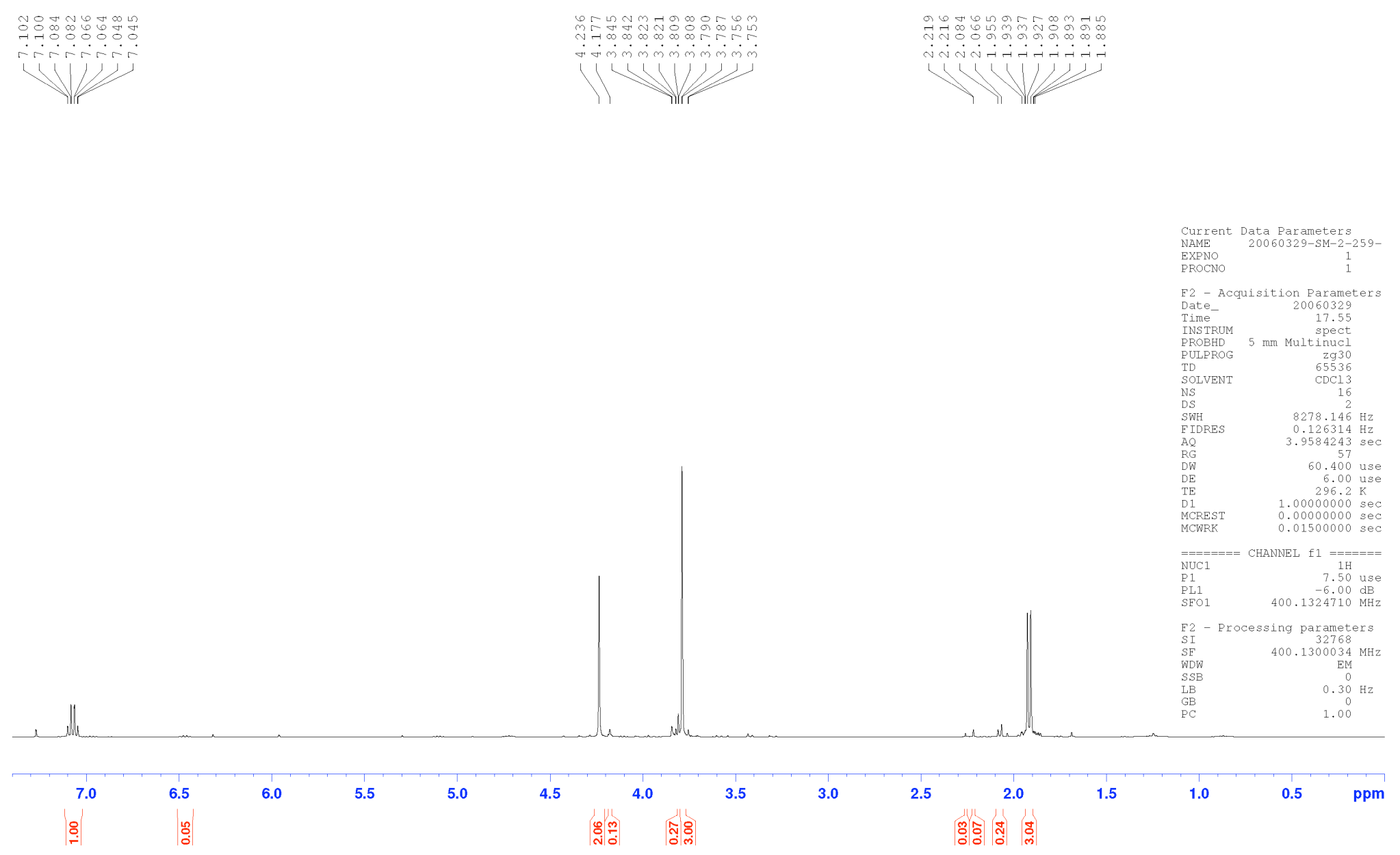
Bromide (35)

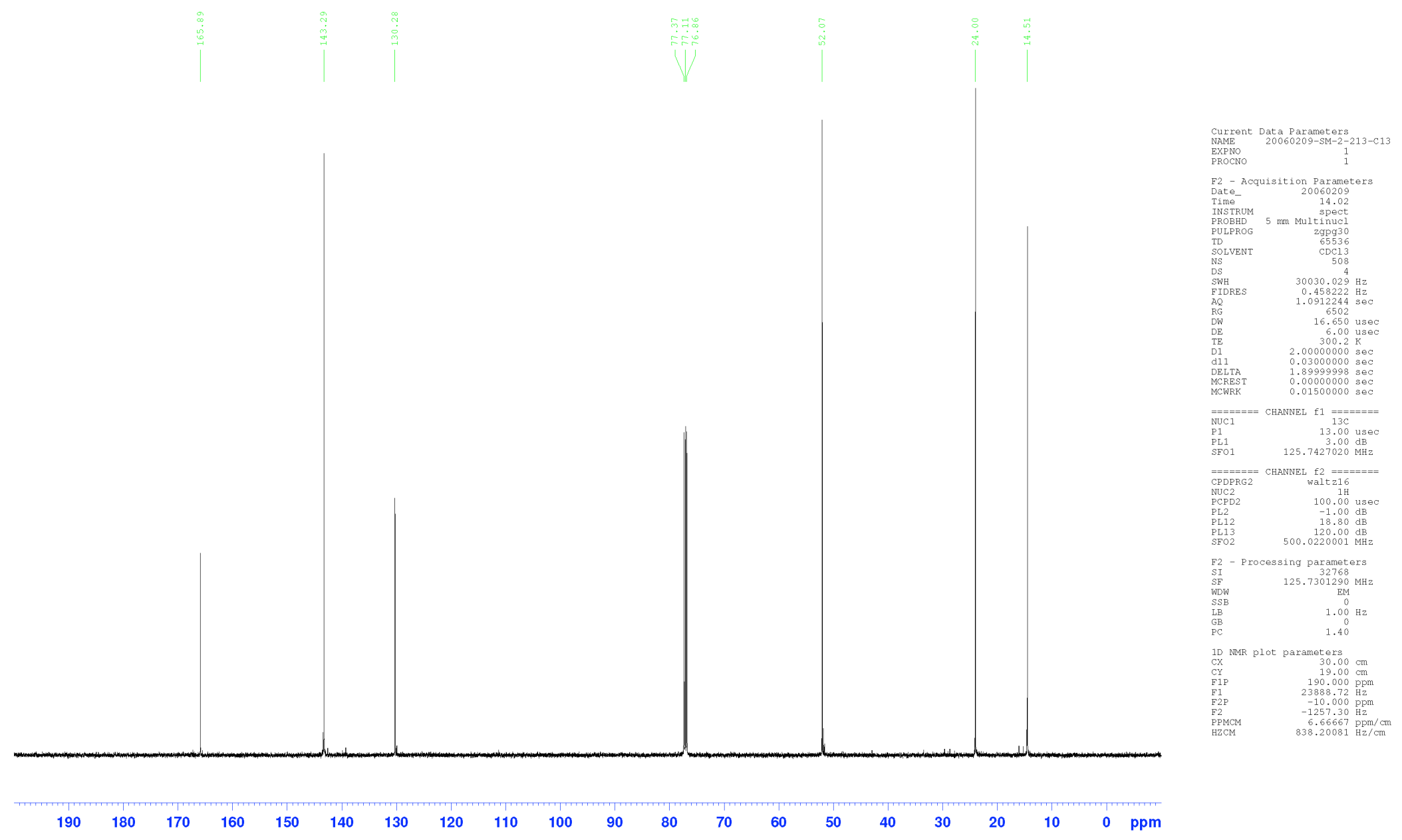


Acetate (44)

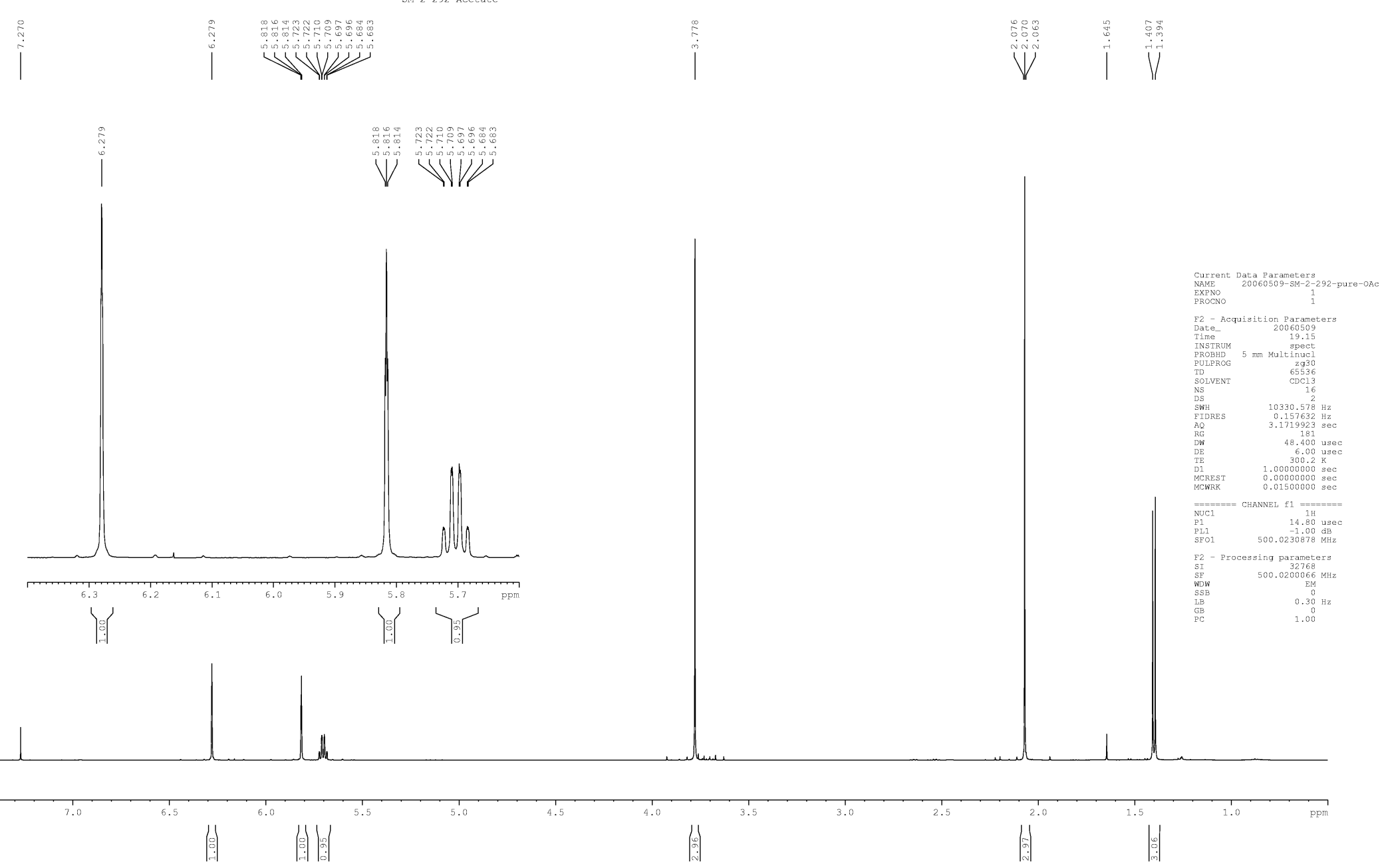


Acetate (44)

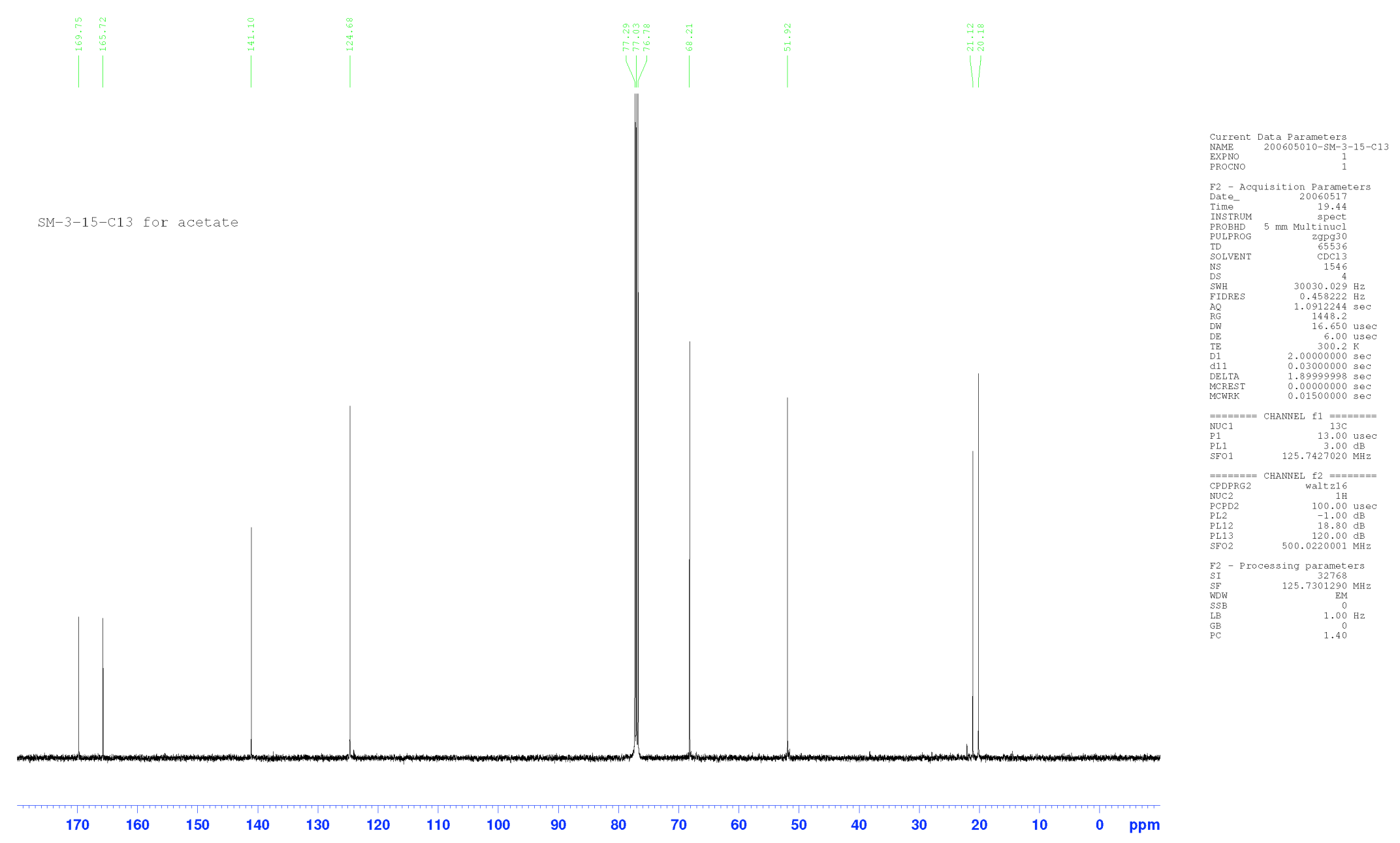


Carbomethoxycrotyl pinacoladoboronate (45)

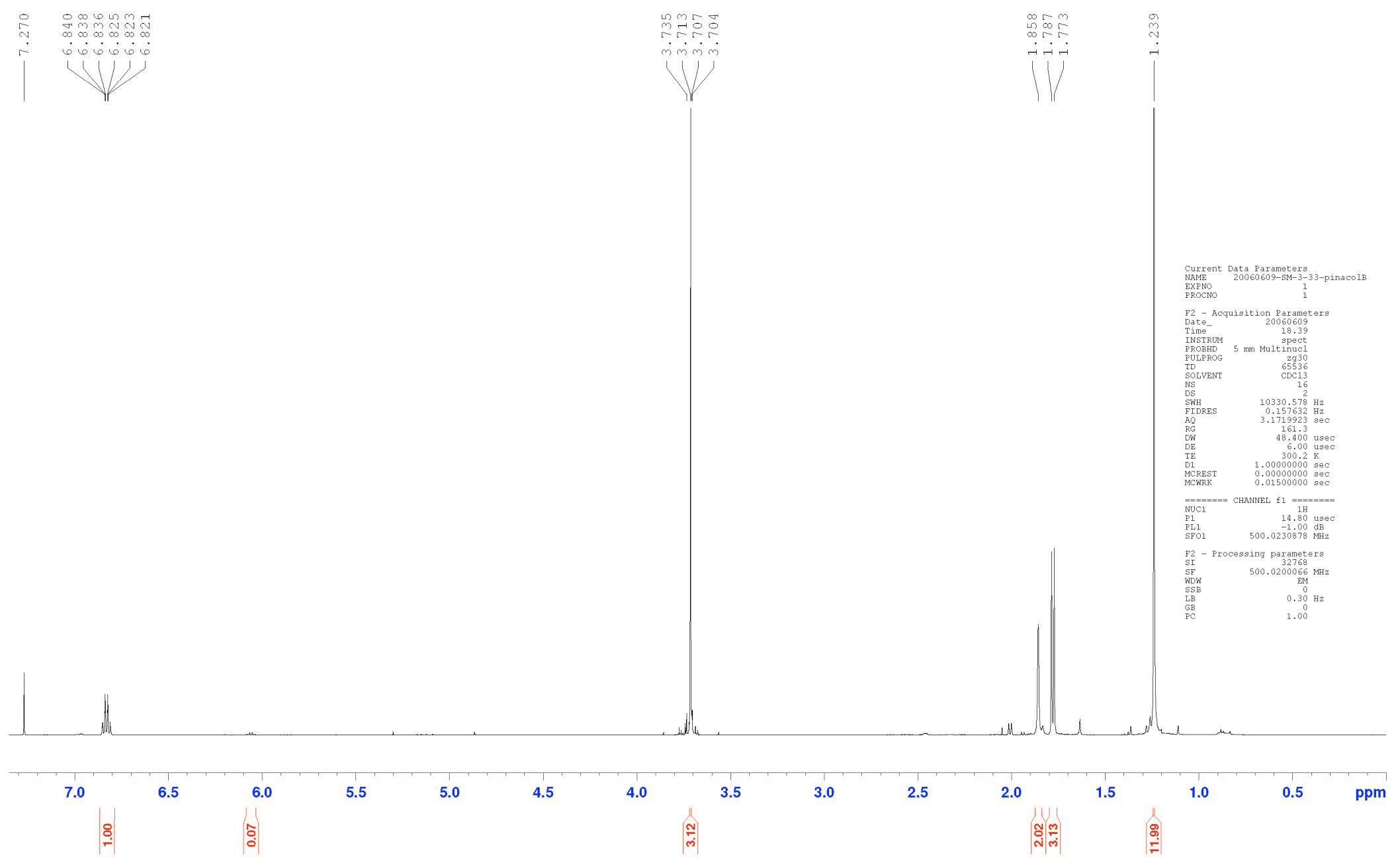


Carbomethoxycrotyl pinacoladoboronate (45)

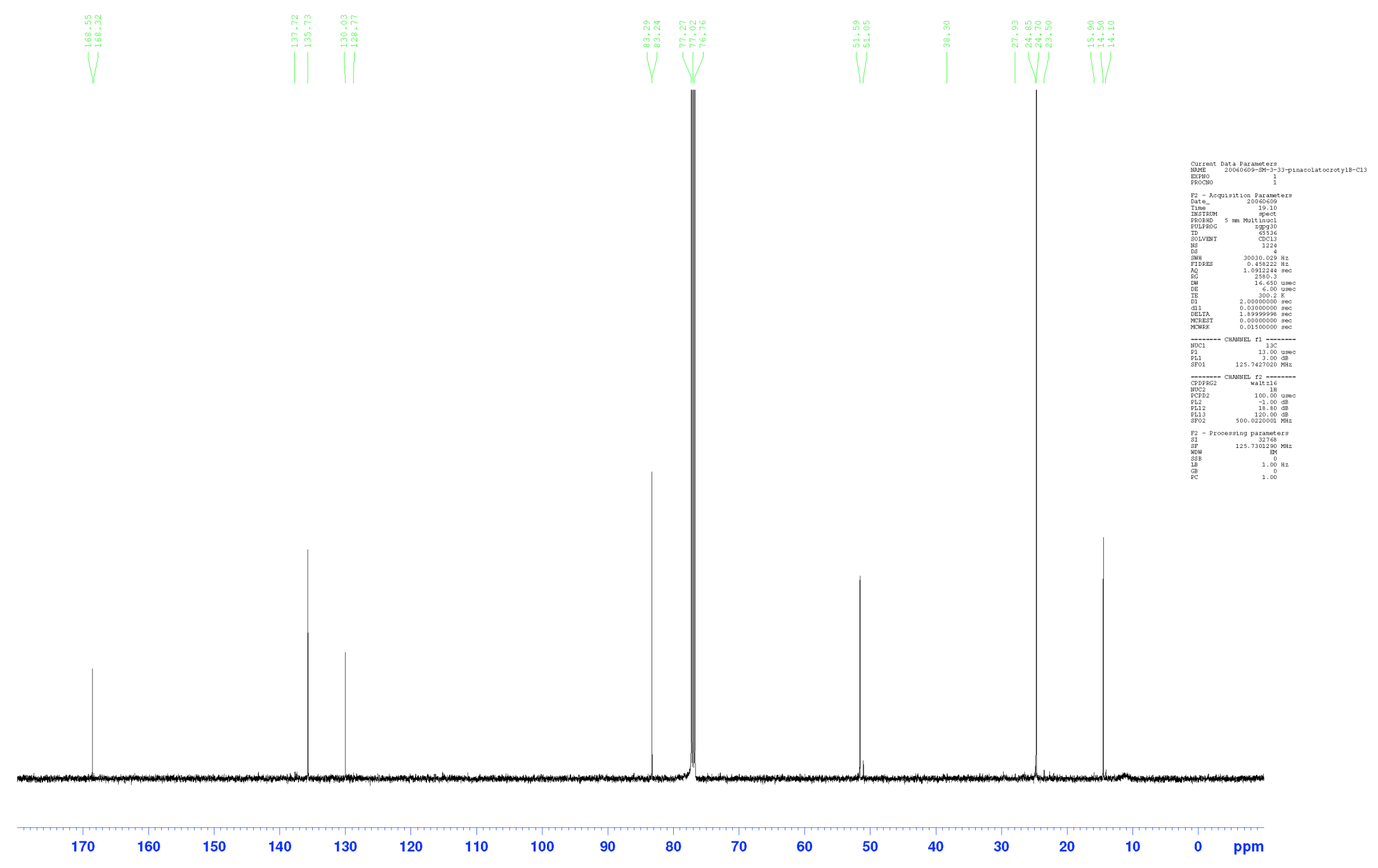


Lactone (46)

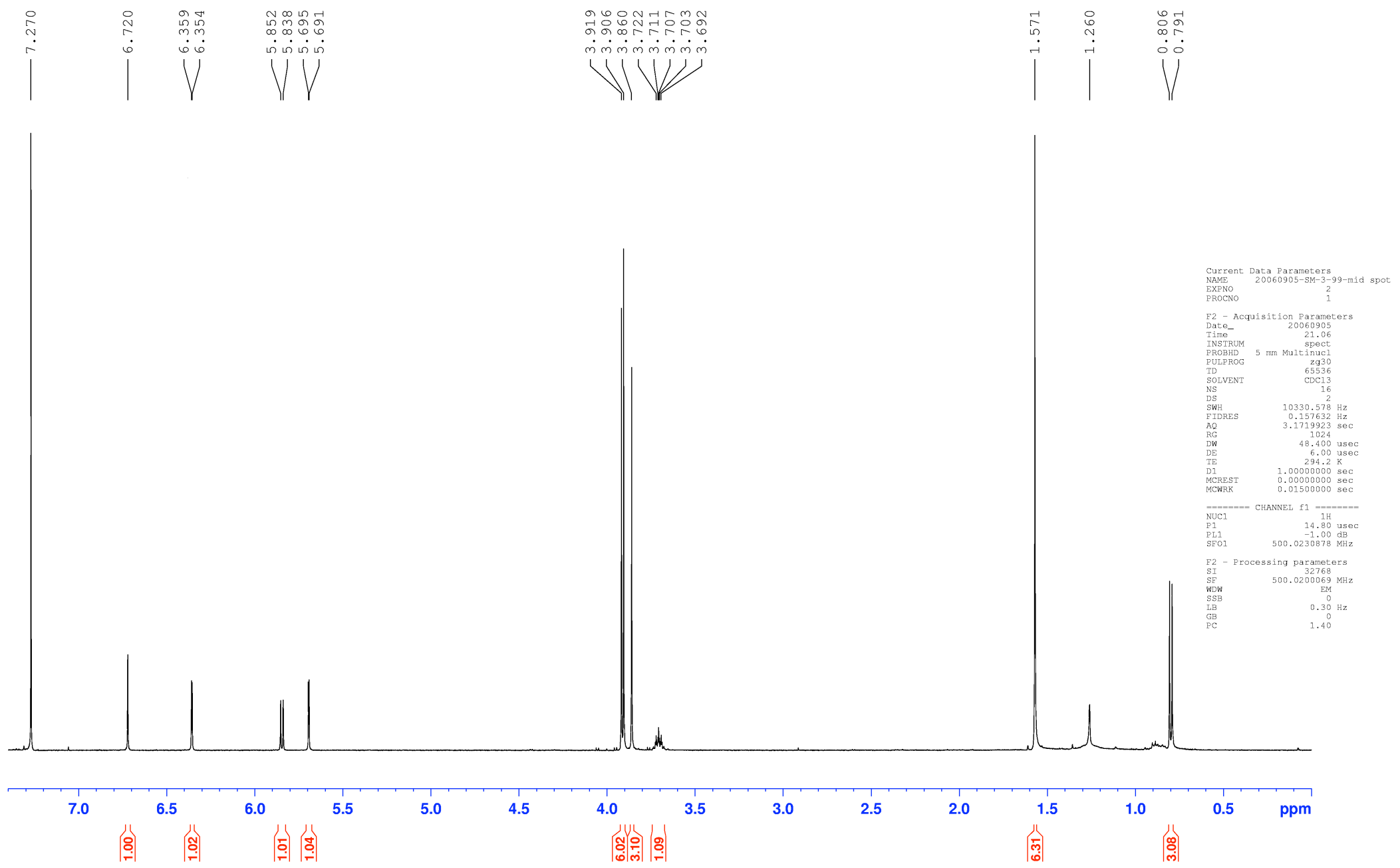


Lactone (46)

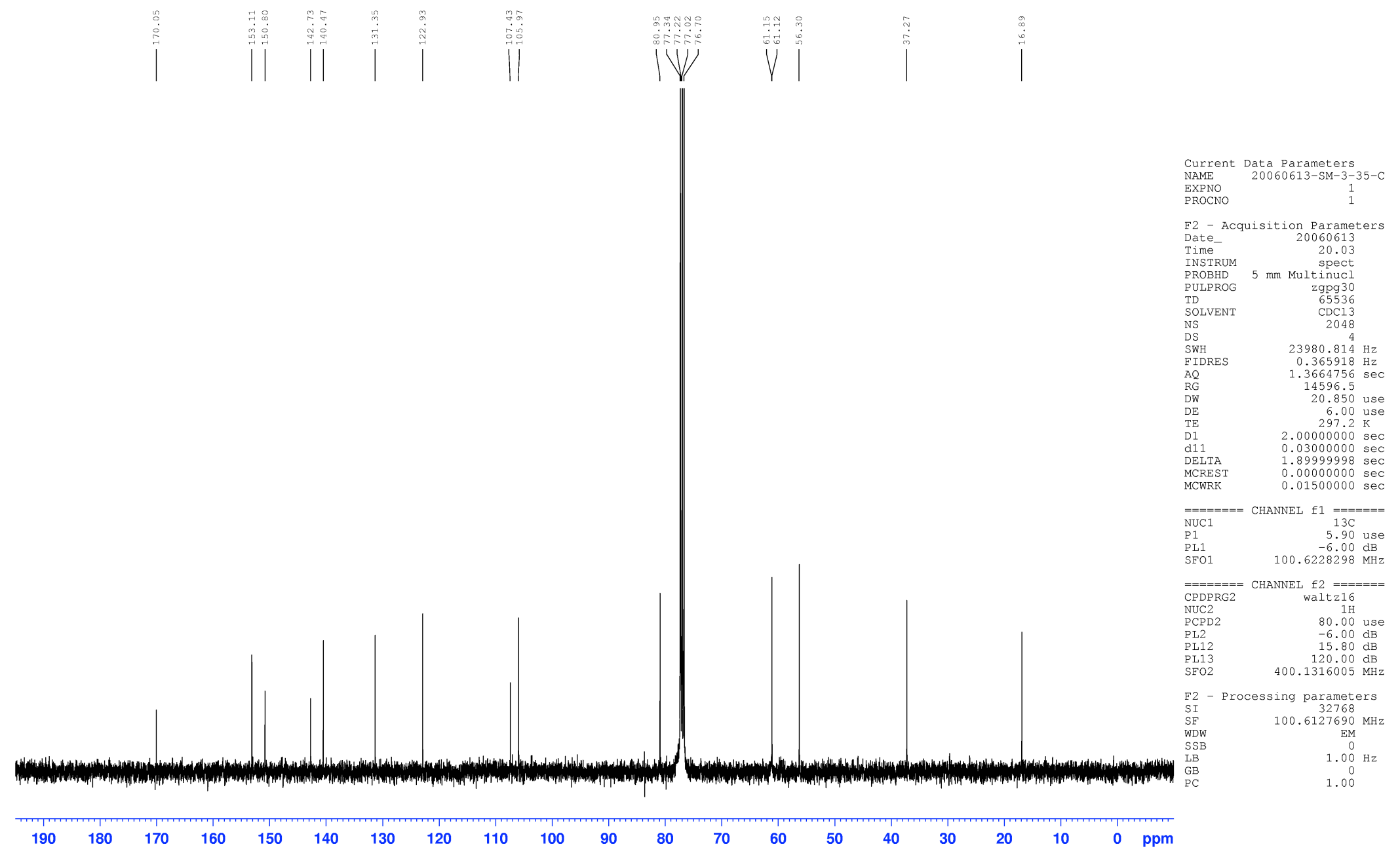


Carbomethoxycrotyl $i$-pinocampheylboronate (47)

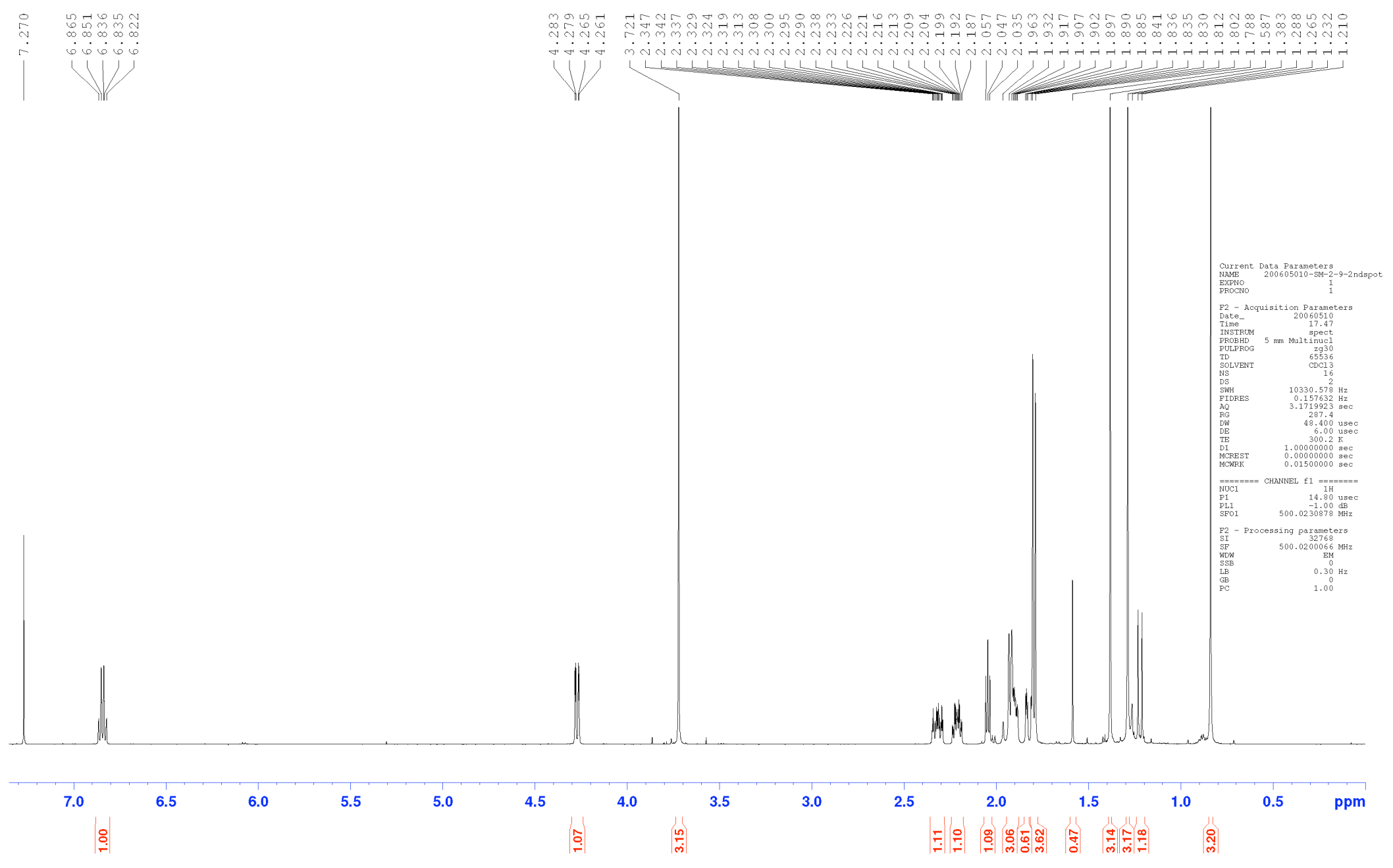


Carbomethoxycrotyl $i$-pinocampheylboronate (47)

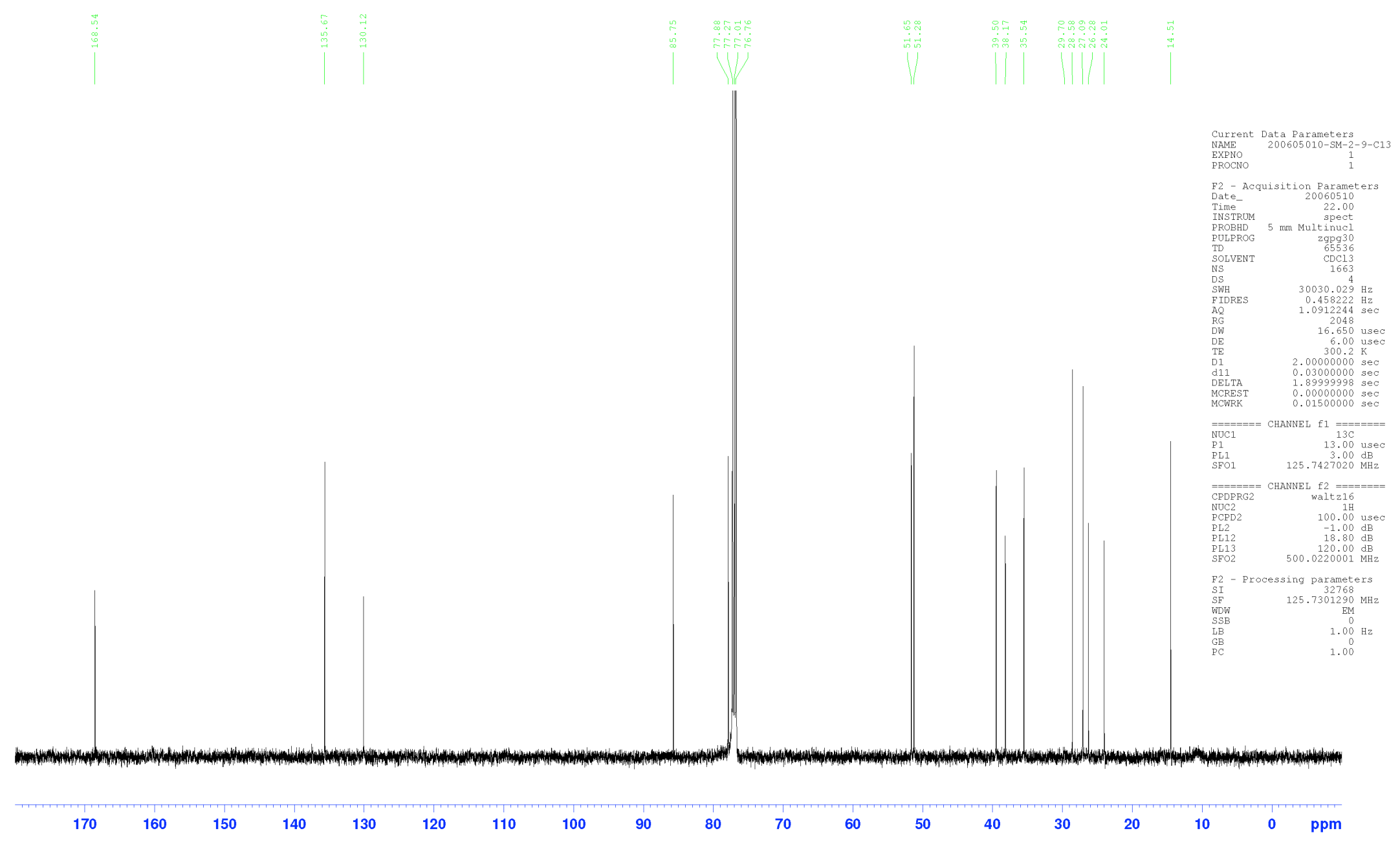


Diol (49)

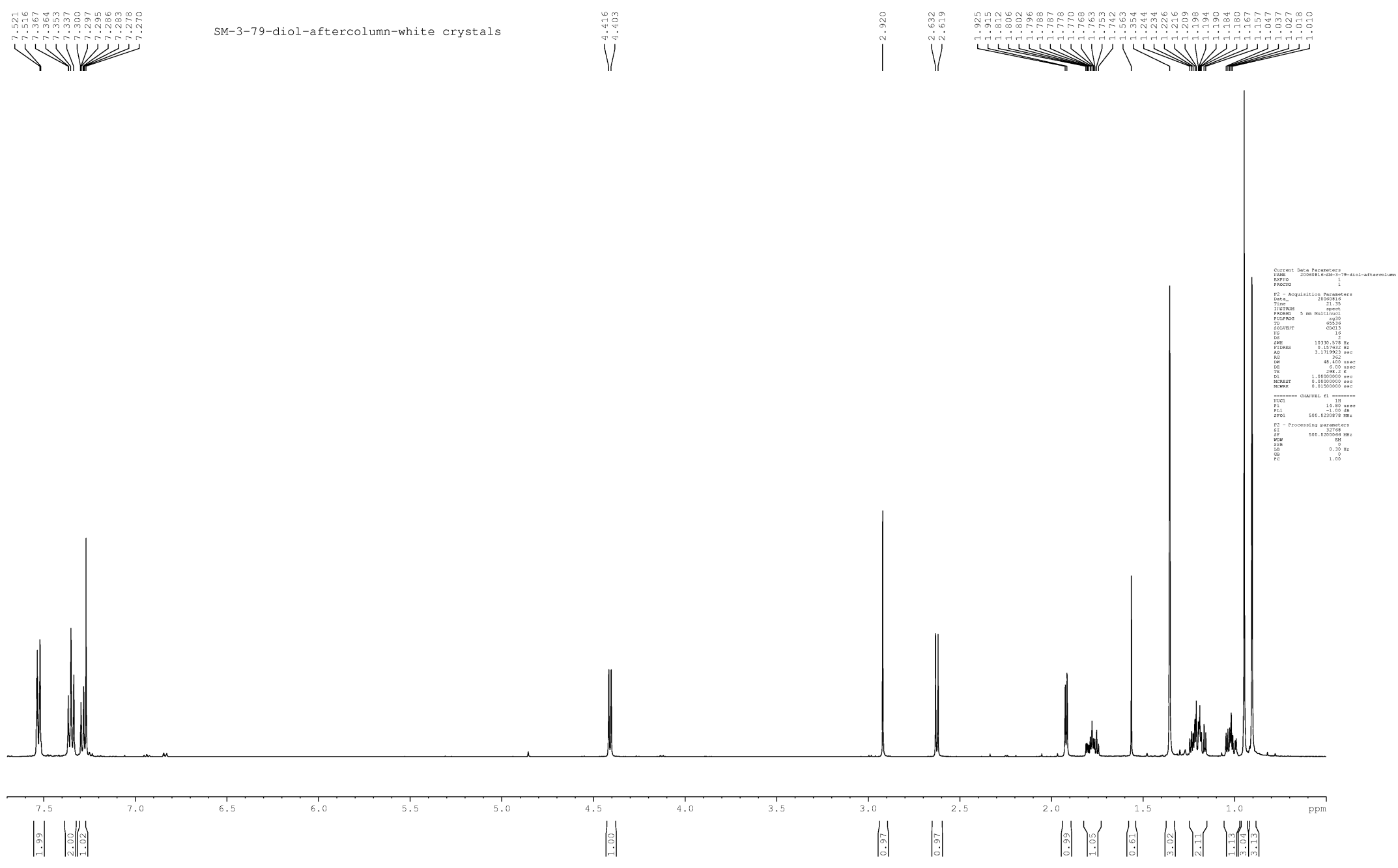


Diol (49)

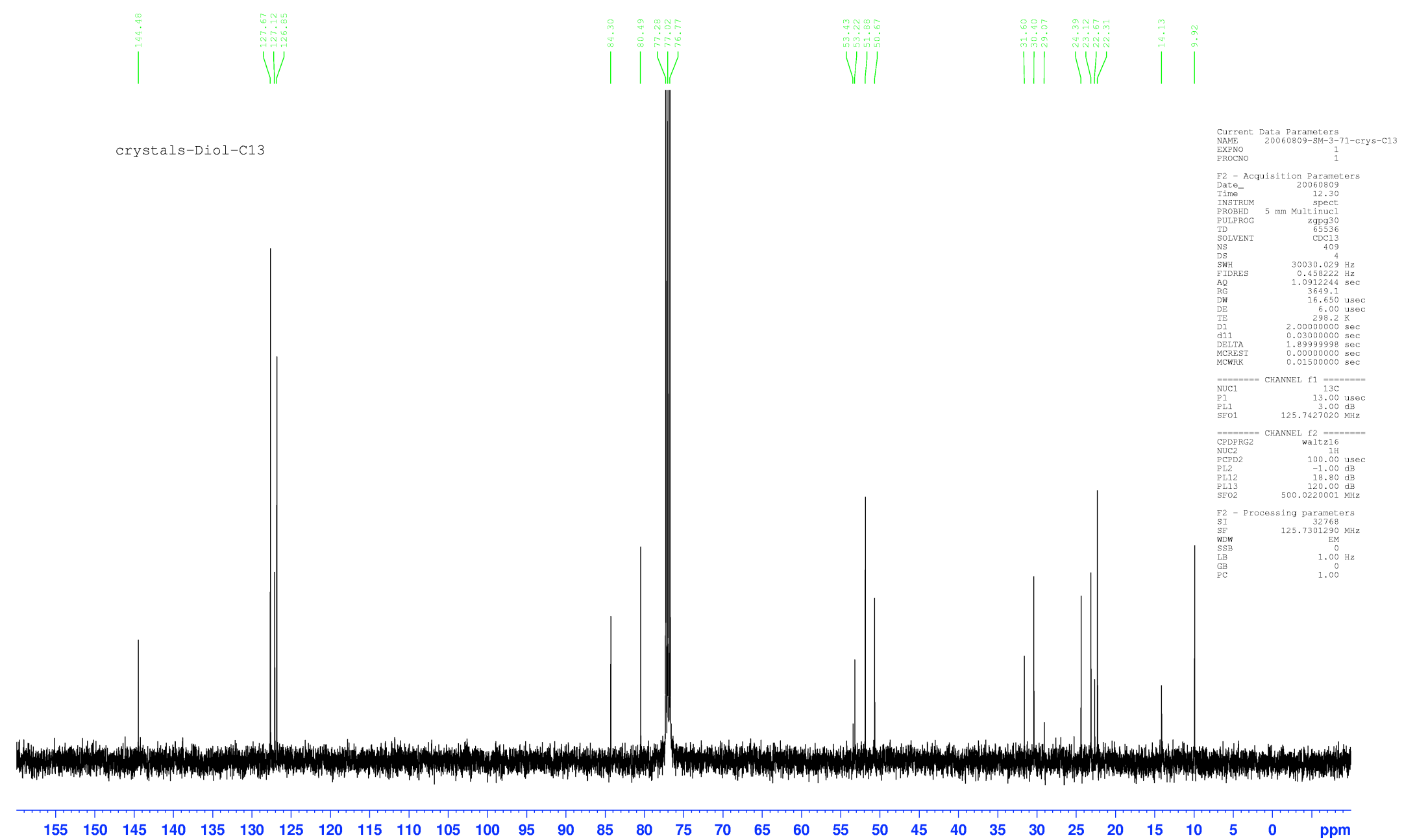


Diboron Reagent (51)

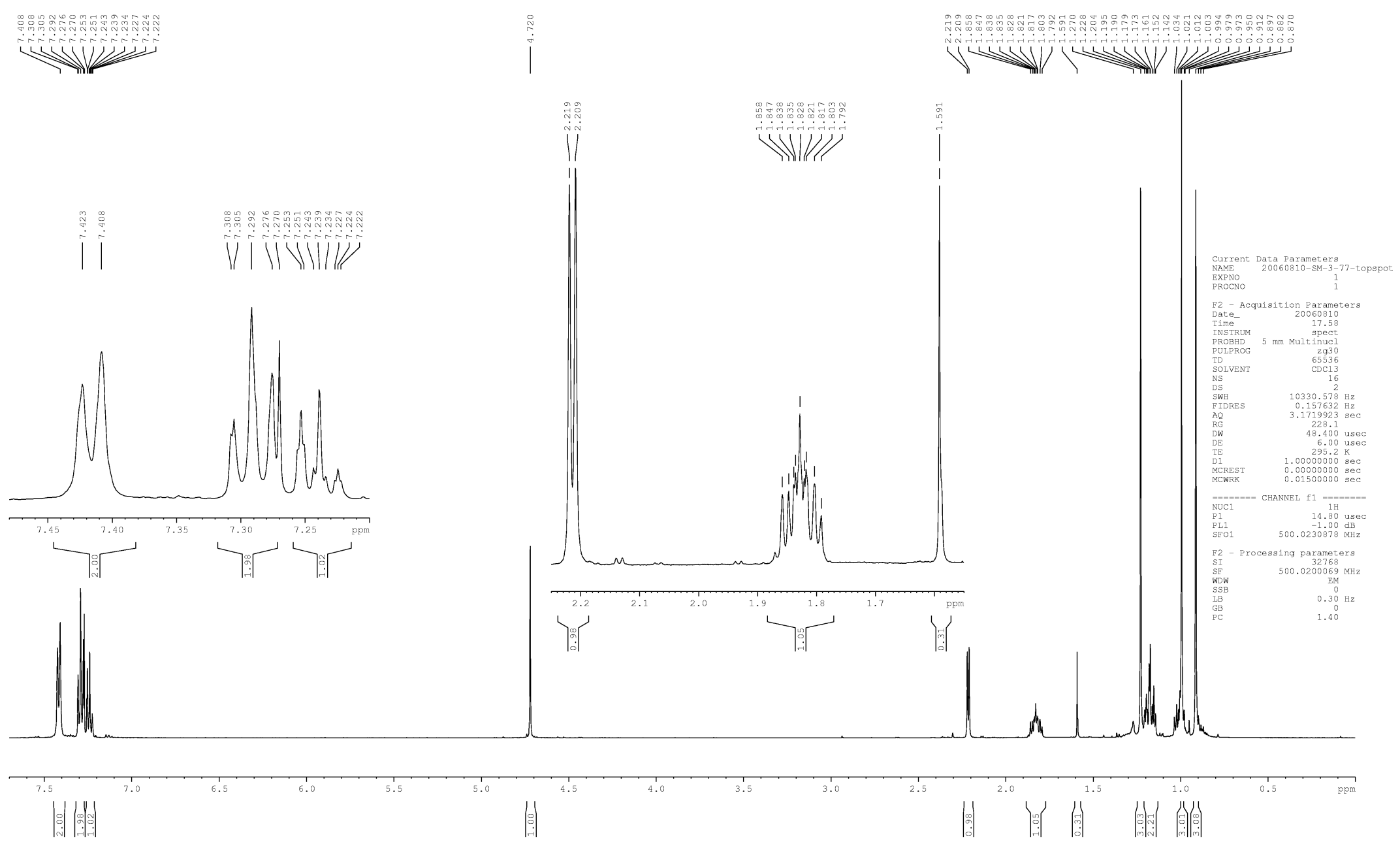


Diborane reagent (51)

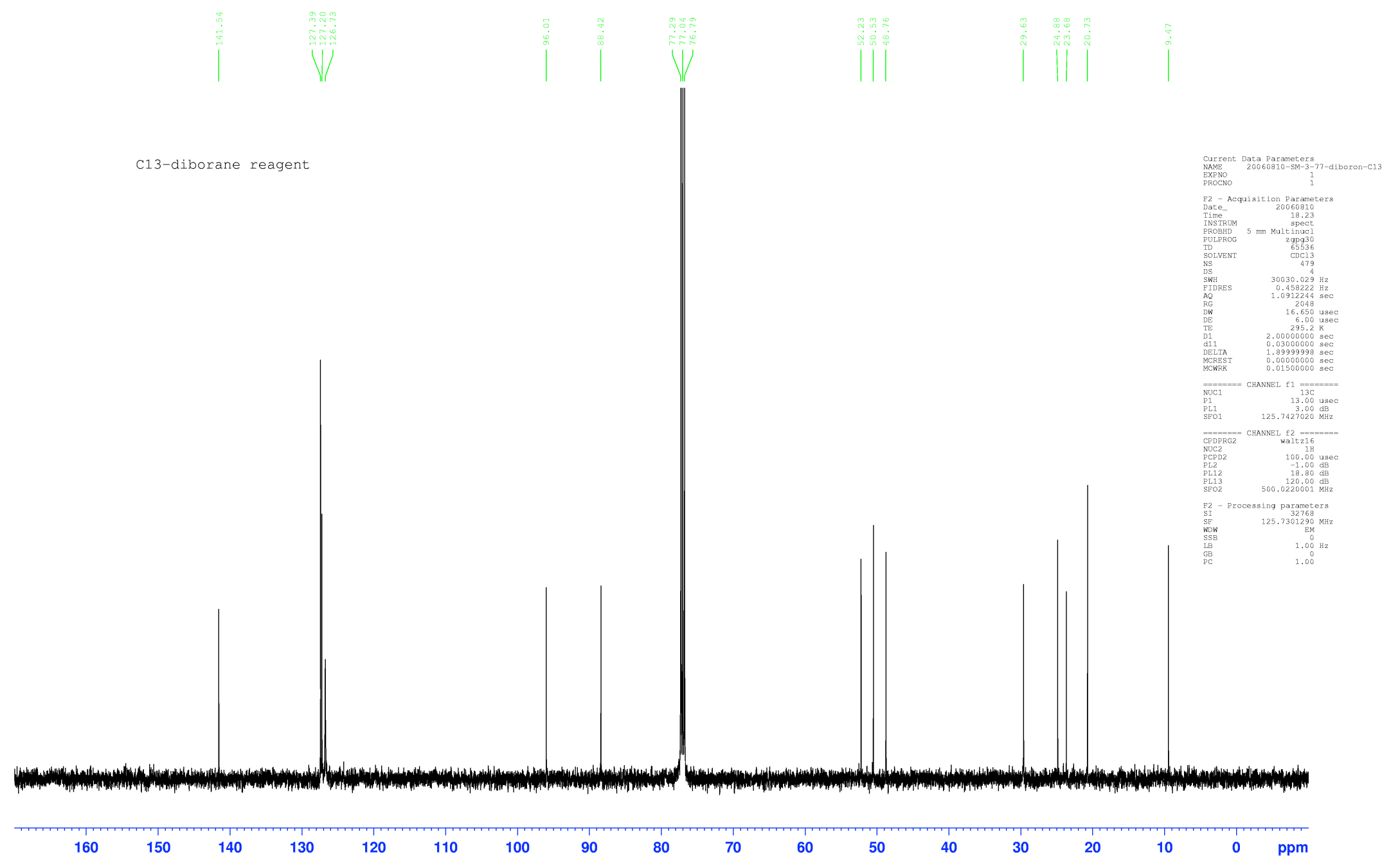


Carbomethoxycrotyl camphorphenylboronate (52)

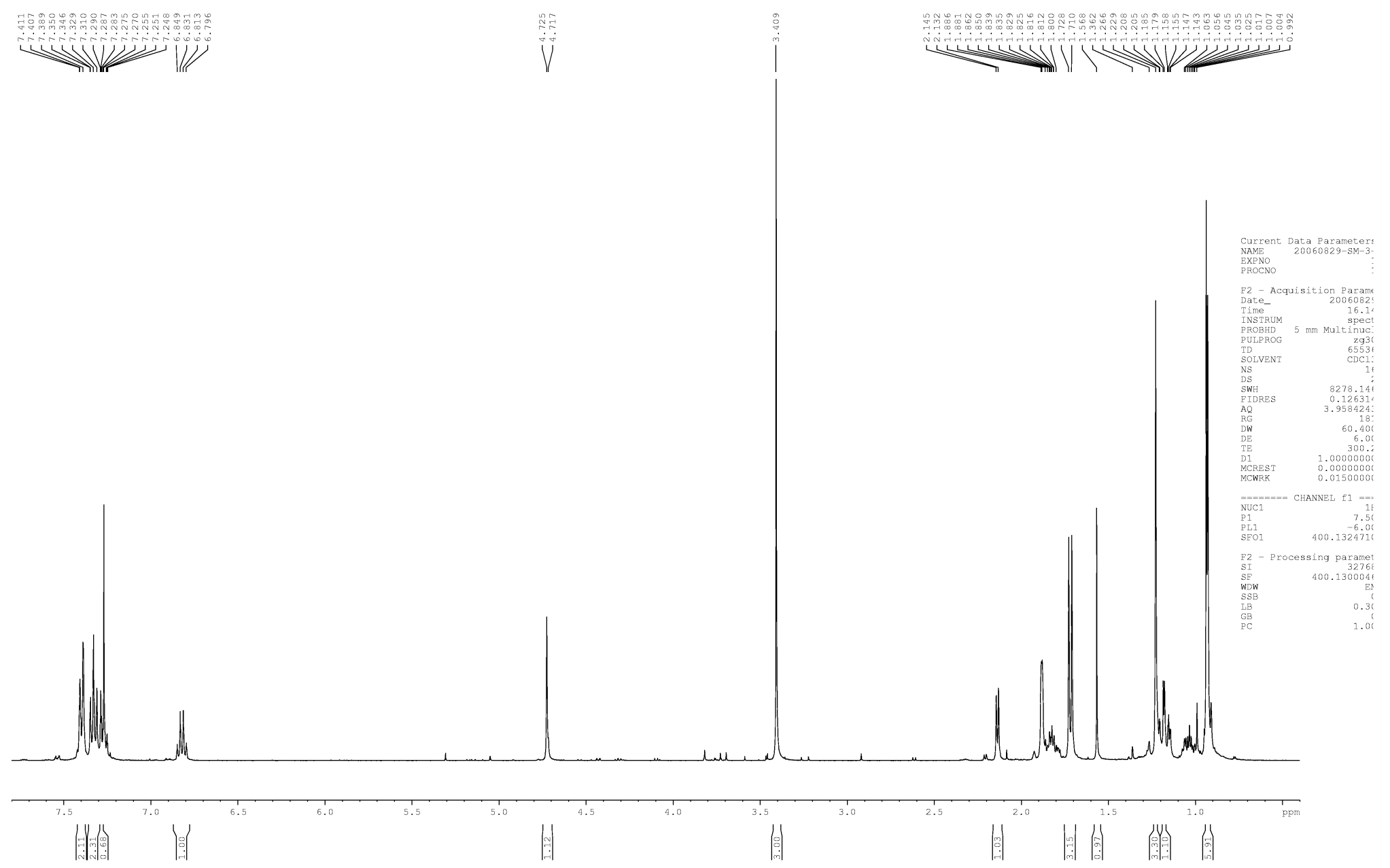


Carbomethoxycrotyl camphorphenylboronate (52)

C13-pure-camphor-phenyl-crotyl borane

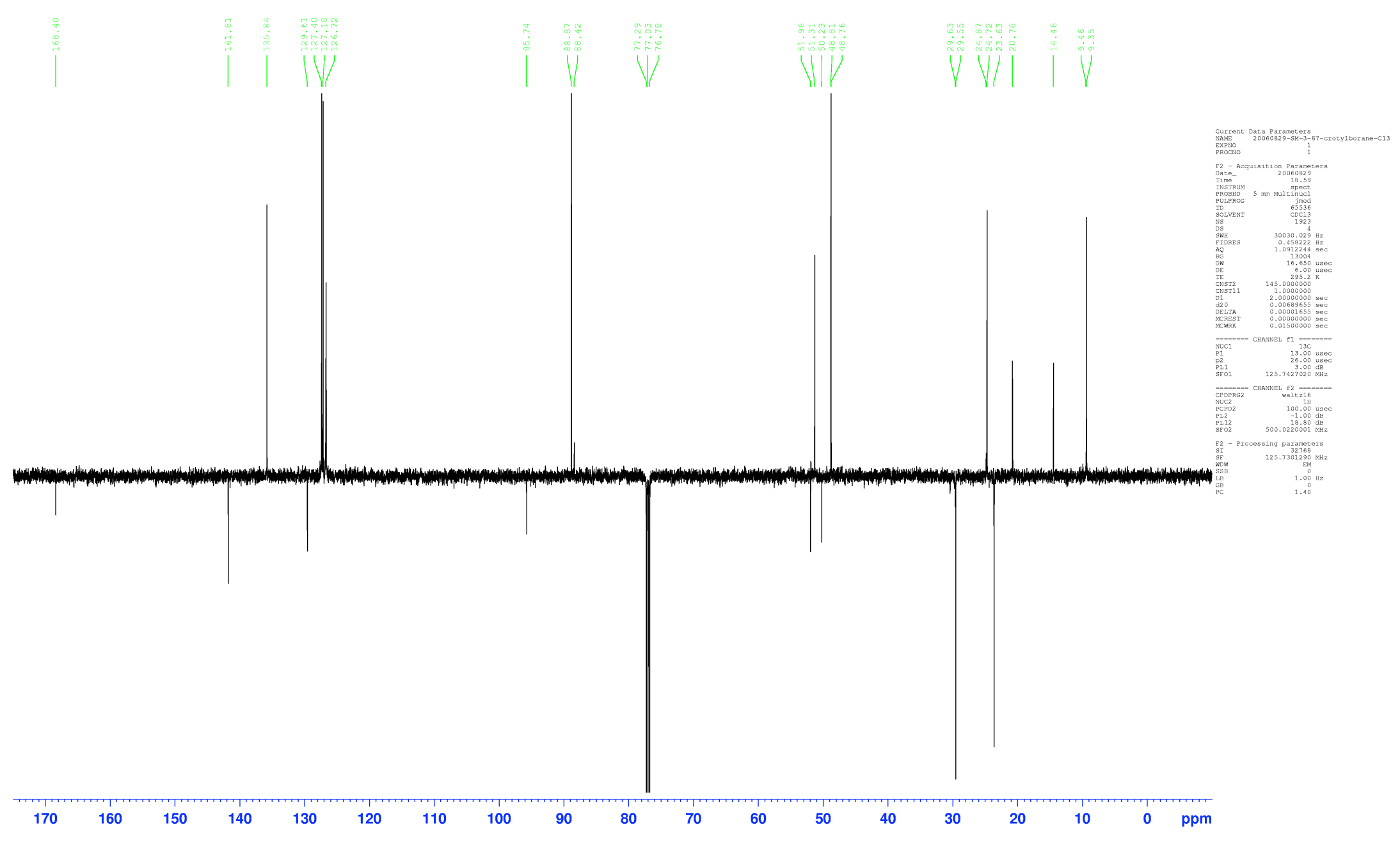


Carbomethoxycrotyl camphorphenylboronate (52)

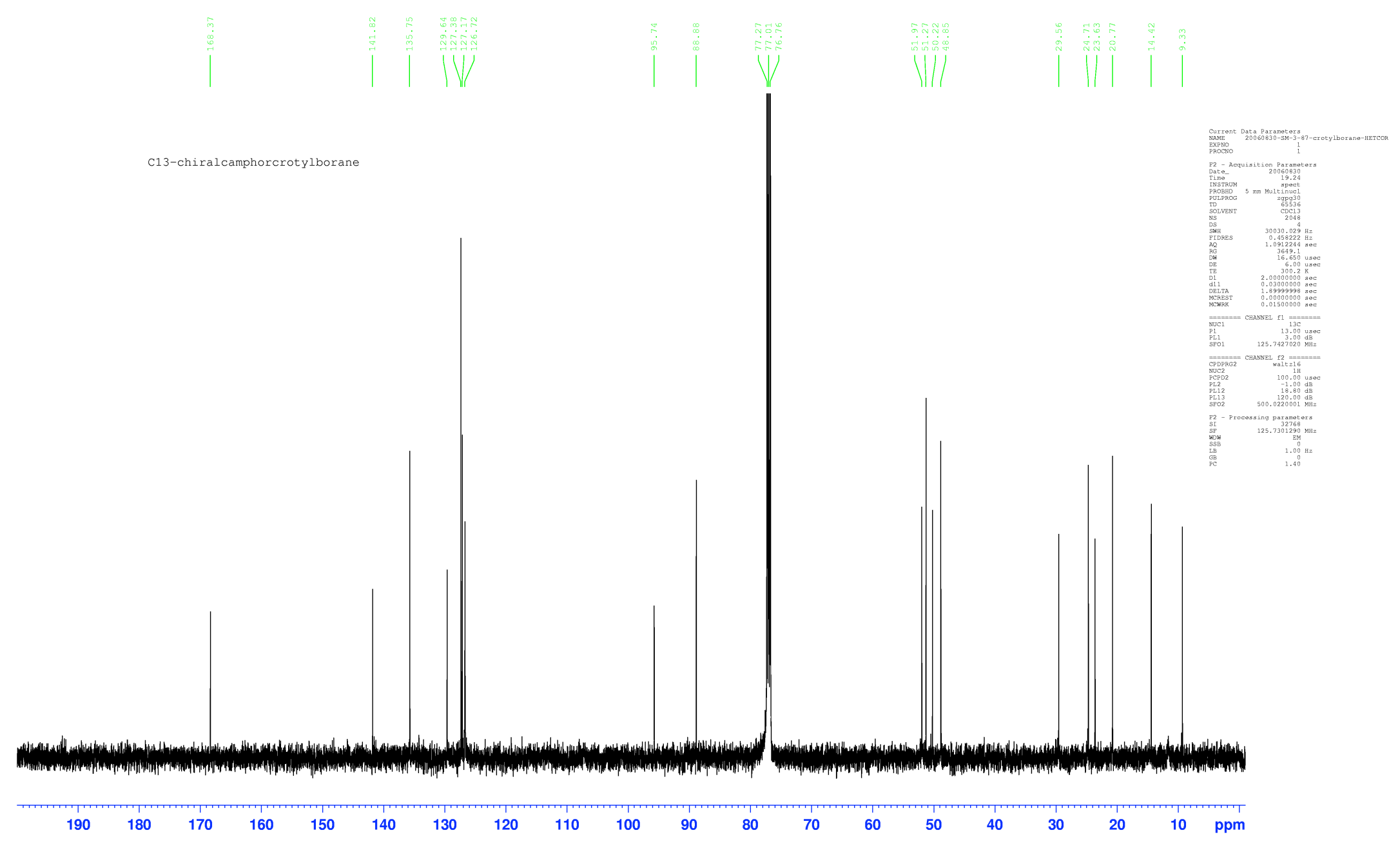


Carbomethoxycrotyl trifluoroborate (54) (>95\% E-isomer by NMR)

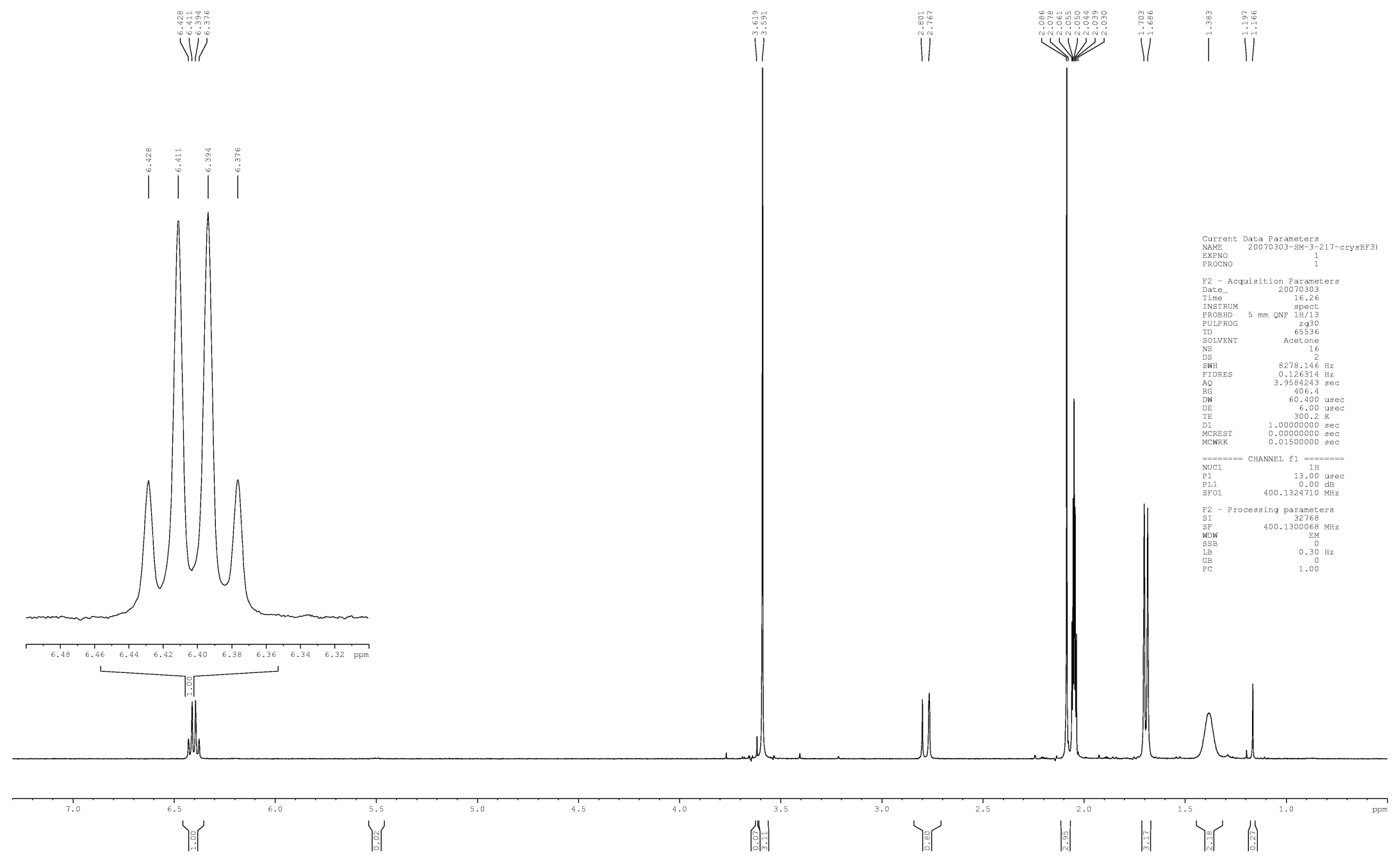


Carbomethoxycrotyl trifluoroborate (54)

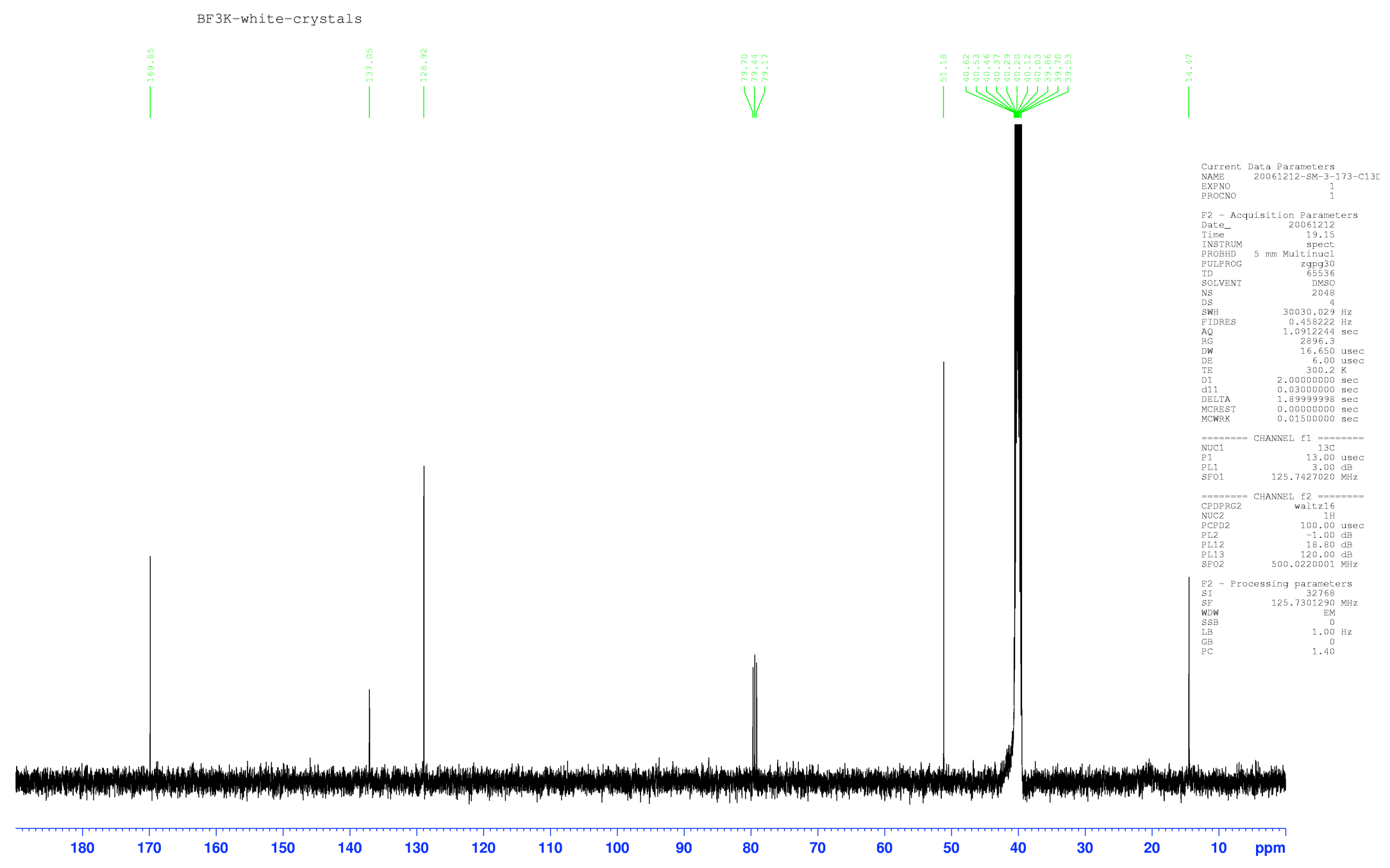


Biaryl aldehyde (57)
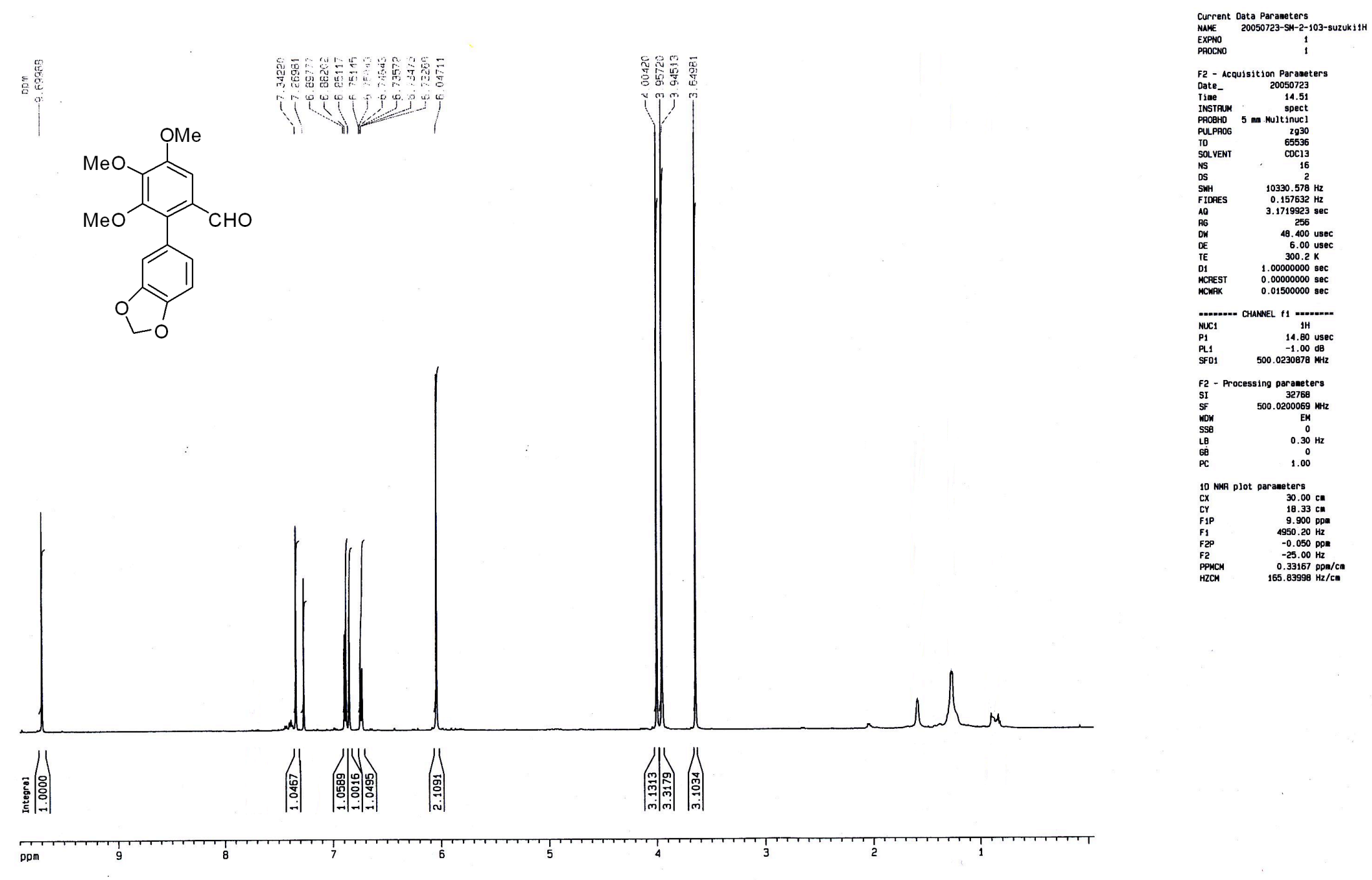
Biaryl aldehyde (57)

C-13 for suzuki SM-2-103
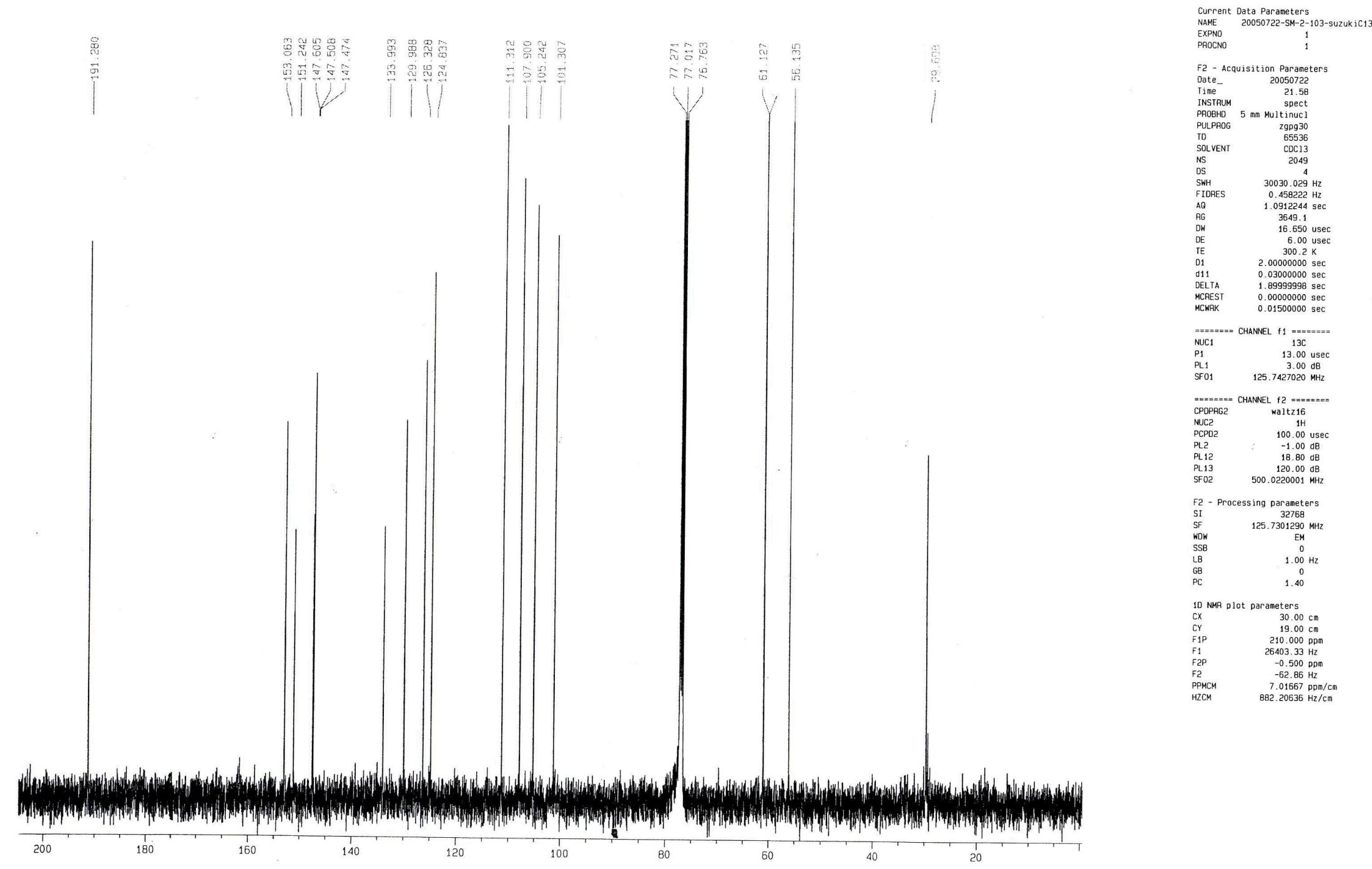
Biaryl aldehyde (58)

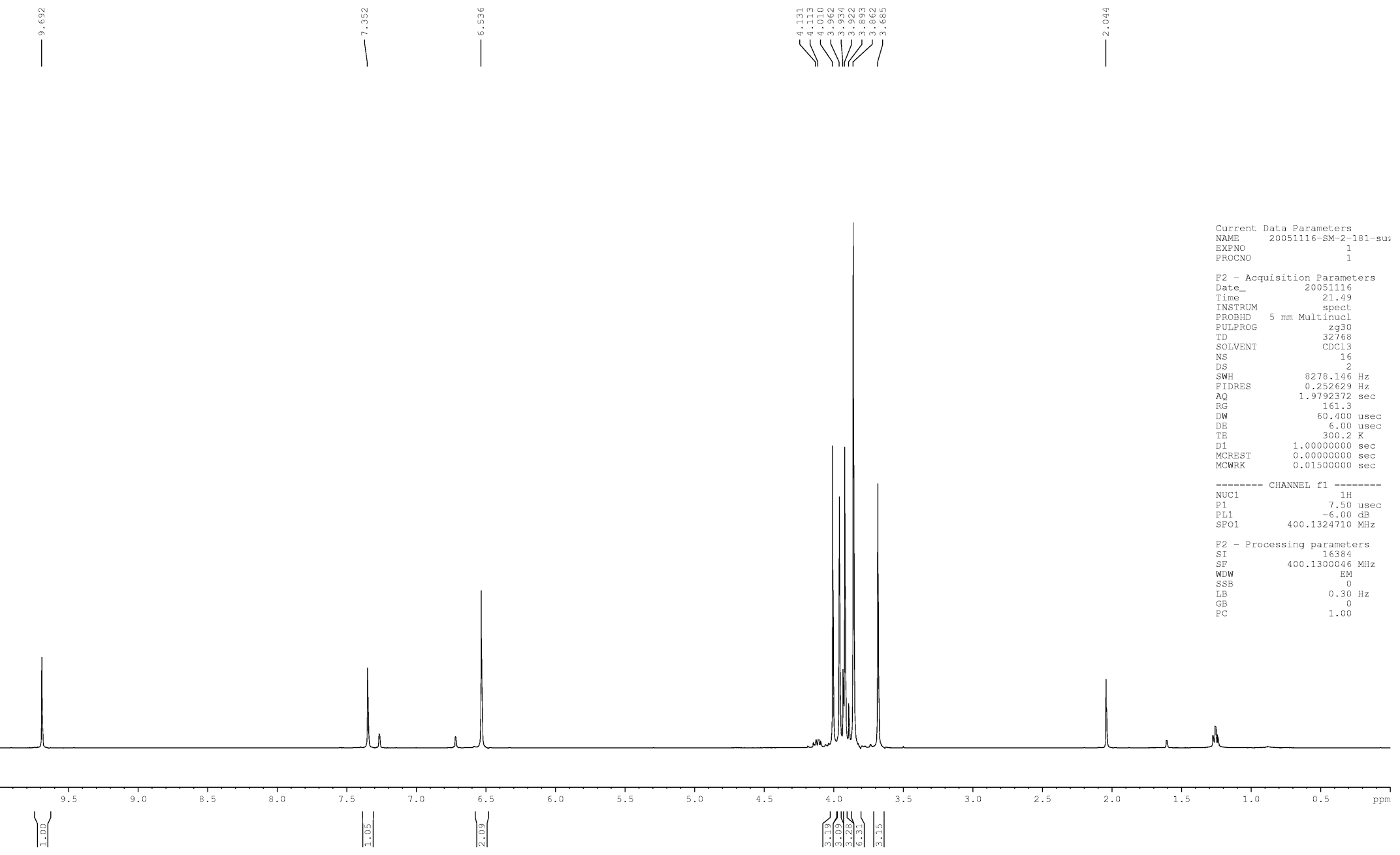


Biaryl aldehyde (58)

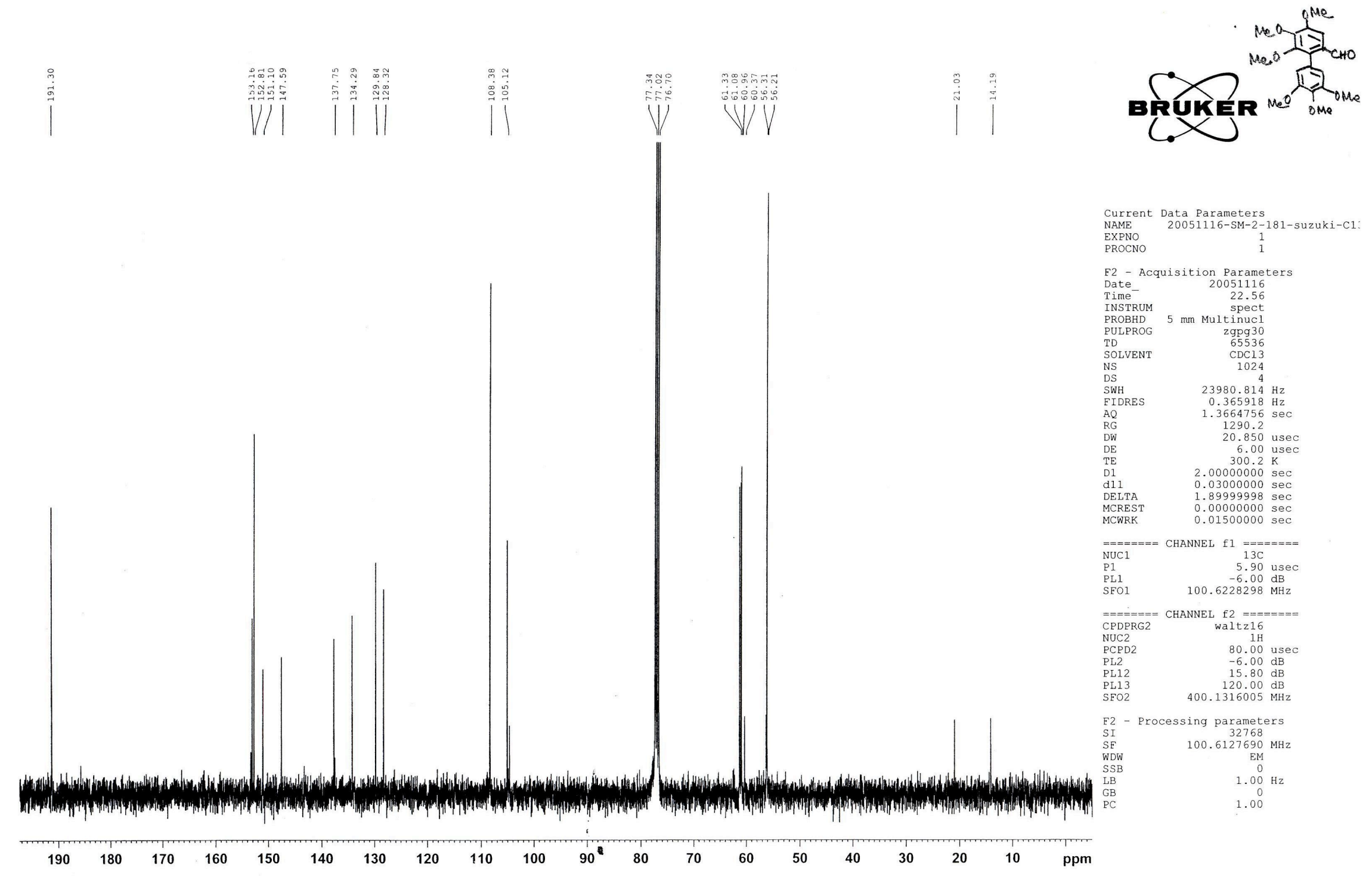


Biaryl aldehyde (59)

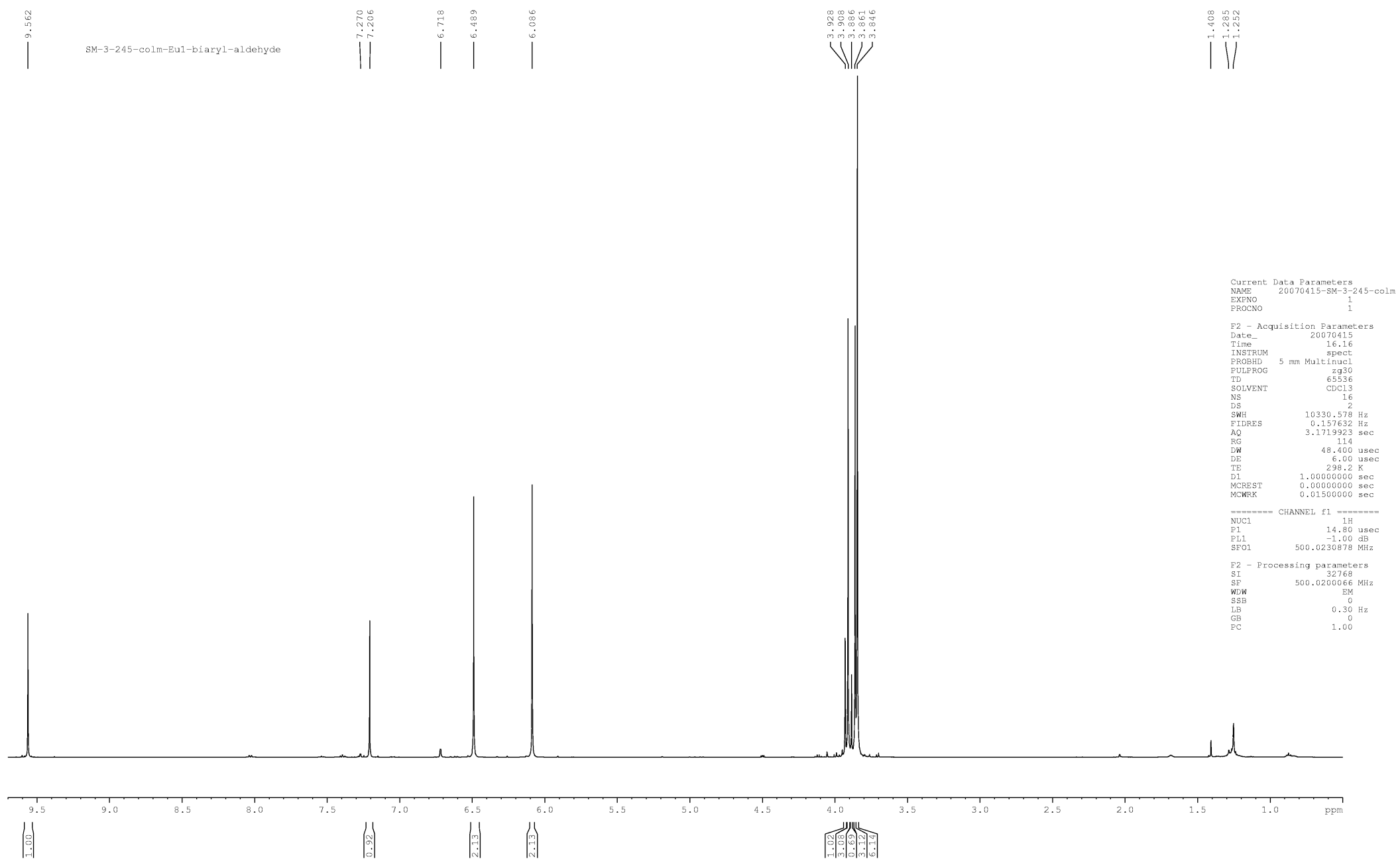


Biaryl aldehyde (59)

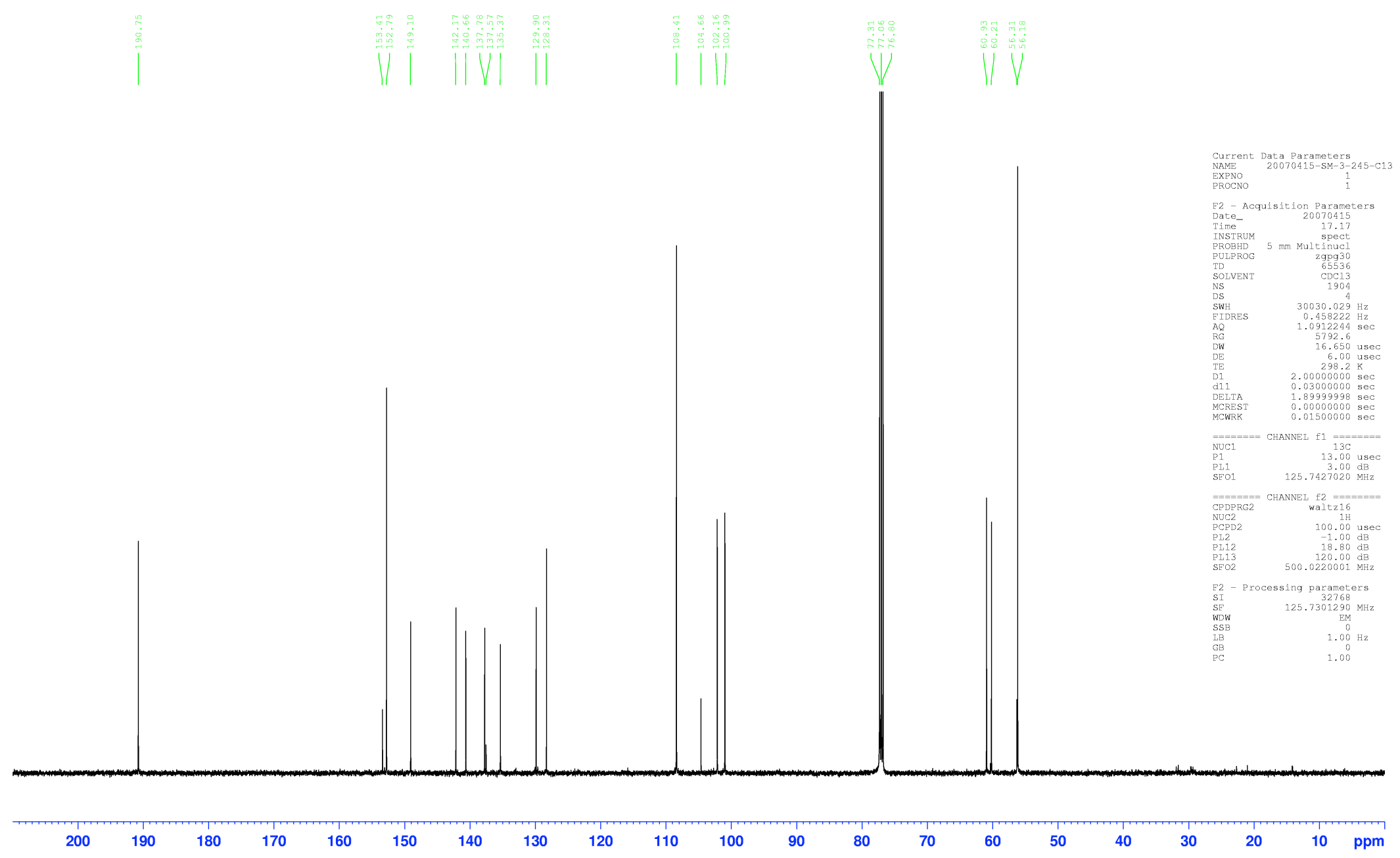


Eupomatilone 5 (1e)

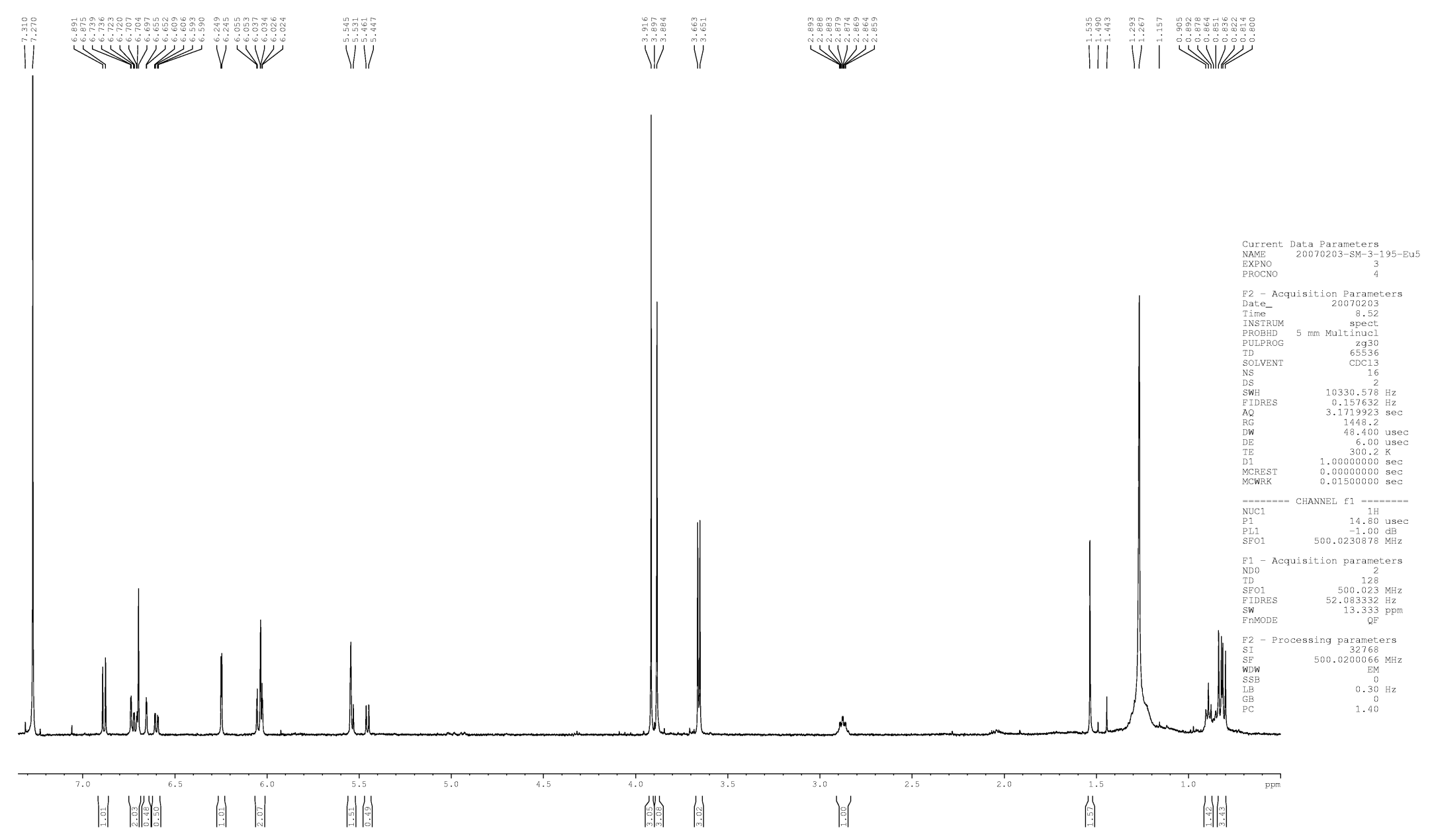


Eupomatilone 5 (1e)

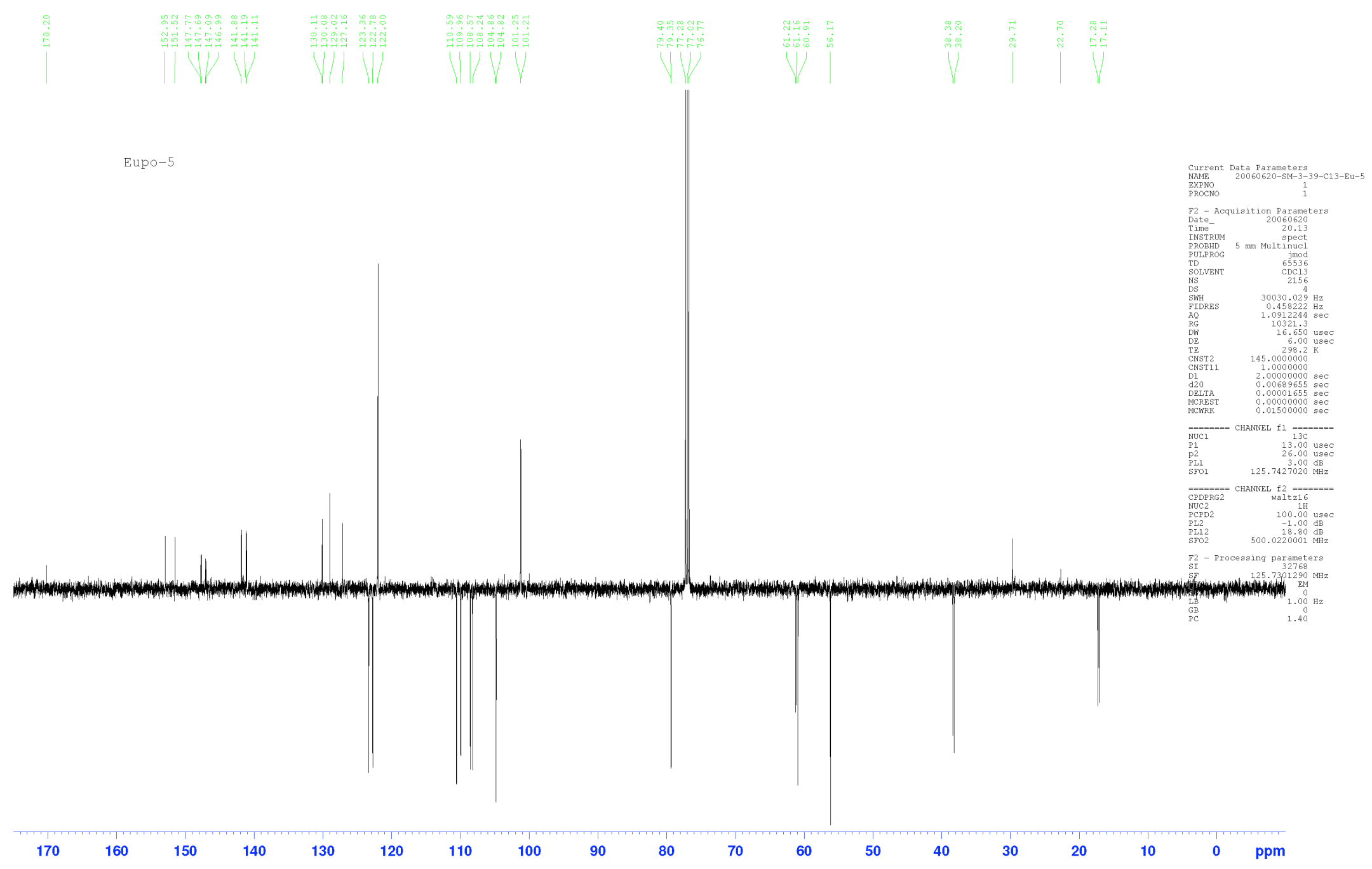


Eupomatilone 5 (1e)

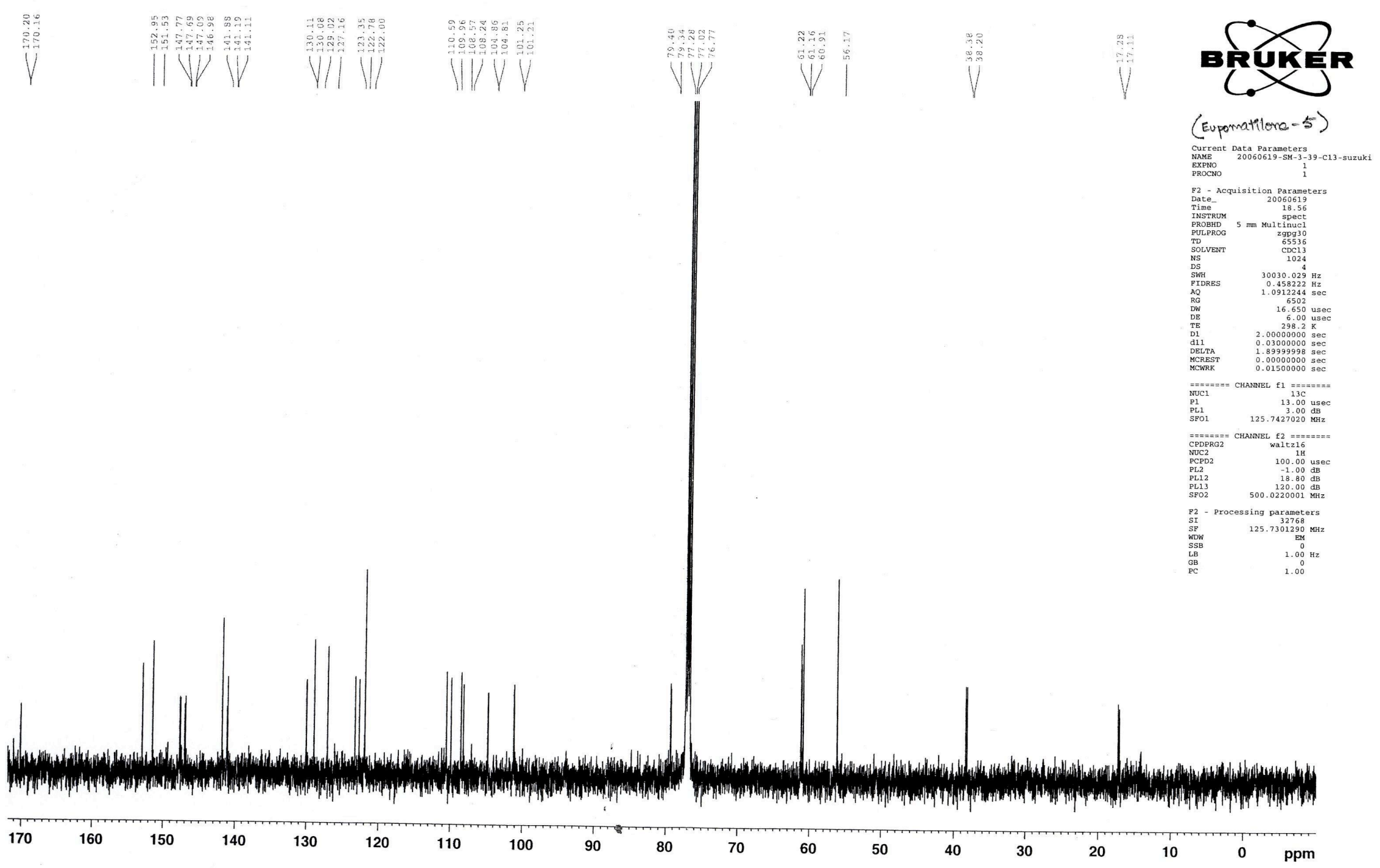


Eupomatilone 2 (1b)

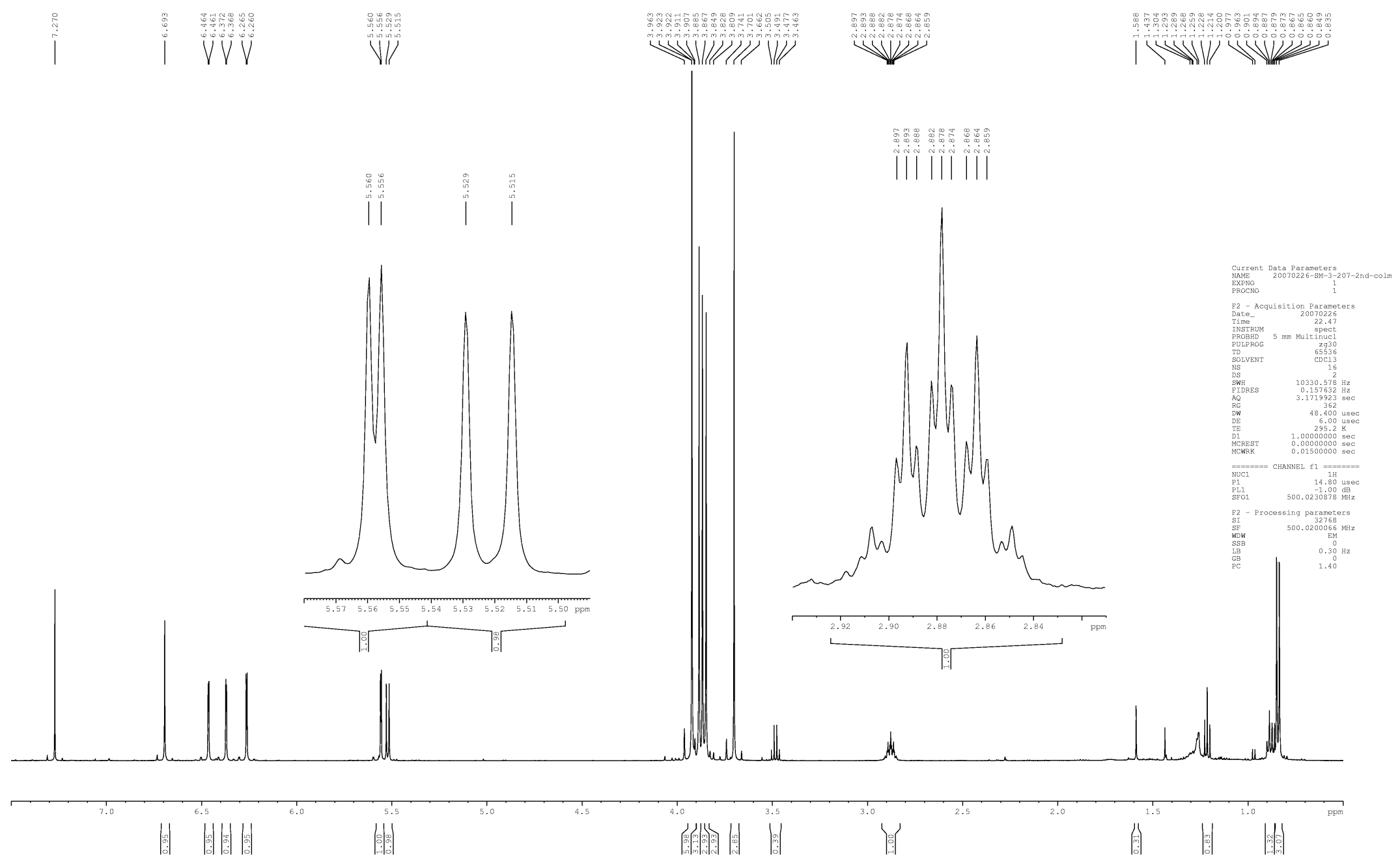


Eupomatilone 2 (1b)

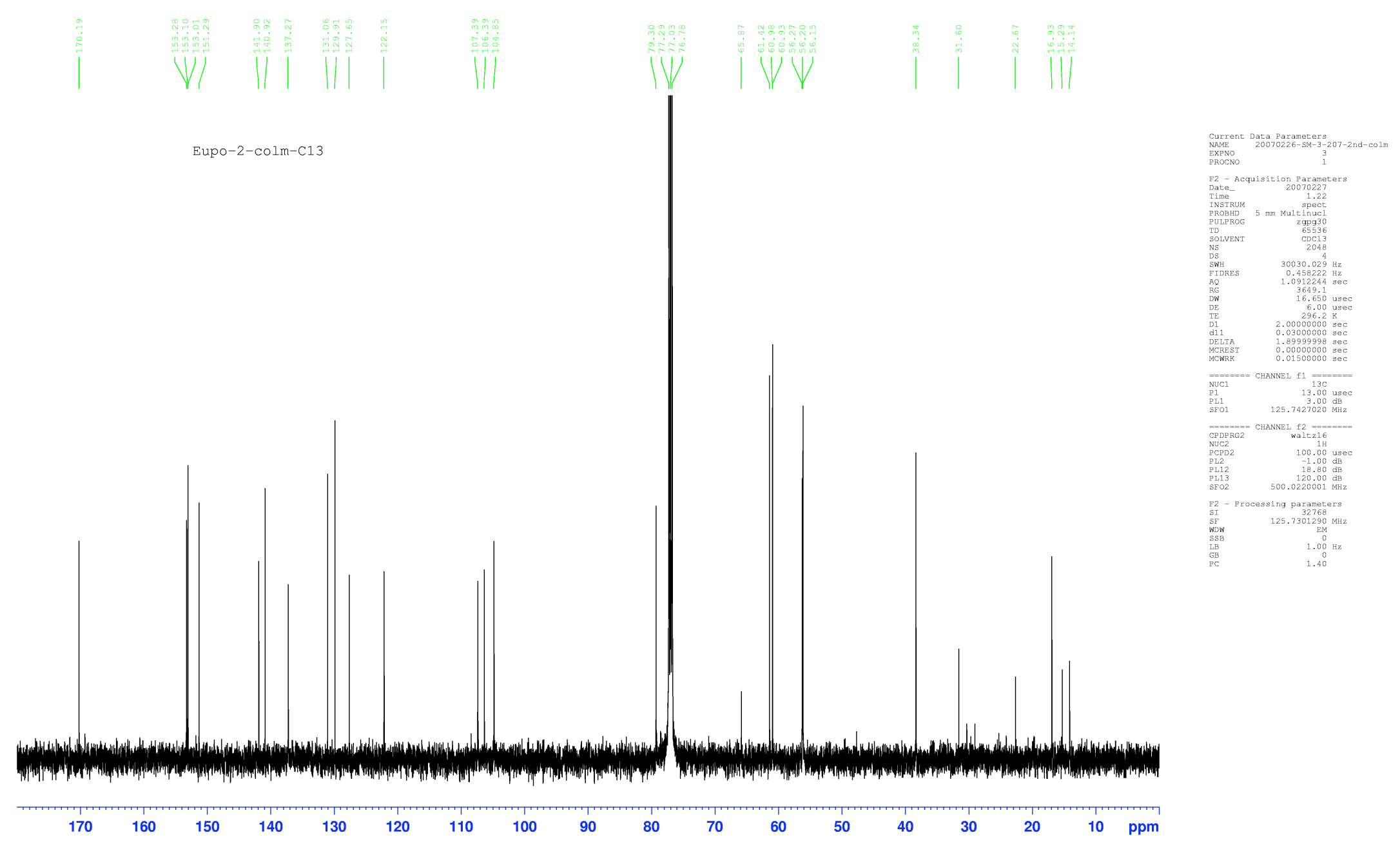


Eupomatilone 1 (1a)

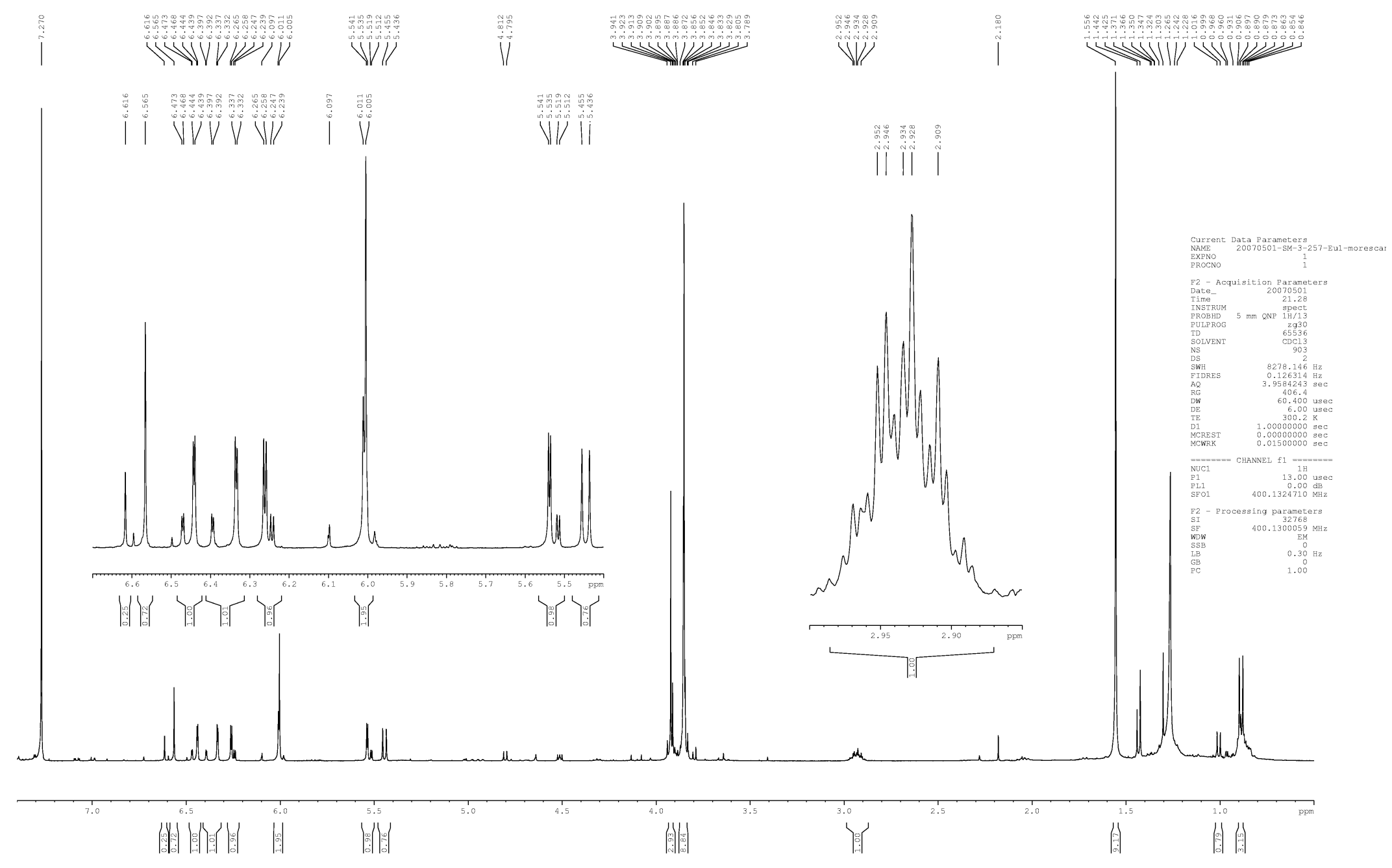


Eupomatilone 1 (1a)

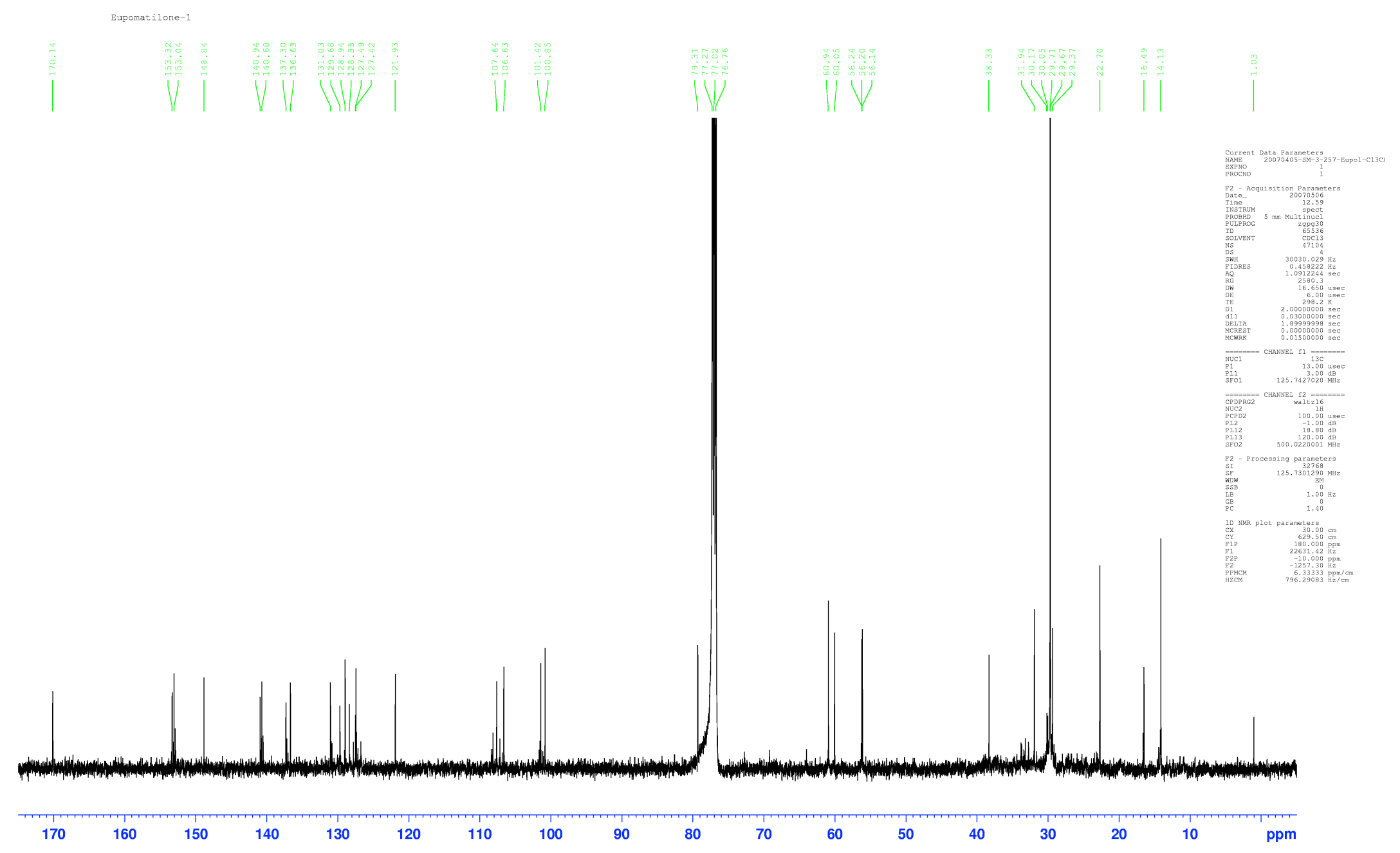

